\title{
THE COMPOSITION, STRUCTURE, TEMPERATURE AND DYNAMICS OF THE UPPER THERMOSPHERE IN THE POLAR REGIONS DURING OCTOBER TO DECEMBER 1981
}

\author{
D. REES, R. GORDON, T. 3. FULLER-ROWELL and M. SMITH \\ Department of Physics and Astronomy, University College, London, Gower Street, \\ London WC1E 6BT, U.K.
}

G. R. CARIGNAN, T. L. KILLEGN and P. B. HAYS

Space Physics Research Laboratory, University of Michigan, Ann Arbor, MI 48105, U.S.A.

and

N. W. SPENCER

NASA Goddard Space Flight Center, Greenbelt, MD 20771, U.S.A.

(Received in final form 22 November 1984 )

\begin{abstract}
During the period October to December 1981, the Dynamics Explorer-2 (DE-2) spacecraft successively observed the South polar and the North polar regions, and recorded the temperature, composition and dynamical structure of the upper thermosphere. In October 1981 , perigee was about $310 \mathrm{~km}$ altitude, in the vicinity of the South Pole, with the satellite orbit in the 09.00-21.00 L.T. plane. During late November and December, the perigee had precessed to the region of the North Pole, with the spacecraft sampling the upper thermosphere in the $06.00-18.00$ L.T. plane. $D E-2$ observed the meridional wind with a Fabry-Perot interferometer (FPI), the zonal wind with the wind and temperature spectrometer (WATS), the neutral temperature with the FPI, and the neutral atmosphere composition and density with the neutral atmosphere composition spectrometer (NACS). A comparison between the South (summer) Pole and the North (winter) Pole data shows considerable seasonal differences in all neutral atmosphere parameters. The region of the summer pole, under similar geomagnetic and solar activity conditions, and at a level of about $300 \mathrm{~km}$, is about $300 \mathrm{~K}$ warmer than that of the winter pole, and the density of atomic oxygen is strongly depleted (and nitrogen enhanced) around the summer pole (compared with the winter pole). Only part of the differences in temperature and composition structure can be related to the seasonal variation of solar insolation, however, and both polar regions display structural variations (with latitude and Universal Time) which are unmistakeable characteristics of strong magnetospheric forcing. The magnitude of the neutral atmosphere perturbations in winds, temperature, density and composition within both summer and winter polar regions all increase with increasing levels of geomagnetic activity.

The UCL 3-dimensional time dependent global model has been used to simulate the diurnal, seasonal and geomagnetic response of the neutral thermosphere, attempting to follow the major features of the solar and geomagnetic inputs to the thernosphere which were present during the late 1981 period.

In the UCL model, geomagnetic forcing is characterized by semi-empirical models of the polar electric feld which show a dependence on the $Y$ component of the Interplanetary Magnetic Field, due to Heppner and Maynard (1983). It is possible to obtain an overall agreement, in both summer and winter hemispheres, with the thermospheric wind structure at high latitudes, and to explain the geomagnetic control of the combined thermal and compositional structure both qualitatively and quantitatively. To obiain such agreement, however, it is essential to enhance the polar ionosphere as a consequence of magnetospheric particle precipitation, reflecting both widespread auroral (kilovolt) electrons, and "soft" cusp and polar cap sources. Geomagnetic forcing of the high latitude thermosphere cannot be explained purely by a polar convective electric field, and the thermal as well as ionising properties of these polar and auroral electron sources are crucial components of the total geomagnetic input.
\end{abstract}

\section{INTRODUCTION}

The upper thermospheric regions of the Earth's atmosphere respond in the main to two dominant forcing functions. Solar e.u.v. and u.v. heating is usually the largest global input of energy to the thermosphere, and is virtually always so at lower geographic and geomagnetic latitudes. At high latitudes, the energy and momentum sources associated with the auroral oval and polar cap are frequently the dominant forcing functions on a local scale. Occasionally, the total geomagnetic input (globally integrated) may exceed the solar u.v. and e.u.v. energy deposited in the thermosphere. At such times, and in the vicinity of the auroral oval and polar cap, the geomagnetic energy 
input may locally exceed the global average solar u.v. and e.u.v. input by several orders of magnitude.

The dramatic response of the Earth's thermosphere to geomagnetic forcing has been described in observations of extremely high wind speeds in the high latitude thermosphere by rocket and ground-based techniques (for example, Rees, $1971 \mathrm{a}, \mathrm{b}$; Meriwether et al., 1973; Kelley et al., 1977; Hays et al., 1979; Smith and Sweeney, 1980; Rees et al., 1980a; Heppner and Miller, 1982). These studies have shown that high latitude thermospheric winds respond both to geomagnetic momentum sources (ion drag) and to the high latitude geomagnetic energy input. Data from the Dynamics Rxplorer (DE-2) spacecraft have recently demonstrated that the two-cell response of the thermospheric winds to ion drag forcing is present under all but the most quiet of geomagnetic conditions. This was suggested by most of the previous empirical results which were made from single, fixed, locations and thus were incapable of following the poleward and cquatorward migration of the auroral oval as a function not only of geomagnetic local time, but also of geomagnetic activity.

The results presented by Killeen et al. (1982, 1983), Hays et al. (1984), Rees et al. (1983), and Roble et al. (1983), based on the $D E-2$ data, all demonstrate that the two-cell wind circulation within the polar thermosphere can be directly related to ion-drag forcing by the polar ion convection pattern, as had been predicted by the global numerical 3-dimensional models of FullerRowell and Rees $(1980,1981)$ and Roble et al. (1982).

Since the geomagnetic energy and momentum effects in the polar regions are important relative to the solar u.v. and e.u.v. inputs, it has been pointed out that vertical winds caused by strong "auroral" Joule and friction heating will serve to change the composition at constant altitude (Hays et al., 1973) by raising the altitude of a given pressure level. This is, however, only part of the thermospheric response. Large scale horizontal wind circulations occur in the thermosphere as a result of diurnal, latitudinal and seasonal asymmetries in the global energy input from both solar and geomagnetic sources. These systematic horizontal (and global scale) wind systems are associated with mean vertical winds of modest magnitude $\left(1-10 \mathrm{~ms}^{-1}\right)$. The consequences of modest vertical convection correlated with large-scale horizontal advection, is most important. In particular, the compositional structure of the thermosphere, both at constant altitude, and at constant pressure levels, may be changed considerably by such correlated horizontal and vertical circulation systems. The very large seasonal/latitudinal variations of helium density in the thermosphere, and the summer to winter polar changes of the atomic oxygen to molecular nitrogen ratio are caused by very modest systematic updrafts in the summer pole $\left(1-3 \mathrm{~m} \mathrm{~s}^{-1}\right)$, with comparable downdrafts in the winter pole, and a connecting mean meridional circulation of about $30-50 \mathrm{~m} \mathrm{~s}^{-1}$.

Mayr and Harris (1978) and Volland (1979) have compared the effects of Joule heating and ion drag momentum on thermospheric composition. They have shown that the Joule heat source is the dominant cause of high latitude compositional changes. Ion drag induces very large local wind speeds, but these winds are confined within the auroral oval and polar cap and follow the two-cell ion convection pattern. The circulation is nearly divergence-free, and thus the momentum source itself tends not to create large composition changes. In reality, magnetospheric particle precipitation may increase ionospheric conductivity significantly in regions of rapid ionospheric convection, so that a "pure" separation of ion drag and Joule heating processes will not naturally occur. The heat directly deposited by magnetospheric electrons, and particularly by "soft" electrons of the polar cusp and polar cap regions is an additional and major cause of thermospheric compositional change of equivalent importance to Joule heating, which was not considered by Mayr and Harris (1978). High latitude particle heating and Joule and friction heating, drive relatively low wind speeds, compared with those due to ion drag, but drive large-scale circulations (hemispheric or global) which are very effective at forcing departures of thermospheric composition from that which would exist in an atmosphere in static diffusive equilibrium.

Early observations of atmospheric composition revealed remarkable variations in the densities of heavy and light constituents associated with geomagnetic disturbances. Taeusch et al. (1971) used data from a mass spectrometer on $O G O$-VI to show a longitude or Universal Time dependence of very large scale variations in composition. Many subsequent studies of the morphology of thermospheric composition using data from $O G O$-VI, Atmosphere Explorer and ESRO-4 have further confirmed and elucidated the geomagnetic control of high latitude thermospheric composition (Hedin and Reber, 1972; Reber and Hedin, 1974; Taeusch and Hinton, 1975; Hinton, 1978; Prolss and von Zahn, 1978).

Moreover, empirical global models constructed from these measurements by Hedin et al. (1979) and Loux and von Zahn (1979) and incorporating radar backscatter measurements (Hedin, 1983), show unmistakeable geomagnetic control of the morphology of thermospheric composition at high latitudes. Prolss (1980, 1981, 1982) and Prolss and Roemer (1983) have analysed many major disturbances, and their results 
indicate a U.T. variation of the regions of maximum compositional disturbance, which can be related to the rotation of the entire geomagnetic polar regions about the geographic pole during a diurnal cycle. Their analyses show clearly an enhancement in geomagnetically correlated changes at auroral and sub-auroral latitudes in the midnight to dawn local time sector. The effects of large horizontal and vertical thermospheric winds during geomagnetically disturbed periods may contribute to this relationship.

Despite the success in relating compositional variability to geomagnetically controlled energy and momentum sources, a full understanding of the variability has not emerged. The large number of geophysical variables from storm to storm, and the prescribed observational limits due to the geometry of the orbits of specific satellites, together present a data set which is inadequate for a definitive explanation of the phenomenon. The purpose of this work is to put the observations in the context of all of the variables, and to constrain a theoretical model to the observed variations to attempt to evaluate the major geomagnetic processes.

The UCL 3-dimensional time-dependent (3DTD) global model of the thermosphere (Fuller-Rowell and Rees, 1980, 1981, 1983) includes the effects that combined large-scale horizontal and yertical wind circulation systems have in competing with molecular and turbulent diffusive processes to maintain a compositional structure which may be very different from that which would be imposed by static diffusive equilibrium. Fuller-Rowell and Rees (1983) have shown that during both quiet and disturbed geomagnetic periods, at the equinox and near the solstices, the 3DTD model displays the average compositional features of the MSIS model (Hedin et al., 1979; Hedin, 1983). In particular, the large enhancements of molecular nitrogen density, and somewhat smaller depletions of atomic oxygen density that occur in the summer polar region and that are observed as an average feature of the thermosphere at altitudes of above $200 \mathrm{~km}$, are seen to be due to the combined effects of solar insolation of the permanently sunlit summer polar cap, combined with an additional and relatively localised geomagnetic heat input.

With the launch of the Dynamics Explorer satellites (Hofmann and Schmerling, 1981), one of which $(D E-2)$ was equipped with a range of instrumentation to observe the composition, temperature and dynamics of the upper thermosphere, came the opportunity to compare the measured structure of the upper thermosphere with the predictions of the 3DTD model. Statistical surveys of temperature, composition and wind velocity have been completed for the satellite data for two specific periods. The first of these periods was when the satellite perigee was at high southern latitudes in Octoher/November 1981, and the second was when perigee had precessed to high northern latitudes, in December 1981. These data sets present mean neutral winds, temperature, density and thermospheric composition structure, all corrected to an altitude of $300 \mathrm{~km}$ and as functions of latitude, centred on the geographic pole, and sampled by Universal Time, in $2-h$ U.T. intervals. The south polar study includes a separate study of thermospheric composition carried out for periods when $A_{p}$ was below 20 and those periods when $A_{y}$ was above 20 , corresponding to geomagnetic quiet and disturbed periods respectively. The satellite data sets will be compared with results from several numerical simulations using the UCL 3DTD model. The geomagnetic input to the thermosphere is described by the polar electric field, magnetospheric particle precipitation and by consequent changes in the polar ionosphere. These have been changed between the different simulations. This has been done in an attempt to investigate the relative importance of specific features of the empirical or theoretical models that are incorporated within the 3DTD model using the critical tests afforded by the unique north and south polar samples accumulated by $D E-2$.

\section{THE OBSERVATIONAL DATA BASE}

The Dynamics Explorer satellites, launched in August 1981, were instrumental to observe a wide range of parameters of the inner magnetosphere, ionosphere and upper thermosphere (Hoffmann and Schmerling, 1981) and to study the strong interactions between the magnetosphere, polar ionosphere and thermosphere which occur over a wide range of geomagnetic conditions. One of the two Dynamics Explorer spacecraft $(D E-2)$, in an orbit of low eccentricity, was specifically instrumented to observe the neutral thermosphere density, composition, temperature and dynamics between about 300 and $500 \mathrm{~km}$ altitude, and also the density, composition and dynamics of the ionosphere, including the magnetospheric plasma precipitation.

The neutral wind velocity vector determined by $D E-2$ is derived from the meridional component as measured along the direction of the satellite motion by the FabryPerot interferometer (Hays et al., 1981) and the zonal component as measured in a direction perpendicular to the satellite track by the Wind and Temperature sensor (WATS) (Spencer et al., 1981), suitably combined to obtain the vector wind, as described by Killeen et al. (1982). Neutral temperature is measured by the FPI. Neutral atmosphere composition and density is 
derived from the Neutral Atmosphere Composition Spectrometer (NACS), described by Carigan et al. (1981). Data for vector wind velocity, temperature, neutral atmosphere density, mean molecular weight, and the densities of atomic oxygen and molecular nitrogen have becn statistically combined to form sets of average values for epochs when perigee was successively close to the South Pole and the North Pole, as functions of geographical latitude and Universal Time. The presentation is shown in Figs. 1 and 2 for the mean neutral wind and neutral temperature distributions for the South (summer, October 1981) and North (winter, December 1981) polar regions respectively. The abscissa is Universal Time, with data binned in 2-h intervals (centred on the odd hours): The vertical coordinate is latitude in each of the figures. In Fig. 1, data in the lower half has been taken at a local time of 21.00 , while that in the upper half has been taken at $09.00 \mathrm{~L}$.T. The geographic South Pole is at $-90^{\circ}$, and the locus of the nearest passage of the satellite to the south geomagnetic pole is marked by the sinusoidal curve. The satellite, being in a strictly polar orbit, only crosses directly over the geomagnetic south pole at two periods in the U.T. day, one close to midnight (U.T.), and the second close to midday (U.T.). In Fig. 2, data in the lower part has been taken at $18.00 \mathrm{~L}$.T., while data in the upper half has been taken at 06.00 L.T., and the North Pole crossings are across the centre of the figure. The locus of closest approach to the north geomagnetic pole is again marked by a sinusoidal curve.

In the southern (summer) polat region (Fig. 1) and in the northern (winter) polar region (Fig. 2), the major variations seen in the wind and temperature data, for example the fast anti-sunward winds in the polar cap, follow the diurnal migration of the geomagnetic polar region about the geographic pole. It will be seen that this U.T. and geomagnetic "control" in the polar regions applies to the neutral temperature and composition as well as to the dynamics of the thermosphere. In Figs. $3 \mathrm{~A}$ and $3 \mathrm{~B}$ respectively, the orbital track of $D E-2$ at $00.00,06.00,12.00$ and 18.00 U.T. is shown for the South (16 October) and the North polar regions (21 December). A model polar potential electric field (which will be discussed later) is used to illustrate the way in which the satellite path, crossing directly over the geographic pole, samples quite different geomagnetic regions at particular times in the U.T. day. The location of the terminator is also shown, indicating which parts of the satellite track, and of the geomagnetic polar region, will be sunlit tor an orbit at a particular Universal time.

In the Southern Hemisphere the geomagnetic pole is offset from the geographic pole by a much larger angle $\left(22^{\circ}\right.$ rather than $\left.11^{\circ}\right)$. This has two important effects.
The first is to cause a very large diurnal modulation of the solar insolation and photoionisation of the geomagnetic polar region. In mid-October, the entire southern geomagnetic polar region is in sunlight except between 10.00 and 20.00 U.T., when the midnight parts of the polar cap and auroral oval dip into darkness. The second effect is due to the large diurnal migration of the southern geomagnetic polar region relative to the $D E-2$ orbit. For example, about 18.00 U.T. in the Southern Hemisphere, the $D E-2$ orbit only grazes the dusk auroral oval. This partly explains the modest atmospheric perturbations observed in that region. In contrast, during December, the northern geomagnetic polar region is almost always in darkness, with a brief illumination of the dayside polar cusp by sunlight near 18.00 U.T. The geometrical sampling of the geomagnetic polar region is less variable with Universal Time than in the Southern Hemisphere, but is still of significance, since near 06.00 U.T., the orbit passes close (in the $06.00-18.00$ L.T. plane) to the dayside cusp, while near 18.00 U.T., the orbit crosses close to the midnight auroral oval.

\section{The vector wind data}

Figure 1 shows the distribution of vector winds and neutral temperature sampled by latitude and Universal Time for the South polar region during October 1981. As described by Hays et al. (1984) a region of $400-$ $500 \mathrm{~m} \mathrm{~s}^{-1}$ winds directed from right to left, or antisunward, follows closely the location of the magnetic polar cap during the U.T. day. The highest antisunward winds occur between 21.00 and 06.00 U.T, and close to 12.00 U.T.

Where the satellite orbit intersects the dusk auroral oval, and the associated region of fast sunward ion convection (Fig. 3), about $20^{\circ}$ from the closest approach to the geomagnetic pole (below the sinusoid in Fig. 1), there is a region of $200-300 \mathrm{~m} \mathrm{~s}^{-1}$ sunward winds at all U.T.s. Only in the period 03.00-05.00 U.T. is there an indication of sunward winds associated with the dawn crossing of the auroral oval (above the sinusoid). Below about $50^{\circ}$ geomagnetic latitude the wind vectors are anti-sunward at 09.00 L.T., and weakly sunward at 21.00 U.T., with moderate velocities of between 100 and $200 \mathrm{~ms} \mathrm{~s}^{\mathrm{i}}$.

Figure 2 shows the results of a complementary study of the North polar region, using data obtained in late November and December 1981. As noted by Hays et al. (1984), the polar cap is again dominated by a strong anti-sunward flow, averaging $500 \mathrm{~m} \mathrm{~s}^{-1}$, with a tendency for the highest velocities to occur on the dawn side of the magnetic pole crossing. In the dusk auroral oval there are sunward winds of, typically, 100$300 \mathrm{~m} \mathrm{~s}^{-1}$. However, average winds in the dawn oval 
show only a tendency to decrease to small values between the high anti-sunward values of the polar cap and the smaller anti-sunward values associated with the midlatitude regions.

\section{Neutral temperature structure}

The temperature structure of the South polar region (Hays et al., 1984) is dominated, in this presentation, by a broad band of elevated temperature, approx. $50^{\circ}$ of latirude in extent, which follows the diurnal (U.T.) migration of the South geomagnetic pole. In reality, this band observed at variable geographic latitude as a function of U.T. is a region, approximately circular, and centred on the South geomagnetic pole. The highest temperatures appear to occur near midday U.T., and near midnight U.T., both at times when the $D E-2$ orbit crosses the late morning part of the auroral oval and the dayside polar cusp. Temperatures in the period 15.00 23.00 U.T. are significantly lower than those between 23.00 and 15.00 U.T., i.e. when the orbit is crossing the afternoon parts of the auroral oval, and when that region is at low solar elevation. The temperature data have not been separately analysed for geomagnetic quiet and disturbed periods.

Neutral temperature over the North polar region (Fig. 2) is rather more complex than that of the South polar region. The temperatures within the mid-latitude regions at 18.00 L.T. are significantly higher than those in the mid-latitude regions at $06.00 \mathrm{~L}$.T. Moving poleward from mid-latitude at 18.00 L.T., there is a steady decrease toward the pole to a latitude of about $60^{\circ}$. The geomagnetic polar region is surprisingly hot (also noted by Blamont and Luton, 1972), with the region of highest temperatures located toward the dawn side of the polar cap (but distinctly poleward of the dawn auroral oval).

A cold region appears between 60 and $80^{\circ}$ geomagnetic latitude in the evening hours, most pronounced about $12.00 \mathrm{U} . T$., when this geomagnetic region is at highest geographic latitude, and thus has a low or zero level of solar u.v./e.u.v. input during this winter solstice period. The temperature contrast between the hot region of the geomagnetic pole and this cold auroral and sub-auroral evening region is about $300 \mathrm{~K}$. This strong contrast was not well predicted by the comparisons with models described earlier by Hays et al. (1984). The mechanisms which combine to cause this strong temperature contrast are included in the present model simulations and will be discussed later.

\section{Neutral gas composition and density}

(a) Composition and density in the South polar region (October 1981). In Fig. 4, a composite of the temperature (FPI) and composition (NACS) data are displayed. In panel (A), the FPI temperatures are shown (same as Fig. 1), while panel (B) shows the mean molecular weight distribution derived from NACS. Panels (C) and (D) show the individual (NACS) densities of atomic oxygen and molecular nitrogen, in the same format as that described previously for the neutral wind and temperature data. The neutral composition data is selected for geomagnetic quiet periods, i.e. for $A_{p}<20$, while the temperature data is the average of all activity for October 1981.

Mean molecular weight increases from midlatitudes at either 09.00 L.T. or at 21.00 L.T. toward the southern (summer) polar region. However, the region of the highest mean molecular weight follows the diurnal variation of the locus of the south geomagnetic pole but is displaced toward the morning auroral oval. Molecular nitrogen densities are observed to be strongly enhanced when the satellite crosses the geomagnetic polar region, and particularly so on the morning side of the polar cap, close to the boundary with the morning auroral oval, and in the U.T. period between 04.00 and 12.00 U.T.

The major reason that the post U.T.-noon data shows smaller nitrogen enhancements is apparently only that the $D E-2$ orbit does not cross the dawn auroral oval in this period. It should, however, be recalled (Fig. 3) that the $D E-2$ crossings of the morning auroral oval occur when the solar elevation angle is relatively high (maximum solar photo-ionisation). In October 1981, the solar elevation angle is rather low when $D E-2$ crosses the dusk auroral oval.

The temptation to associate the maximum compositional perturbation with the region of the morning auroral oval should thus be tempered with the recollection that for the $D E-2$ orbit plane alignment in October, photo-ionisation enhances the conductivity of the morning auroral oval to a much larger extent than that of the dusk auroral oval. The maximum compositional enhancement may thus be partly an artifact of the orbit plane alignment of $D E-2$ during this epoch.

Atomic oxygen is depleted in the high magnetic latitude region, but to only about $30 \%$ of the extent to which molecular nitrogen is enhanced. The region of maximum oxygen depletion occurs near to the closest approach of the satellite to the South magnetic pole. The total gas density is not explicitly shown in these figures. In general, and particularly in the summer hemisphere, the opposing senses of the nitrogen and oxygen perturbations mean that total density shows less structure than the densities of the individual major constituents.

In Fig. 5 (A, B, C and D), a complementary study of the South polar region for more disturbed geomagnetic 

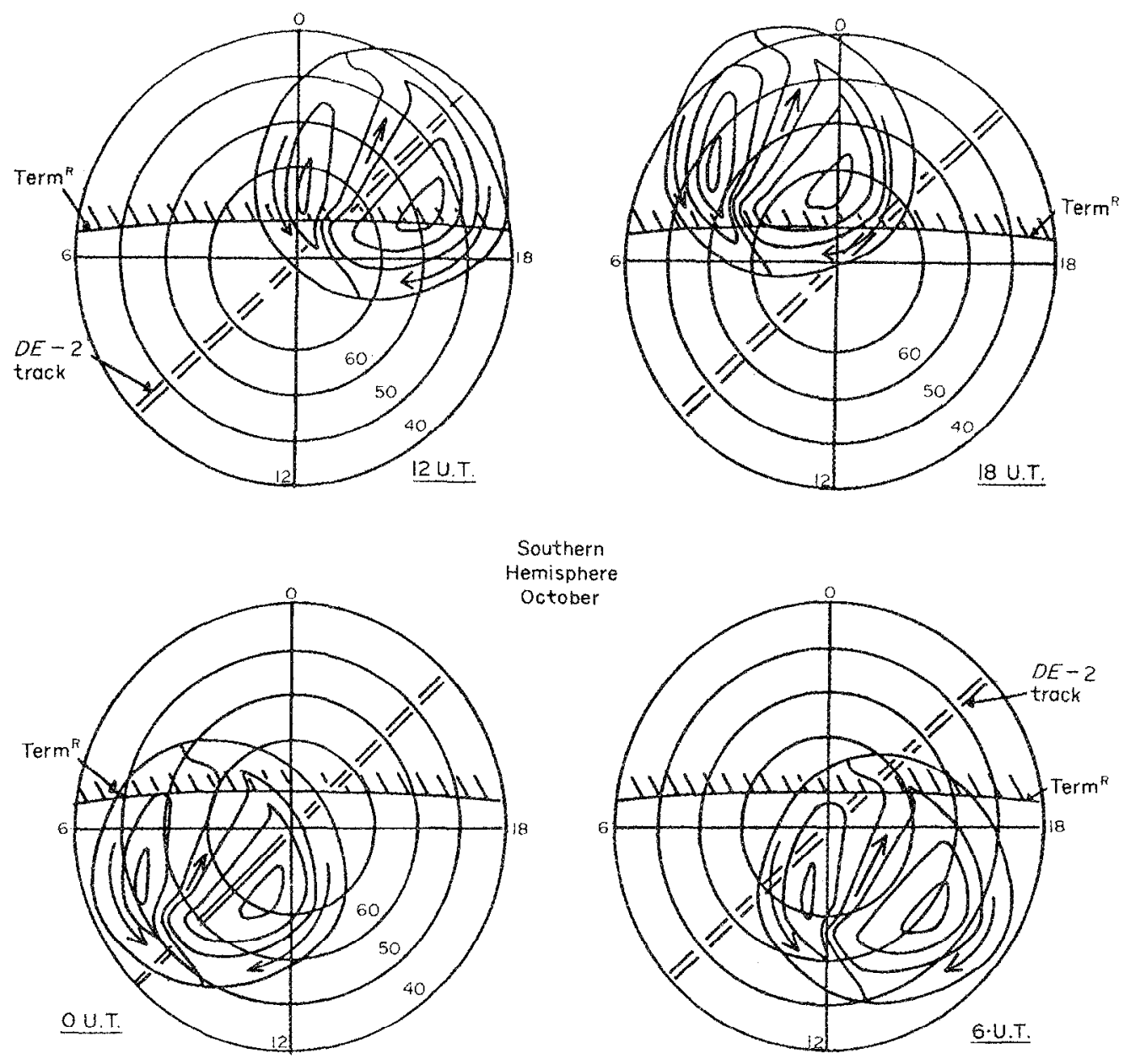

Frc. 3(a)

periods is shown $\left(A_{p}>20\right)$. Note that the same neutral temperature data are shown as in Figs. 1 and $4(A)$. All of the features of the quiet study $\left(A_{p}<20\right)$ which were associated with the southern geomagnetic polar region and the input of geomagnetic energy, are further enhanced above the middle latitude regions. Molecular nitrogen, for example, replaces atomic oxygen as the major constituent over a considerabic latitudinal region about the geomagnetic pole, in particular near 12.00 U.T. There is also a noticeable increase in the latitude range about the geomagnetic pole in which the compositional perturbations occur. This latitudinal extension can beassociated with a general equatorward expansion of the auroral oval during the more geomagnetically disturbed periods covered by this particular sample of data (Siscoe, 1982; Meng, 1983). (b) Neutral composition and density in the winter North Pole region. In Fig. 6, the same neutral composition parameters as those shown in Figs. 4 and 5 for the South polar region are shown for the North polar study (December 1981). The format is similar to that used in Fig. 2. Figure 6(B) shows that the mean molecular weight decreases persistently from midlatitudes at 18.00 L.T., toward the northern pole, and then continues decreasing toward the mid-latitude region at 06.00 L.T., as would be expected from all global models. However, there is an abrupt reversal of this trend in a region of enhanced molecular weight on the dawn boundary of the polar cap and auroral oval. This region follows the locus of the magnetic pole during the U.T. day, but is persistently displaced about $10^{\circ}$ of latitude toward the dawn side of the polar cap. It 

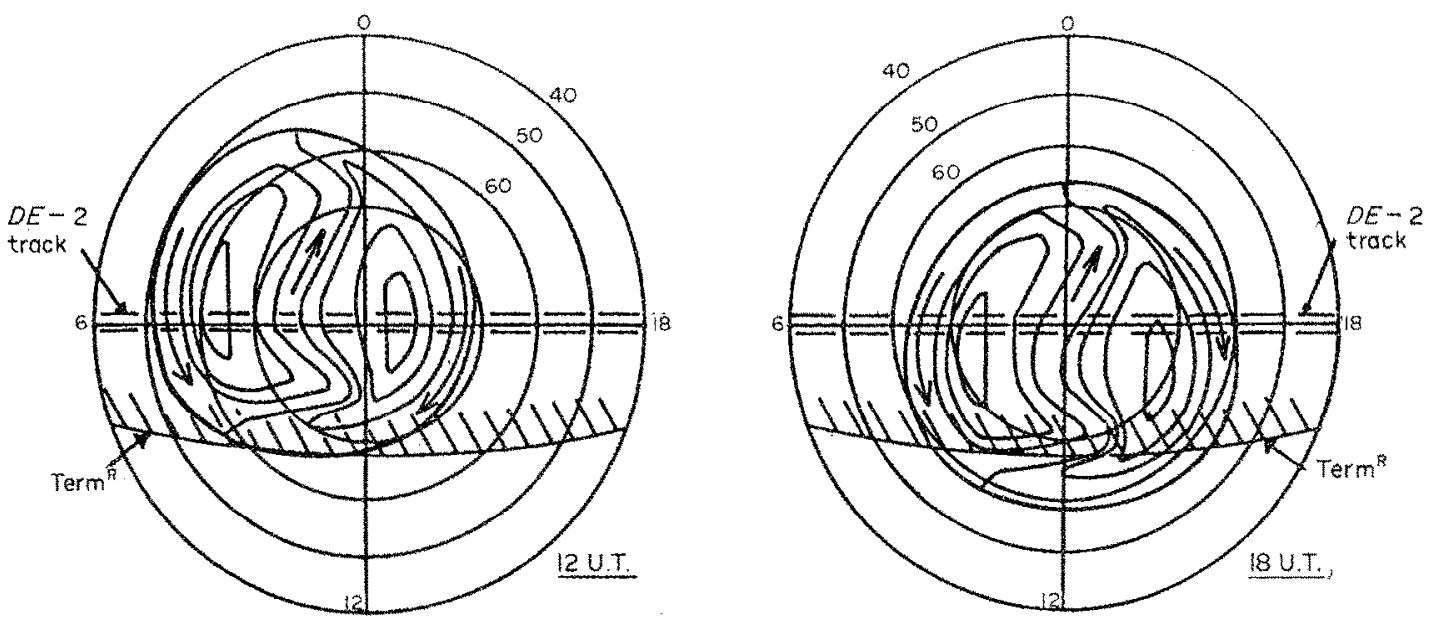

Northern Hemisphere

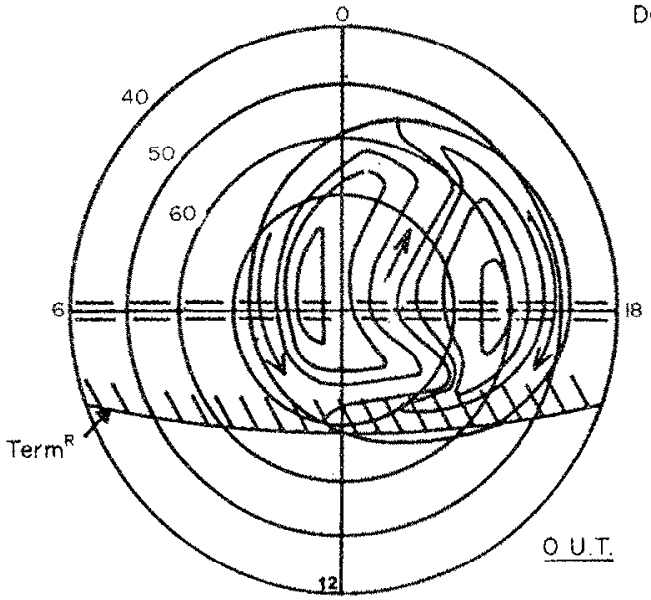

December

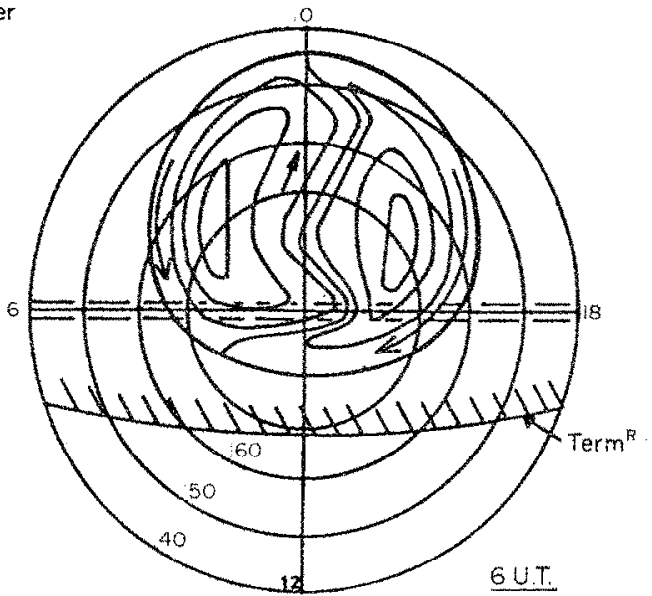

(b)

Fig. 3. (A) ORIENTATION OF THE DE-2 ORBT PLANE, THE TERMINATOR (HATCHED LINE) AND THE CONVECTON PATTERN ASSOCLATED WITH THE SOUTH GEOMAGNETC POLAR REGTON YOR THE OCTOHER 1981 PERIOD.

The orbit plane is approx. between 21,00 and $09,00 \mathrm{~L}$.T. Average solar declination (16 October) is about $-12^{4}$. (B) ORIENTATION OF THE DE-2 ORBTT PLANE, THE TERMINATOR (HATCHED LNE) AND THE CONVECTION PATTERN ASSOCIATED WITH THE NORTH GEOMAGNETIC POLAR REGKON FOR THE DECEMBER 1981 PERIOD.

The orbit plane is approx, between 06.00 and 18.00 L.T. Average solar declination (21 December) is about $-23^{\circ}$.

should be noted that the mean molecular weight in the winter polar cap region is much lower than in the summer polar cap. Atomic oxygen is always the dominant component at $320 \mathrm{~km}$ in these winter polar regions, and the highest average values of mean molecular weight are 18.5 , compared with values of 23 in the summer South Pole region.

Figures $6(C)$ and (D) show that it is an enhancement of molecular nitrogen density that is responsible for the highest values of mean molecular weight on the dawn side of the winter geomagnetic polar cap, rather than a depletion of atomic oxygen density. Reference back to Fig. 2 indicates that this region of the dawn side of the polar cap is where the highest anti-sunward winds occur, and is also where the gas temperature is very high. 


\section{THE THEORETICAL GLOBAL NUMERICAL MODEL}

The UCL 3-D T-D thermospheric model has been described in a series of papers (Fuller-Rowell and Rees, 1980, 1981, 1983, 1984; Rees et al., 1980a,b, 1981, 1982, 1983, 1984; Smith et al., 1982; Fuller-Rowell et al., 1984 ; Quegan et al., 1982). The model includes options of using theoretical or empirical models of solar u.v./e.u.v. fluxes, of heating efficiencies, and of the ionosphere and its global and local responses to solar photo-ionisation. Theoretical or empirical models of magnetospheric convection at high latitudes and of ionospheric convection at low latitudes can be used to describe the momentum interactions (ion drag) of the neutral and ionised species. Differentialion and neutral motions aiso create sources of Joule and friction heating. These processes (ion drag and Joule/friction heating) may be strongly enhanced where ionospheric plasma densities are elevated due to magnetospheric particle precipitation. The direct thermal energy deposition caused by magnetospheric particle precipitation, in addition to enhanced Joule heating due to elevated plasma densities, is added to the energy equation in a self-consistent way. However, there is no attempt at a self consistent treatment of coupling between magnetosphere, ionosphere and thermosphere in terms of convection, or for continuity of current carriers for the ionospheric or for the fieldaligned, magnetospheric, current systems in any of the models. The geomagnetic poles are distinet from the geographic poles, so that U.T. and longitude dependencies due to geomagnetic phenomena can be simulated realistically. Lastly, thermosopheric composition responds to systematic convection and advection so that in regions of upwelling, the ratio of molecular nitrogen density to atomic oxygen density will be enhanced at constant altitude and at constant pressure levels, while the atomic oxygen to molecular nitrogen density ratio will be enhanced in regions of persistent downdraft. This composition solution is fully

TAMHE: 1. SOLAR U.V. AND E.U.V. TNERGY INPUTS FOR THE 3D-TD MODEL FOR 16 OCTOBLR AND 21 DECIMBER

\begin{tabular}{lcc}
\hline $\begin{array}{l}\text { A. } 16 \text { October } \\
\text { Northern Hemisphere } \\
\quad \text { (autumn/winter) }\end{array}$ & u.v. & e.u.v. \\
$\begin{array}{l}\text { Southern Hemisphere } \\
\text { (spring/summer) }\end{array}$ & 5.3 & 0.9 \\
& 5.3 & 1.4 \\
B. 21 December & & \\
Northern Hemisphere (winter) & u.v. & e.u.v. \\
Southern Hemisphere (summer) & 3.0 & 0.72 \\
\end{tabular}

All numbers are in units of $10(11) \mathrm{W}$. self-consistent with the proviso that it does not include a detailed photochemical scheme, and thus applies to a light species, atomic oxygen, and a heavy species, a mixture of $\mathrm{N} 2$ and $\mathrm{O} 2$. The compositional (and other) results produced by the model have to be considered with care when approaching the lower boundary of the $\operatorname{model}(80 \mathrm{~km})$.

\section{SIMULATING THE THERMOSPHERIC RESPONSE TO QUIET AND DISTURBED GEOMAGNETIC PERIODS AND THE INFLUENCE OF THE " $Y$ " COMPONENT OF THE INTERPLANETARY MAGNETRC FIELD}

A large number of simulations of the dynamics and structure of the Earth's thermosphere have been carried out with the UCL model. These have been discussed in previous papers referenced in Section 3. The model is in a process of evolution to meet the challenges of new empirical data, and to reflect improving theoretical concepts of treating various sources of energy and momentum for the thermosphere, or the interactions between the thermosphere, ionosphere and magnetosphere.

In this paper, some of the effects on the polar thermosphere of the ionospheric convection distributions of recent models of the polar electric field, which contain a dependence on the " $Y$ " component of the IMF, will be tested. These models have been prepared by Heppner and Maynard (1983) from data obtained by the Vector Electric Field Instrument (VEFI) of Dynamics Explorer-2. For the purpose of comparisons with the Dynamics Explorer data sets described in this paper, ten distinct global simulations will be used. Each of these are quasi-steady state global simulations (i.e. the only variability is that due to Universal Time, local time, latitude and altitude). That is, the UCL model has been run, in each case, to the point where the diurnal variations are fully repeatable. Depending on the extent of changes of energy and momentum inputs relative to a previously-run and stable model, the total process requires between 48 and 80 h of "thermospheric" time to achieve stability for each of the 10 simulations.

Five of these simulations are for December solstice conditions, corresponding to the December $1981 \mathrm{DE}-2$ Northern Hemisphere observations period (i.e. Northern Mcmisphere winter), and five are for the epoch corresponding to mid-October 1981, the period of the southern polar $D E-2$ study. The Northern Hemisphere winter solstice simulation is considered to be adequate for the northern polat perigee period in December 1981, due to the slow rate of change of solar declination between late November and late December. 
Solar u.v. and e.u.v. inputs corresponding to a mean $F 10.7 \mathrm{~cm}$ flux of 150 units have been used in all of these simulations. This value is rather lower than the means for the October 81 epoch (240) or the December 81 epoch (220). The differences can be assessed using studies of the sensitivity of mean thermospheric temperature to e.u.v. fiux carried out by Fuller-Rowell and Rees (1980) and by Smith and Rees (1985).

The gobal mean temperature should be about $200 \mathrm{~K}$ higher when $F 10.7 \mathrm{~cm}=220$ than when $F 10.7 \mathrm{~cm}$ $=150$, assuming the same level of geomagnetic activity and energy input to the thermosphere.

Two simulations have been run for each period using the CHIU (1975) global ionospheric model to describe quiet geomagnetic conditions (Rees et al., 1983). A further three simulations have been run for each period using a merger of the CHIU model at low latitudes with a hybrid high latitude ionospheric model "PIONS" which describes the response of the high-latitude ionosphere to the energetic particle precipitation from the magnetosphere. The PIONS model is based on a study carried out by Roble and Rees (1977), and its development and adaptation to the UCL 3-D T-D model is described in Smith (1984) and Smith et al. (in prepatation, 1985).

The PIONS model is not fully self-consistent, but produces results which, for thermospheric purposes, are consistent with the major structures observed in thermal ionospheric plasma distributions, in the selfconsistent study carried out by Quegan et al. (1982). The major differences are that PIONS more realistically describes $E$-region ionisation response to magnetospheric particle precipitation, and allows the use of values of magnetospheric plasma precipitation which represent average precipitation values as described by Winninghan and Gurgiolo (1982) from $D E-2$ data, by Evans (pers. comm. 1983) from NOOA-7 data, and by Spiro et al. (1982) from Atmosphere Explorer data.

In using the PIONS model, the ionospheric densities are not permitted to fall below the appropriate CHU model values, and at lower latitudes, the two models are merged.

Two simulations for both October and December periods, using the CHIU-PIONS ionosphere models, use as magnetospheric particle input, a description of "soft" polar cusp and polar cap electron sources only. Such "soft" electrons represent a considerable and important heat source to the middle and upper thermosphere, in addition to their ionising effects which augment ion drag and frictional heating.

The last pair of simulations, one for October and one for December, use, in addition to the "soft" electron sources, the energetic electron input described by Spiro et al. (1982) for conditions of $100<A E<300$. These kilovolt or auroral electrons strongly augment heating, ionisation, ion drag and friction (Joule) heating in the lower thermosphere within the auroral oval.

High latitude ionospheric convection is of crucial importance to the behaviour of the thermosphere. Its effects, via ion drag, modulate the wind patterns observed throughout the polar cap and auroral oval and, beyond the local wind effects, the associated Joule and friction heating play a major role in determining the mean meridional wind distribution on a global scale.

In this study, two polar electric field models have been used. These are the two asymmetric convection fields associated by Heppner and Maynard (1983) with the direction of the " $Y$ " component of the Interplanetary Magnetic Field (IMF). These polar potential field distributions are illustrated in Fig. 7. In the Northern Hemisphere, the configuration when BY is negative (the A2 model) is shown in Fig. $7 \mathrm{~A}$, while that when BY is positive (the B2 model) is shown in Fig. 7B. Depending on the sense of the IMF $Y$ component, very large changes will occur, according to these models, in the plasma flow in the vicinity of the polar cusp, and over the cntire polar cap. For a situation when the IMF BY is positive, a cell of high velocity plasma flow will link the afternoon auroral oval and dawn polar cap. When BY is negative, a large-scale convection cell will link the dawn auroral oval and dusk polar cap. The thermospheric consequences of these convection patterns will depend on the covariance (or otherwise) of magnetospheric energetic particle precipitation, which will thus influence the patterns of ionospheric conductivity. As yet, no comparable study of magnetospheric energetic plasma precipitation has been completed. In the absence of better empirical information, the same ionospheric plasma distributions will be used for either of the convective field patterns.

The appropriate use of these patterns is that when BY is positive, the B2 field should be used in the Northern Hemisphere, and the A2 field should be used in the Southern Hemisphere. Conversely, when BY is negative, the $\mathrm{A} 2$ field should be used in the Northern Hemisphere and the B2 field should be used in the Southern Hemisphere.

The one exception relating to the ionospheric plasma is the location of the source of soft electrons corresponding to the polar cusp. It is assumed that the location of the cusp source migrates with the cusp as defined by the convection pattern. When BY is positive the cusp source is centered at earlier local time (about 11.00 L.T.), while when BY is negative, the cusp source is centered about 13.00 L.T. It should be emphasized 


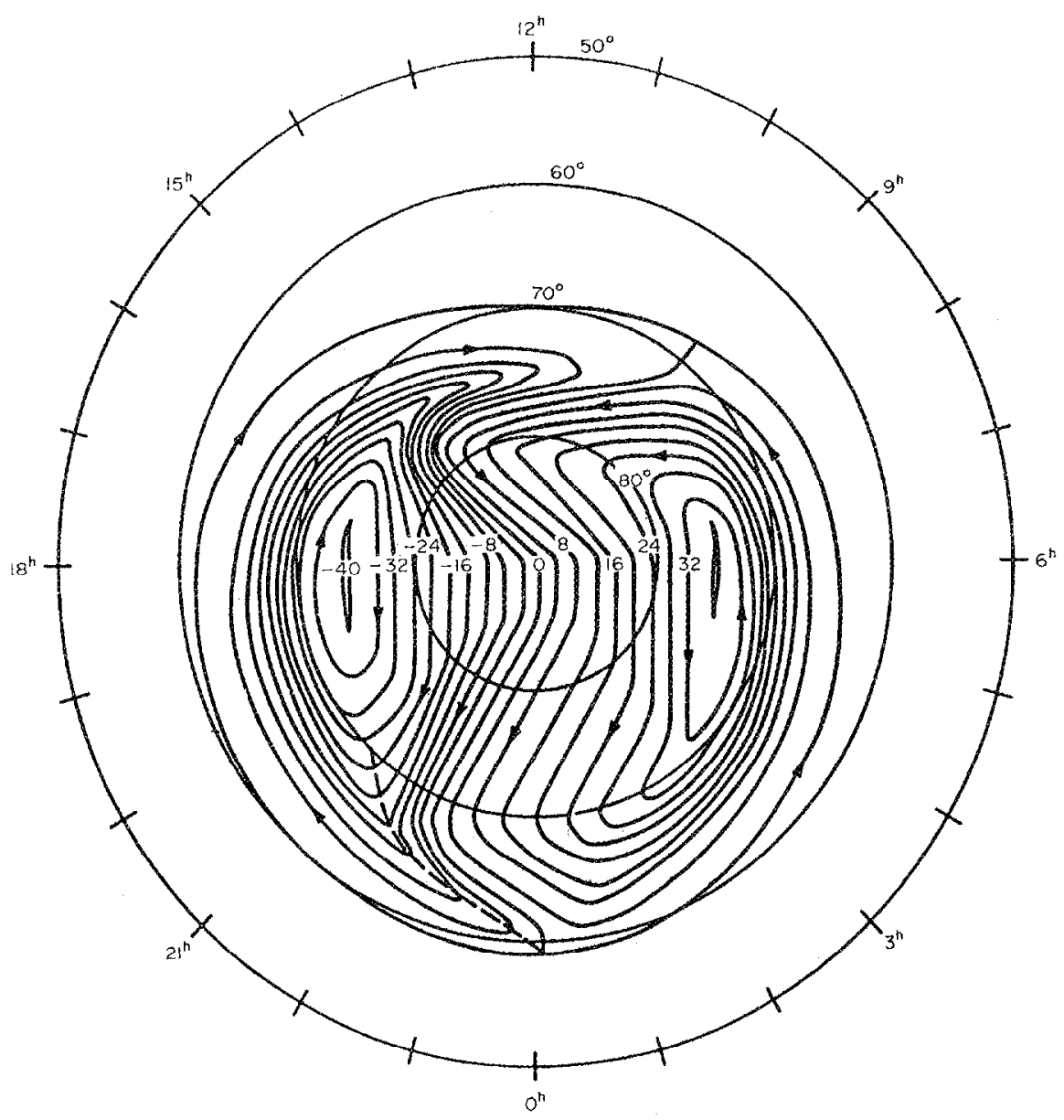

Fig. 7(a)

that this translation of the "soft" cusp electron source is not based on empirical data.

The neutral wind distributions produced by each of these asymmetric polar electric field distributions have been discussed and related to individual wind observations both from $D E-2$ and from ground-based Fabry-Perot interferometers by Rees et al.(1985). They point out that many high latitude thermospheric wind observations, both satellite and ground-based, are difficult to simulate or explain without invoking large asymmetries of ion convection velocity. These asymmetries appear to be associated with persistent trends of the IMF $Y$ component. Quite frequently, asymmetric distributions of thermospheric winds are observed which appear to be consistent with the major features of thermospheric circulation induced by either the $\mathrm{A} 2$ or the $\mathrm{B} 2$ convection models. The complete range of input conditions for the three groups of model simulations which have been carried out are described in Table 2. Many of the details are common to all of the ten simulations, and these common data are described in Table 3.

\section{THERMOSPFIERIC BEHAVIOUR PREDICTED BY THE RANGE OF SIMULATIONS}

\subsection{The instantaneous distribution of wind and} temperature

The DE-2 observations do not, either individually or collectively, present a complete pattern of wind circulation. Neither do the observations sample all regions of geophysical importance at a full range of Universal Times, at all seasons, and under a wide range of geomagnetic activity conditions. If the simulations are to be of value, they must predict the $D E-2$ observations, without generating unrealistic thermo- 


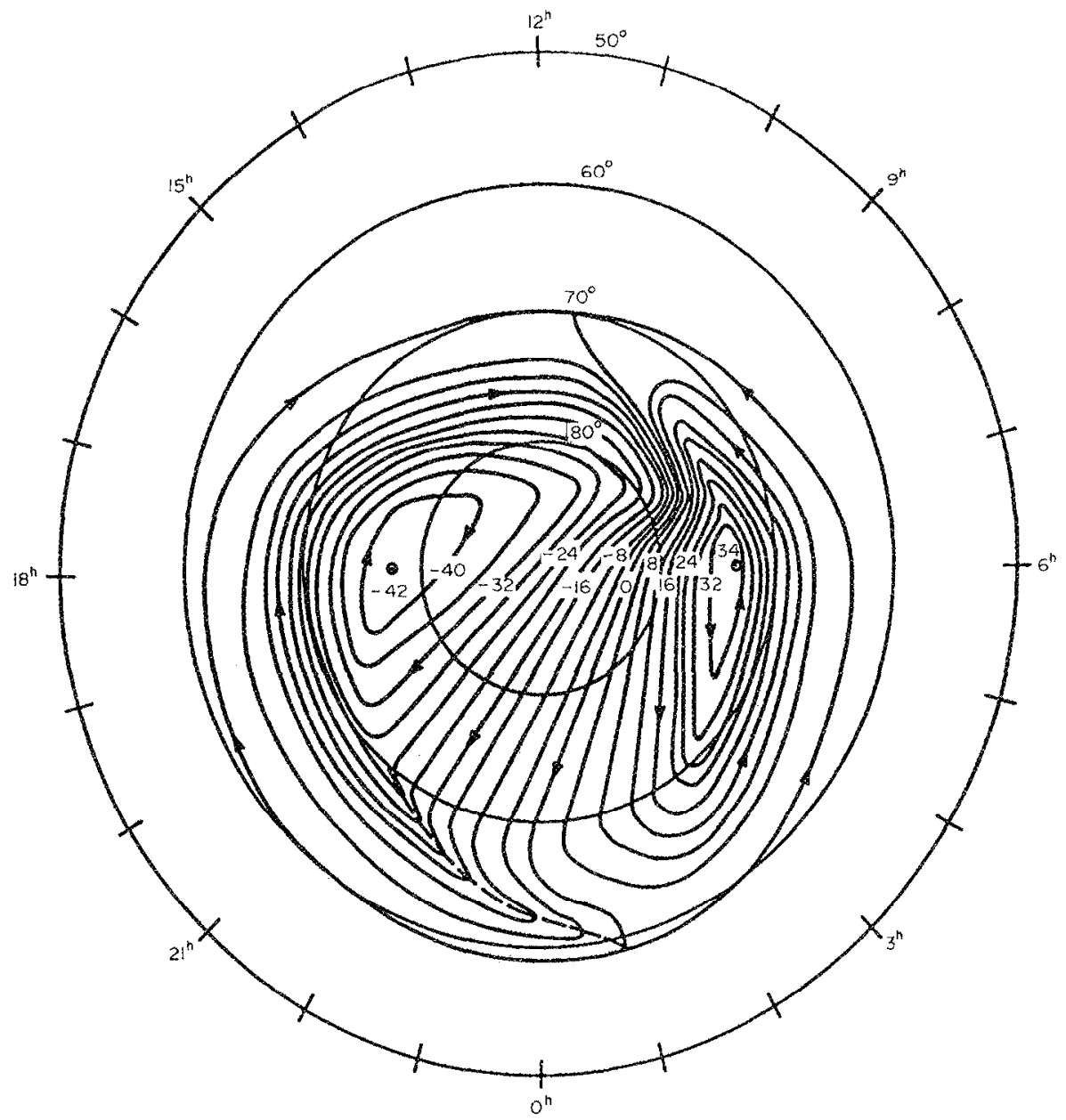

(b)

Fig. 7. Polar convection electric pottential distributions from Heppner (1983), with dependence on THE "Y" COMPONENT OF THE IMF.

(a) The A-2 field - applied to the Northern Hemisphere with BY - ve. Applied to the Southern Hemisphere with BY + ve.

(b) The B-2 feld - applied to the Southern Hemisphere with BY - ve. Applied to the Northern Hemisphere with $B Y+v e$.

spheric phenomena under a combination of conditions which have not yet been described by the DE-2 (or other) observations. The circulation and temperature structures generated by the two convection field models will thus be briefly described.

The polar wind circulation and temperature structure due to the asymmetric convection electric fields

In Fig. 8(A) and (B) two snap-shots of the South (summer) polar region are shown at 19.20 U.T. These contrast the polar circulation induced by the $\mathrm{A} 2$ and the B2 convection models in the Southern Hemisphere (representing the situations when the $Y$ component of the IMF is respectively positive or negative). The ionospheric models used in these two simulations are the same, CHIU/PIONS, reflecting moderately disturbed geomagnetic conditions. The neutral temperature field is shown as a scalar background to the vector wind distribution for an altitude of $320 \mathrm{~km}$. The quasi-steady state condition of these models 


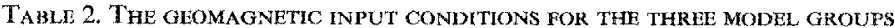

Group 1. Simulations for moderately quiet geomagnetic Southern Hemisphere: conditions.

Global Ionosphere: CHIU (1975)

Particle Heating: None

Particle Ionisation: None

Joule heating due to polar electric field and CHUU ionosphere

Northern Hemisphere:

\begin{tabular}{lcccc} 
& \multicolumn{2}{c}{ A2/B2 CHIU } & \multicolumn{2}{c}{ B2/A2 CHIU } \\
& 16 & 21 & 16 & 21 \\
& October & December & October & December \\
00.00 U.T. & 0.17 & 0.118 & 0.17 & 0.112 \\
06.00 U.T. & 0.12 & 0.100 & 0.11 & 0.090 \\
12.00 U.T. & 0.25 & 0.134 & 0.21 & 0.125 \\
18.00 U.T. & 0.35 & 0.185 & 0.38 & 0.164
\end{tabular}

Southern Hemisphere:

\begin{tabular}{lcccc} 
& \multicolumn{2}{c}{ A2/B2 CHIU } & \multicolumn{2}{c}{ B2/A2 CHIU } \\
& 16 & 21 & 16 & 21 \\
& October & December & October & December \\
00.00 U.T. & 0.98 & 1.20 & 0.84 & 1.26 \\
06.00 U.T. & 0.93 & 1.24 & 1.09 & 1.39 \\
12.00 U.T. & 0.43 & 0.81 & 0.38 & 0.72 \\
18.00 U.T. & 0.30 & 0.67 & 0.34 & 0.74
\end{tabular}

Input is in units of $10(11) \mathrm{W}$.

Group 2. Simulations for moderately disturbed geomagnetic conditions.

Global Ionosphere: CHIU (1975) at low latitudes, merged with PIONS model at high geomagnetic latitudes.

Particle Heating: Polar cusp $-1 \mathrm{erg} \mathrm{cm}^{-2}$ at $100 \mathrm{eV}$, plus Polar cap-0.5 $\mathrm{erg}^{-7}$ at $100 \mathrm{eV}$, Total 0.05(11) W global.

Particle Ionisation: Polar cusp and polar cap ionisation related to particle heat input by PIONS model.

Joule heating: Polar electric field and CHIU ionosphere at low latitudes, with conductivity enhanced in polar cap and polar cusp due to "soft" electron precipitation.

Northern Hemisphere:

\begin{tabular}{lcccc} 
& \multicolumn{2}{c}{ A2/B2 } & \multicolumn{2}{c}{ B2/A2 } \\
& CHIU/PIONS & \multicolumn{2}{c}{ CHIU/PIONS } \\
& 16 & 21 & 16 & 21 \\
00.00 U.T. & 0.38 & 0.18 & 0.35 & 0.17 \\
06.00 U.T. & 0.32 & 0.15 & 0.34 & 0.14 \\
12.00 U.T. & 0.49 & 0.19 & 0.52 & 0.18 \\
18.00 U.T. & 0.56 & 0.25 & 0.59 & 0.23
\end{tabular}

\begin{tabular}{lcccc} 
& \multicolumn{2}{c}{ A2/B2 } & \multicolumn{2}{c}{ B2/A2 } \\
& CHUU/PIONS & \multicolumn{2}{c}{ CHIU/PIONS } \\
& 16 & 21 & 16 & 21 \\
& October & December & Octuber & Dectmber \\
00.00 U.T. & 0.99 & 1.30 & 1.05 & 1.39 \\
06.00 U.T. & 1.04 & 1.35 & 1.17 & 1.53 \\
12.00 U.T. & 0.70 & 0.90 & 0.64 & 0.82 \\
18.00 U.T. & 0.59 & 0.76 & 0.65 & 0.85
\end{tabular}

Input is in units of 10(11) W.

Group 3. Simulations for more disturbed geomagnetic conditions.

Global Ionosphere: CHIU (1975) at low latitudes, merged with PIONS model at high geomagnetic latitudes.

Particle Heating: $\quad$ Polar cusp $-1 \mathrm{erg} \mathrm{cm}^{-2}$ at $100 \mathrm{eV}$, plus Polar cap $\cdots 0.5 \mathrm{erg} \mathrm{cm}^{-2}$ at $100 \mathrm{eV}$. Auroral oval precipitation from Spiro et al. (1982) for $100<$ $A E<300$.

Total 0.36(11) W global.

Particle Ionisation: Polar cusp and polar cap ionisation related to particle heat input by PIONS model.

Joule heating: Polar electric field and CHIU ionosphere heating augmented by particle energy deposition and by consequent ionisation and conductivity increases.

Northern IIcmisphere:

B2/A2 CHIU/PIONS + Spiro.

(B2 Field applied to Northern Hemisphere, BY + ve.)

$\begin{array}{lcc} & 16 \text { October } & \text { 21 December } \\ \text { 00.00 U.T. } & 0.64 & 0.54 \\ \text { 06.00 U.T. } & 0.59 & 0.53 \\ \text { 12.00 U.T. } & 0.63 & 0.53 \\ \text { 18.00 U.T. } & 0.85 & 0.58\end{array}$

Southern Hemisphere:

\section{B2/A2 CHIU/PIONS}

(A2 Field applied to Southern Hemisphere, BY + ve.)

$\begin{array}{lcr}\text { 00.00 U.T. } & 1.27 & 1.71 \\ \text { 06.00 U.T. } & 1.65 & 1.88 \\ \text { 12.00 U.T. } & 0.84 & 1.18 \\ \text { 18.00 U.T. } & 0.97 & 1.22\end{array}$

Input is in units of 10(11) W. 


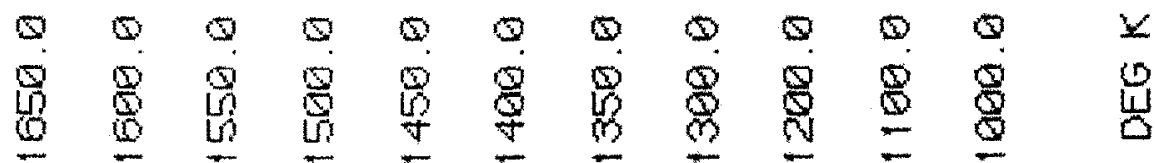
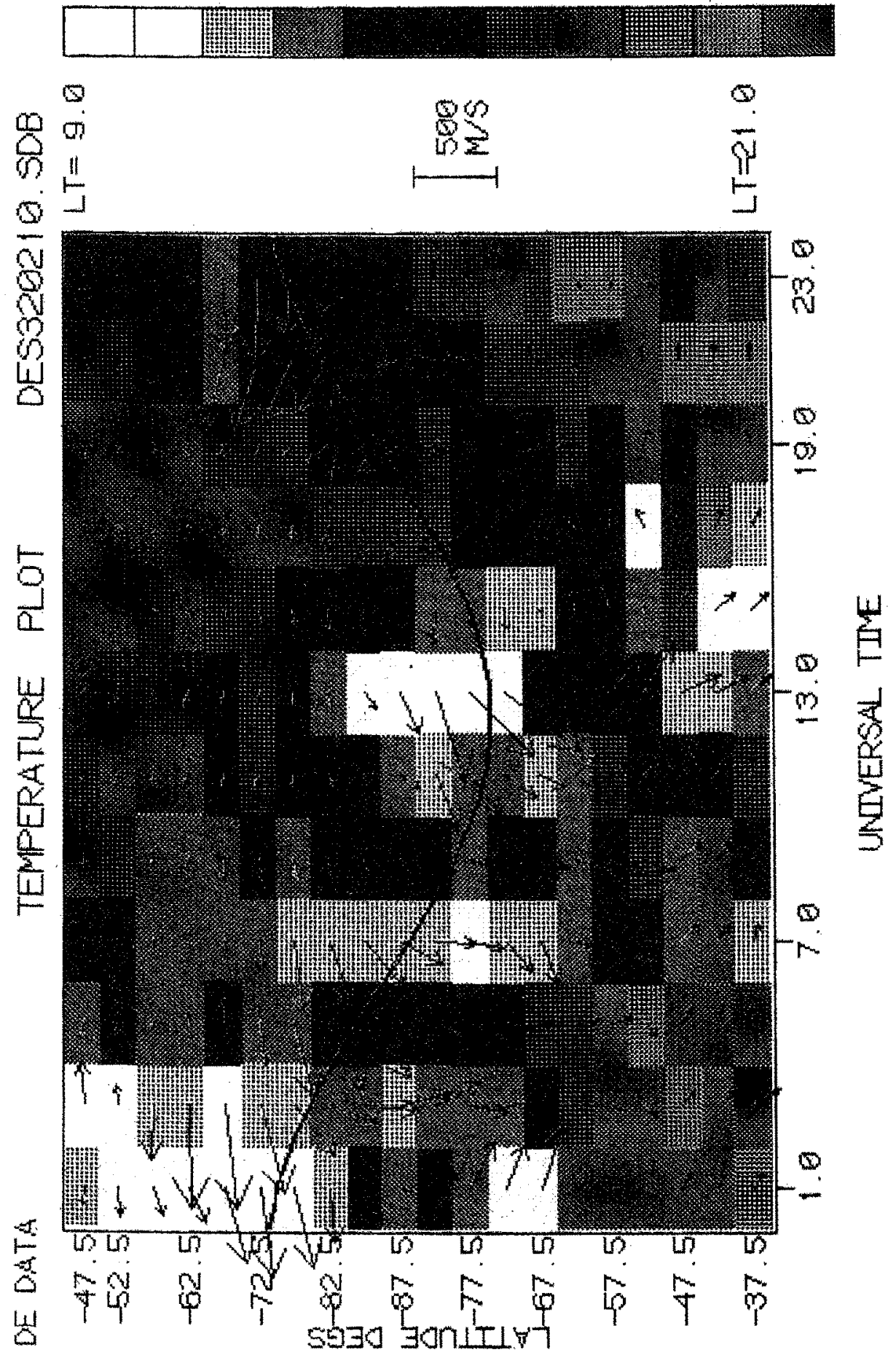

兽焉

要

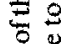

旅

5

\%

줄

웅

亩

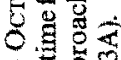

H

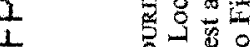

- 1 )

(n) $\quad$ 票焉

II

30 z

on

象影

की

$\alpha \mapsto$

OW

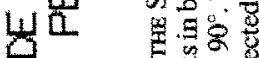

山

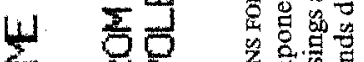

즈 苍总

I

枯

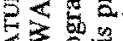

促

至

격영

요용

语焉果

题要

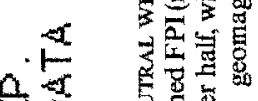

$\frac{0}{4}$

.$\overline{0}$ z

品上路

대용

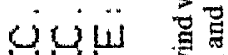

44 45 娄 पा 0 : 


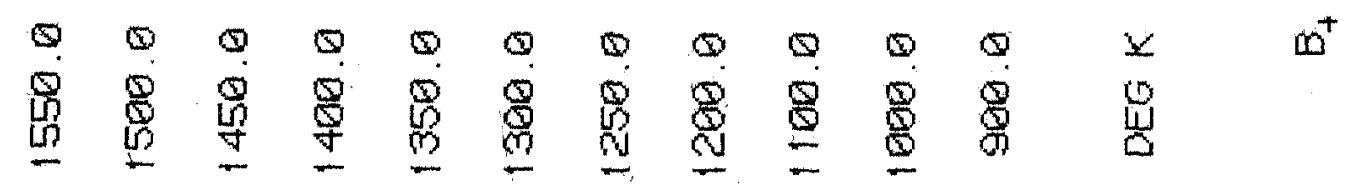

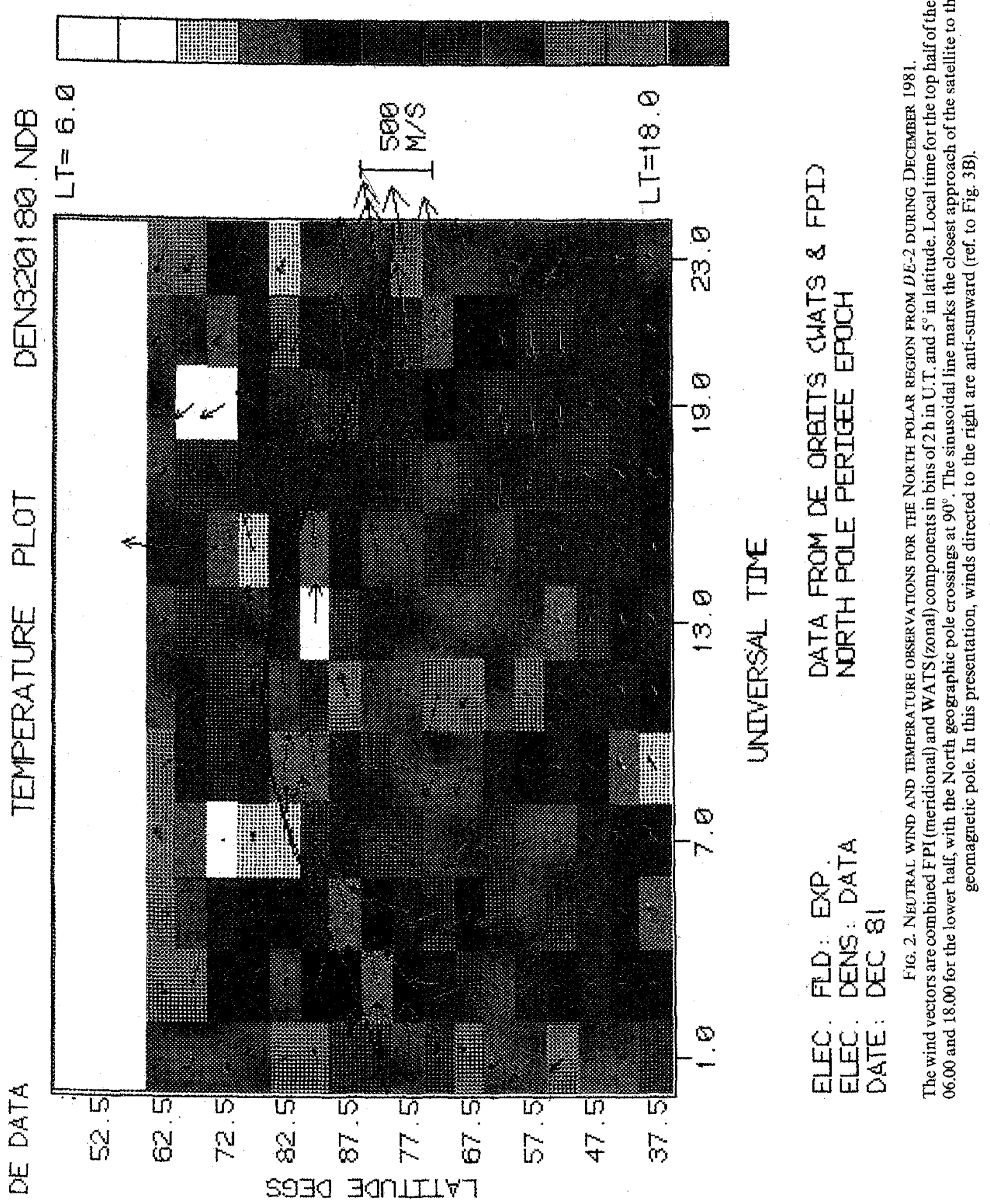


5

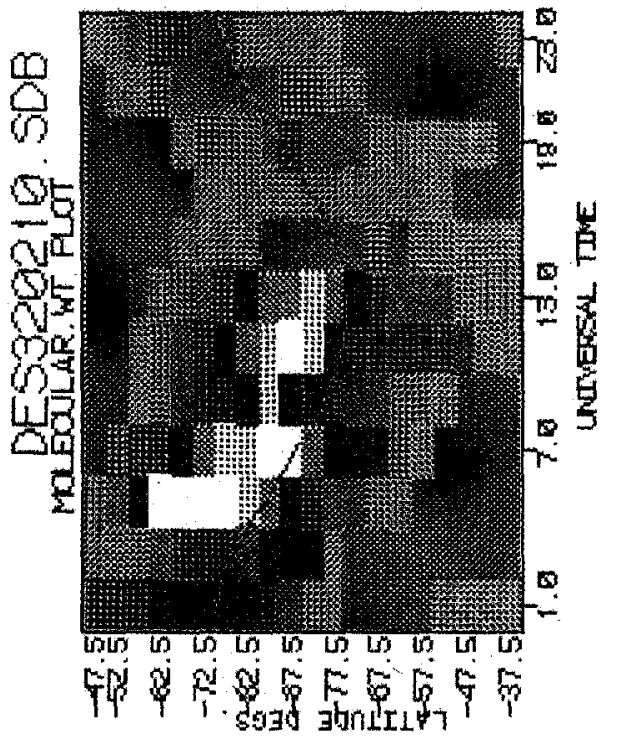

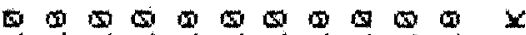

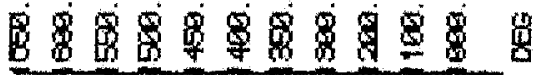
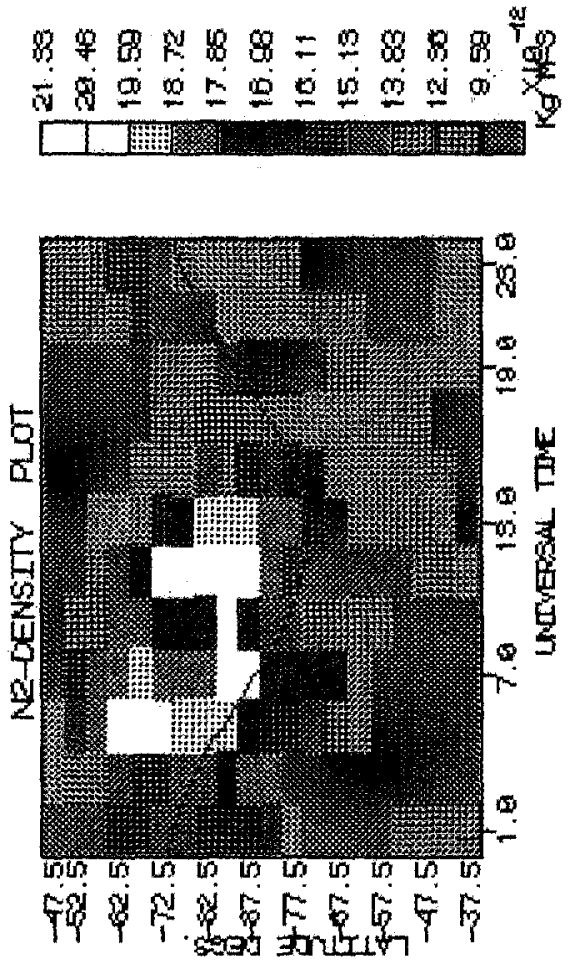

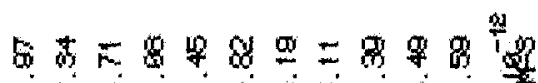
क⿻丷木
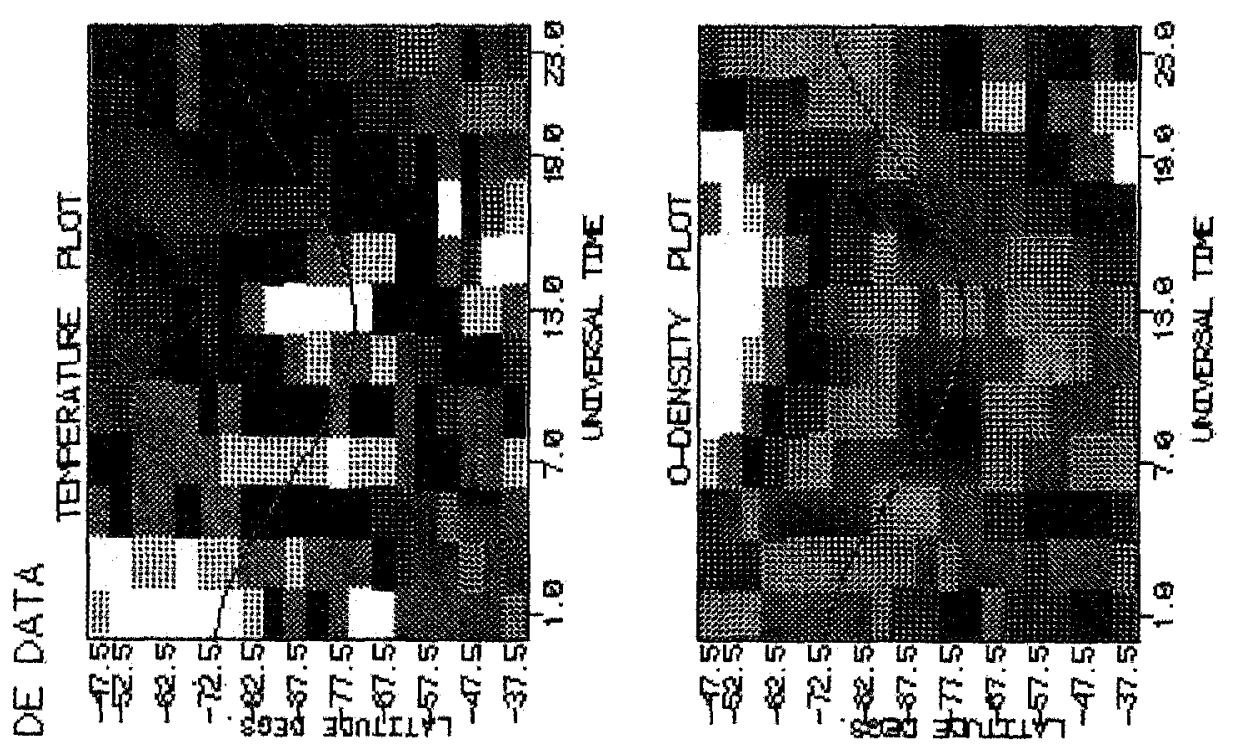

舟出

总

$z$

z

z

궁

$\checkmark \cdot \vec{\nabla}$

$+\frac{1}{8}$

总

善

鄫营

$\frac{1}{0}$

要

ชิ

递它

空

兽

봉

Uᄄ

山 0.0

$8 \overline{0}$

뜨

I

E

$5 \overline{2}$

$8 \frac{5}{7}$

눙

8

证

里

电

E

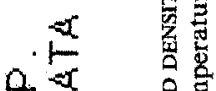

安

(1).$\overline{0}$ 要

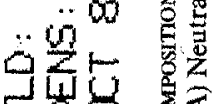

叫帴

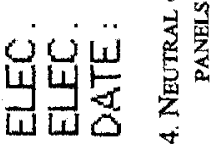

广্் 
$\Delta-r m a \omega-r a b a$

-

il $\square$ I I InE

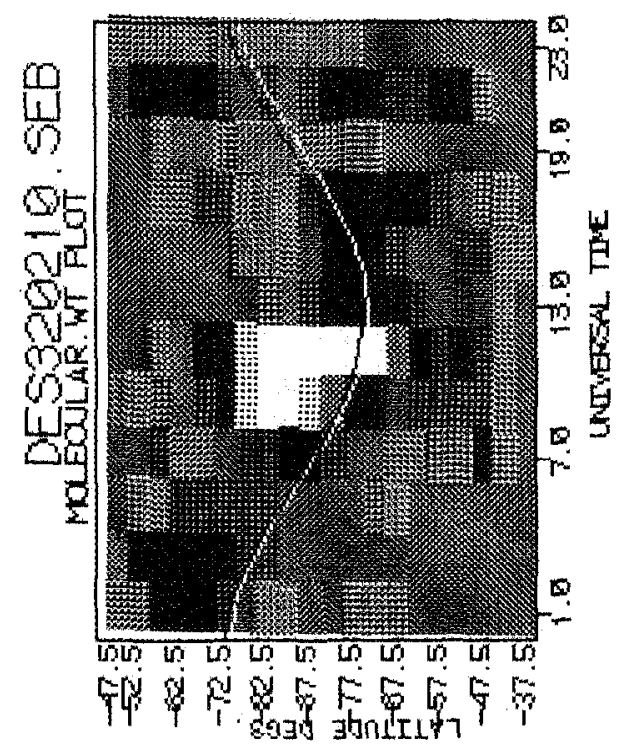

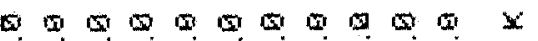

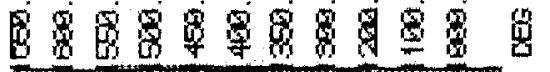

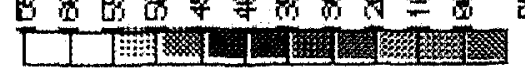

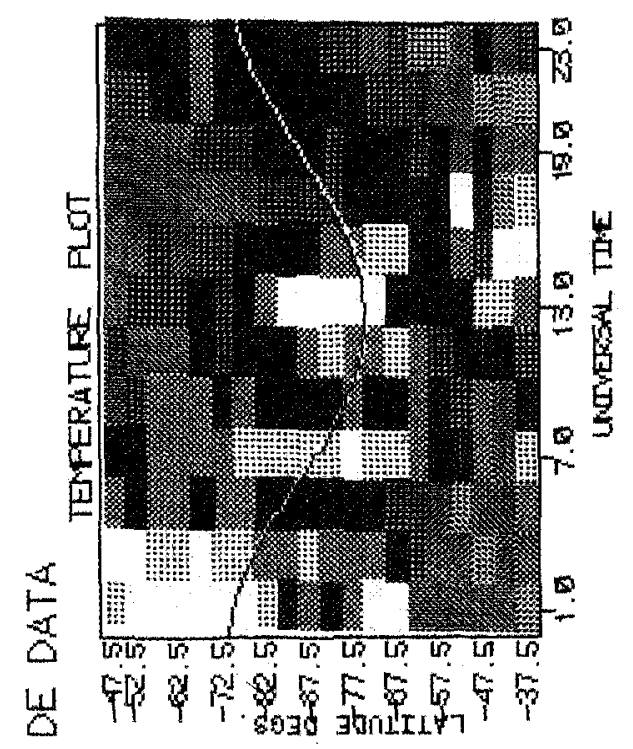

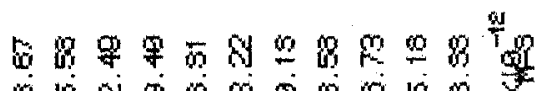

8 \% $8890 \%$

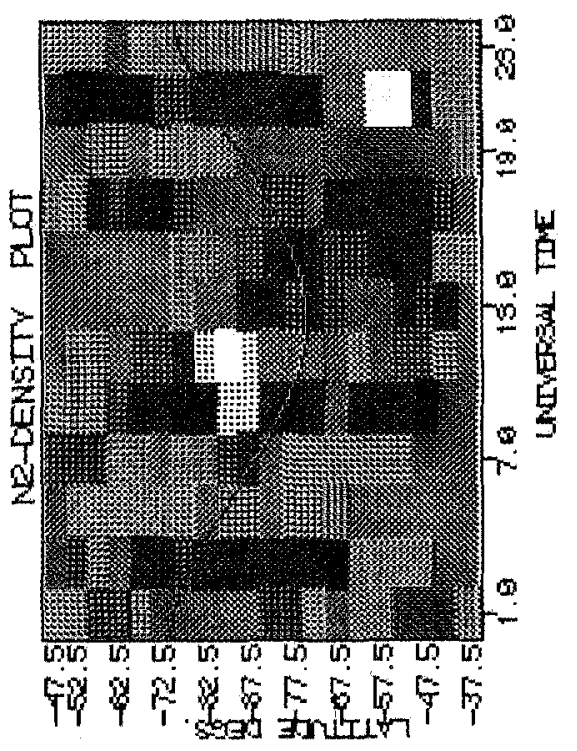

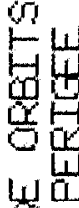
हu $\frac{1}{1}$

8

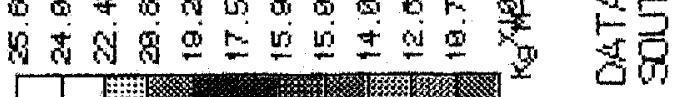

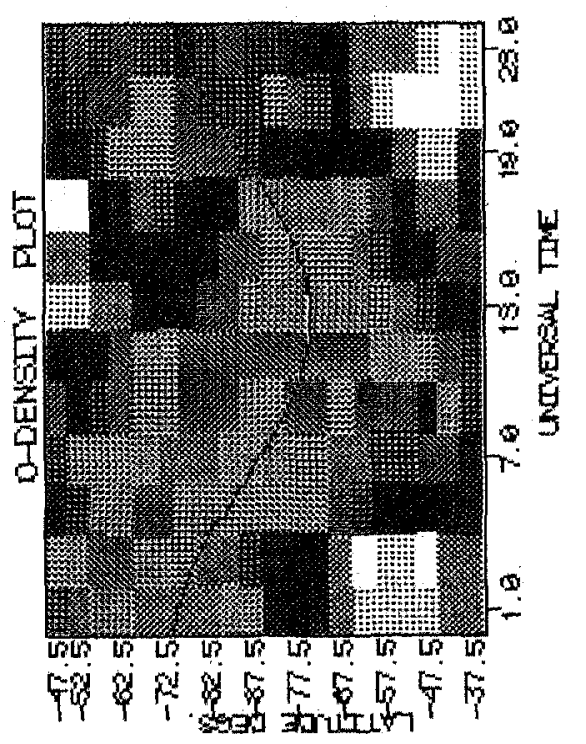

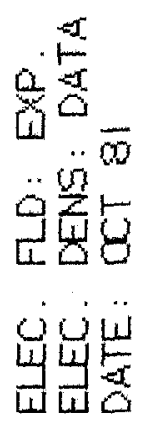

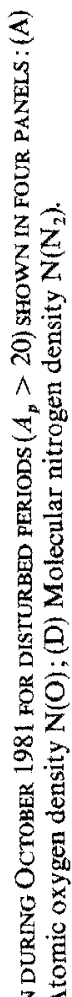
忌造 
SR 88988785

$\infty$ एi

II
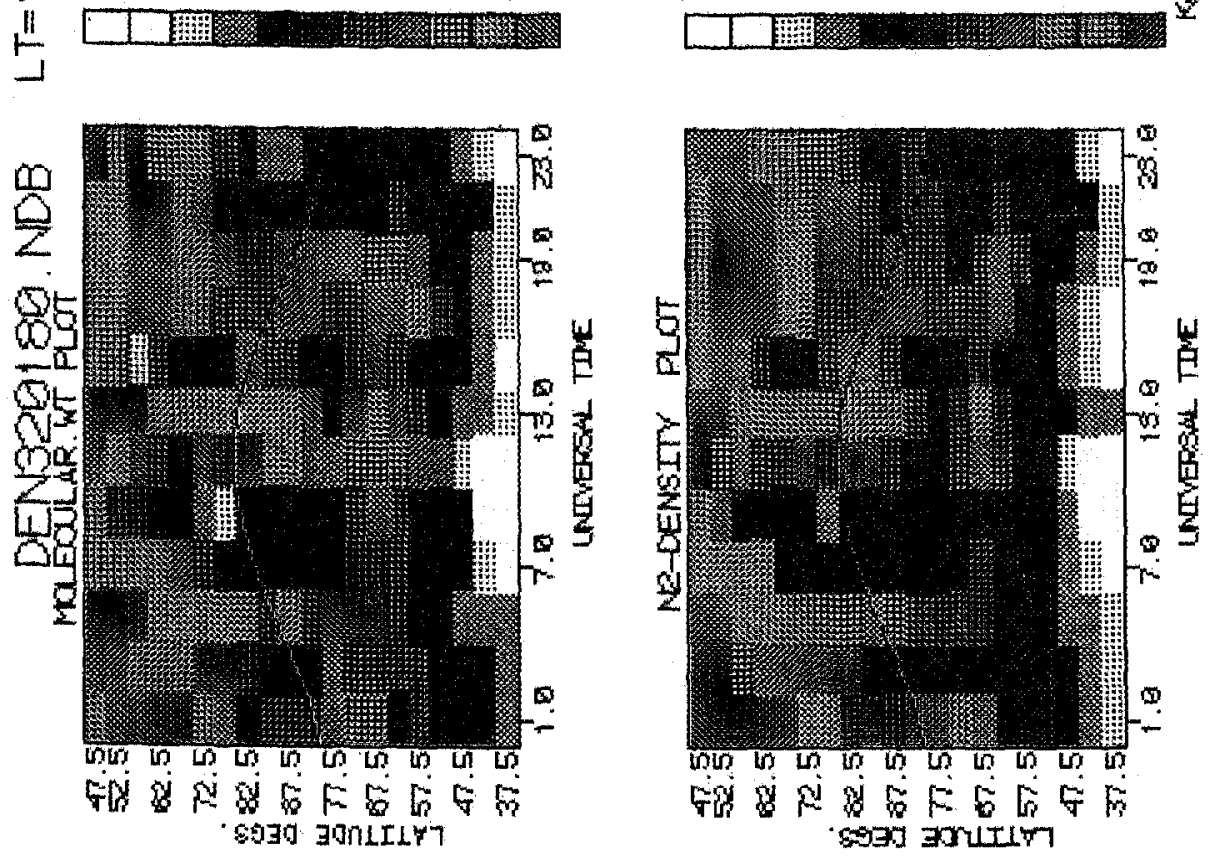

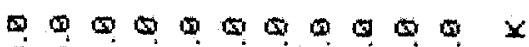

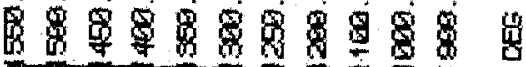
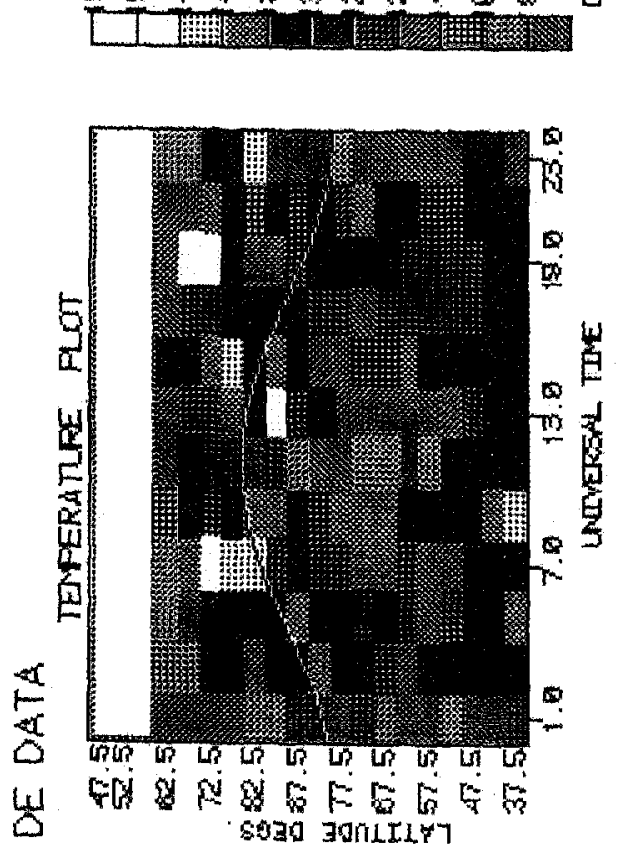

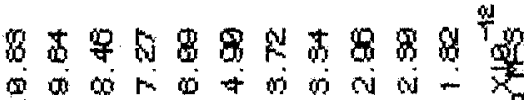

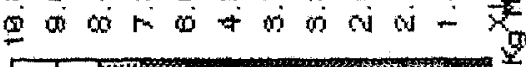

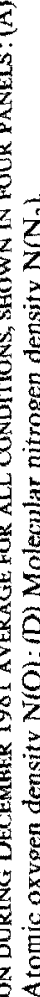

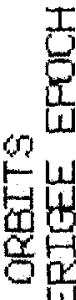

능

这员

8 8 8

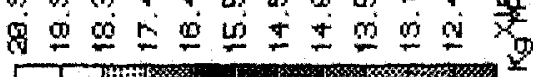

$\forall F$

89

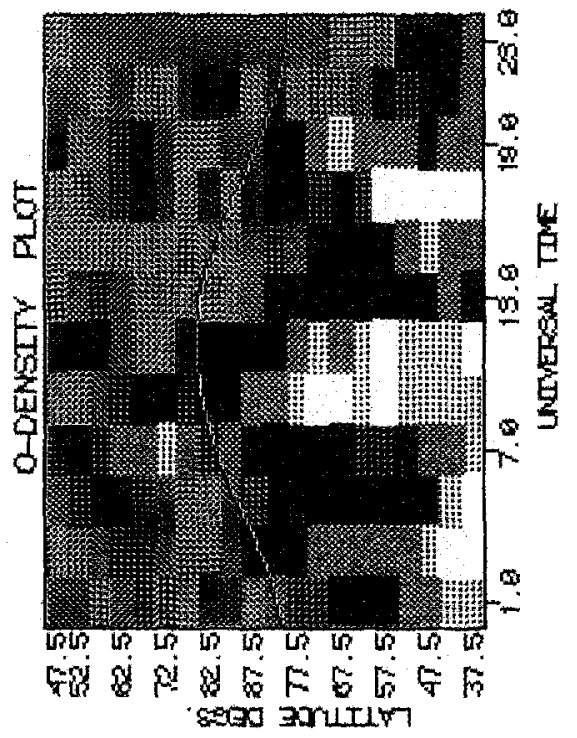

0.10

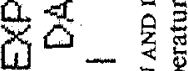
$\ddot{0} 0$ 员

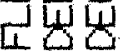

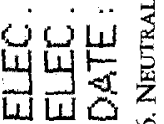



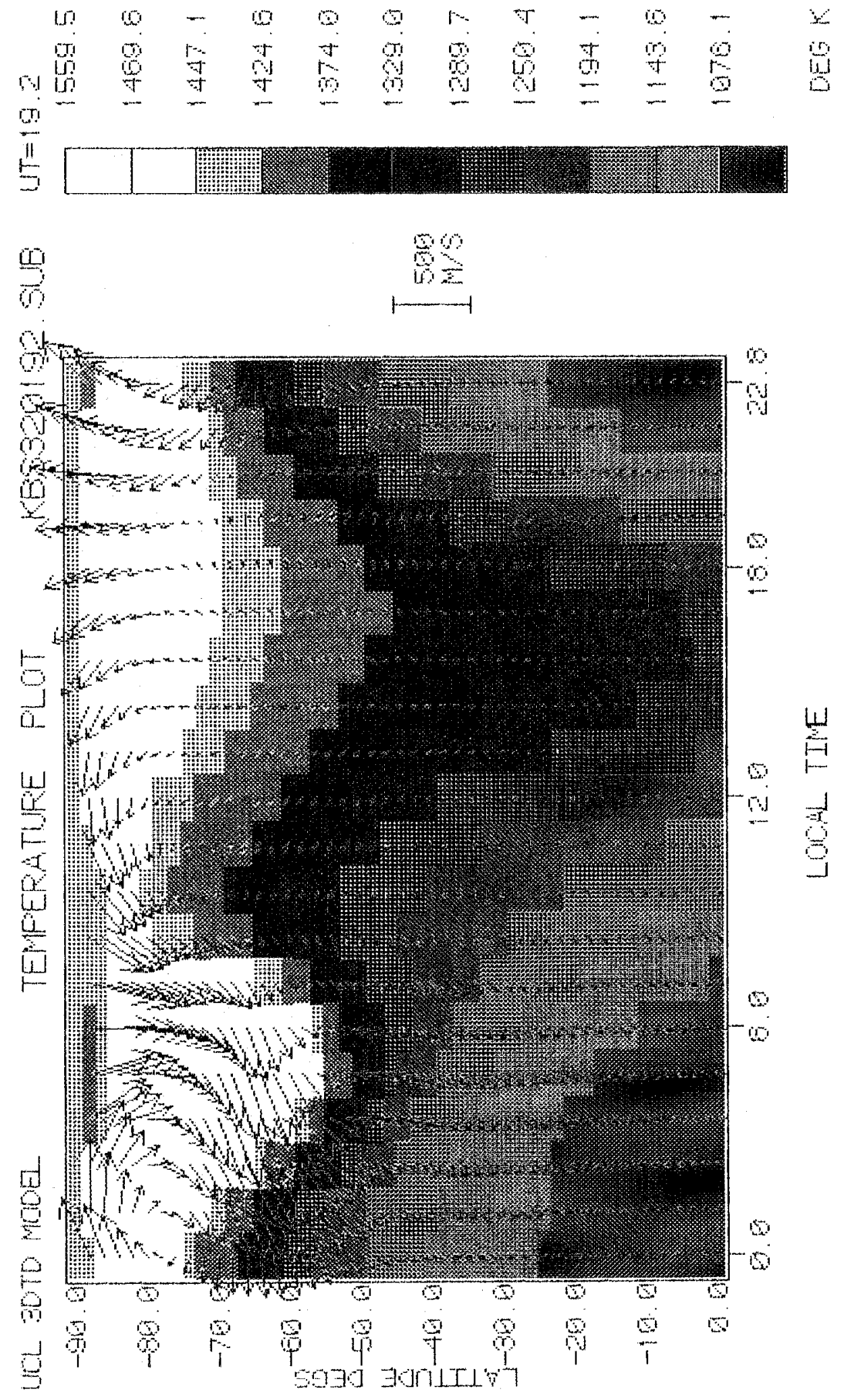

$a$
50
50

w)

$\underbrace{\infty}_{-1} \underbrace{0}$

(1) $x$ L.

正

1- 30

$\Rightarrow \quad 06$

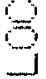

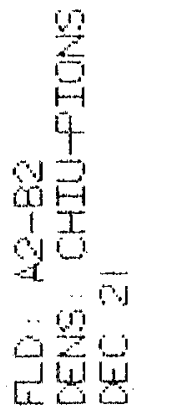

내늘 
The composition, structure, temperature and dynamics of the upper thermosphere in the polar regions

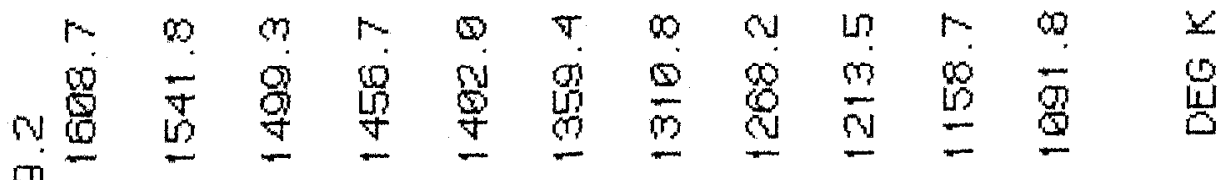
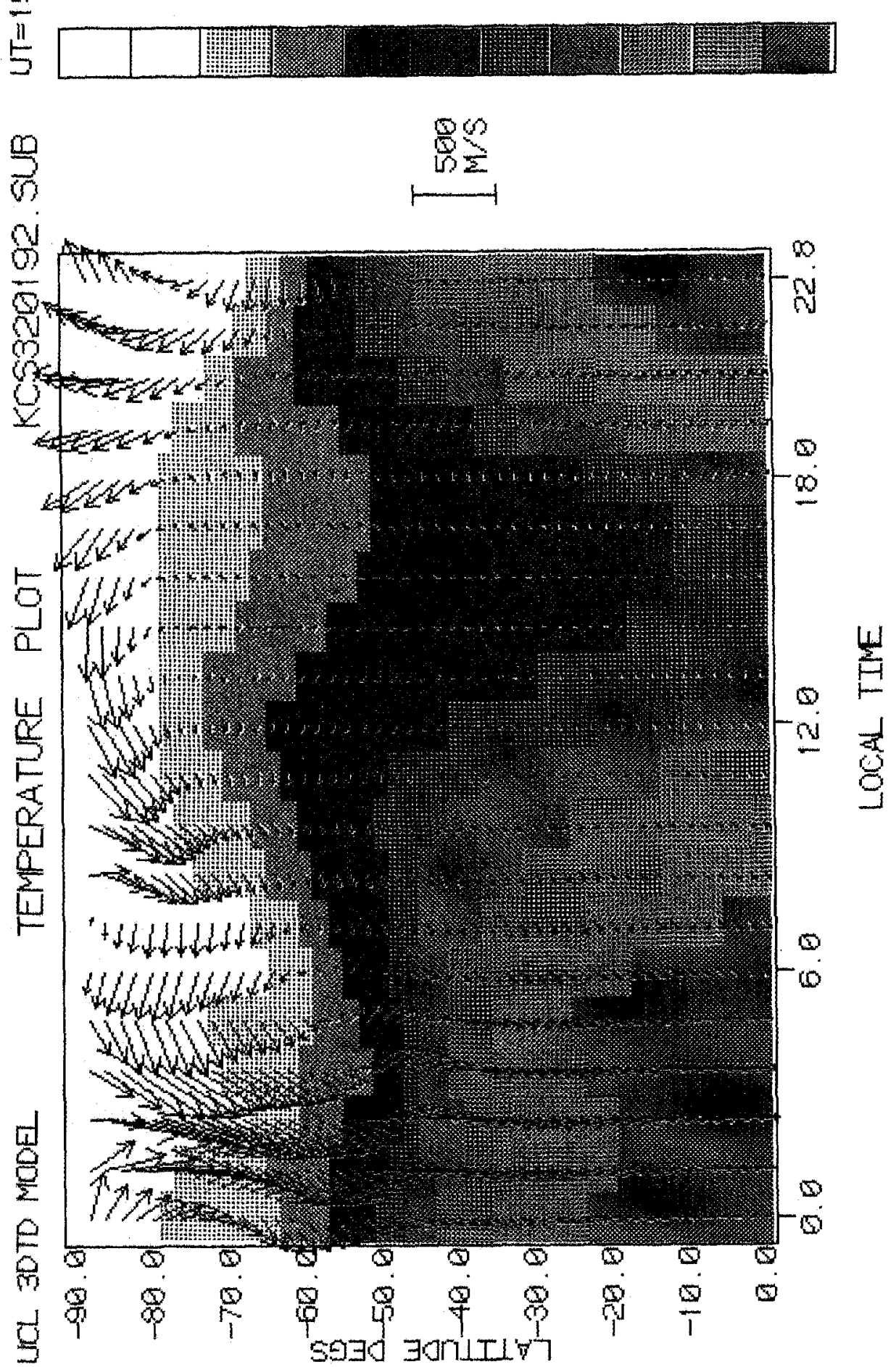

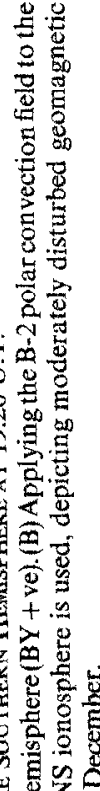

Z

EU

in

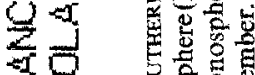

I

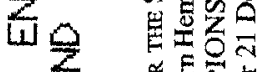

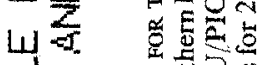

○乙

-

$-H \quad 0 巳 \mathrm{~g}$

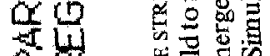

0 峞

这员

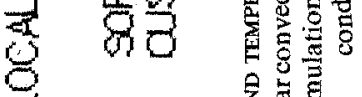

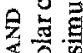

0
2
0
0

ऽ)

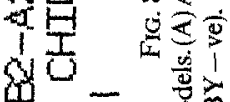

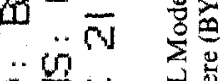

पू山्य

प.0ठ 要

ن门il है

แ4 

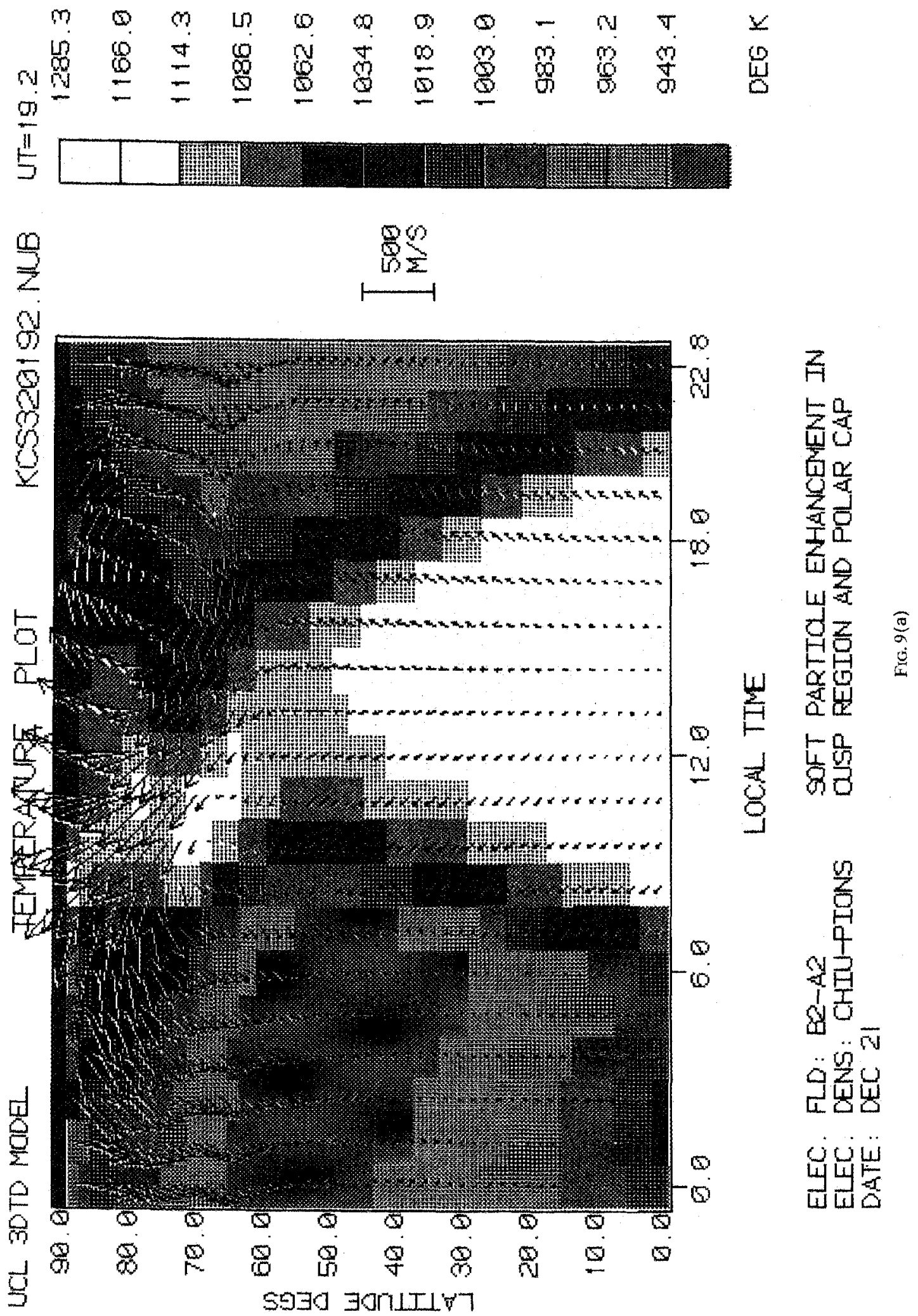
The composition, structure, temperature and dynamics of the upper thermosphere in the polar regions

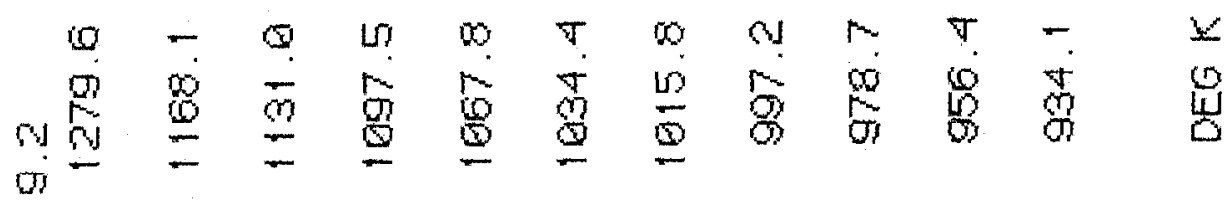
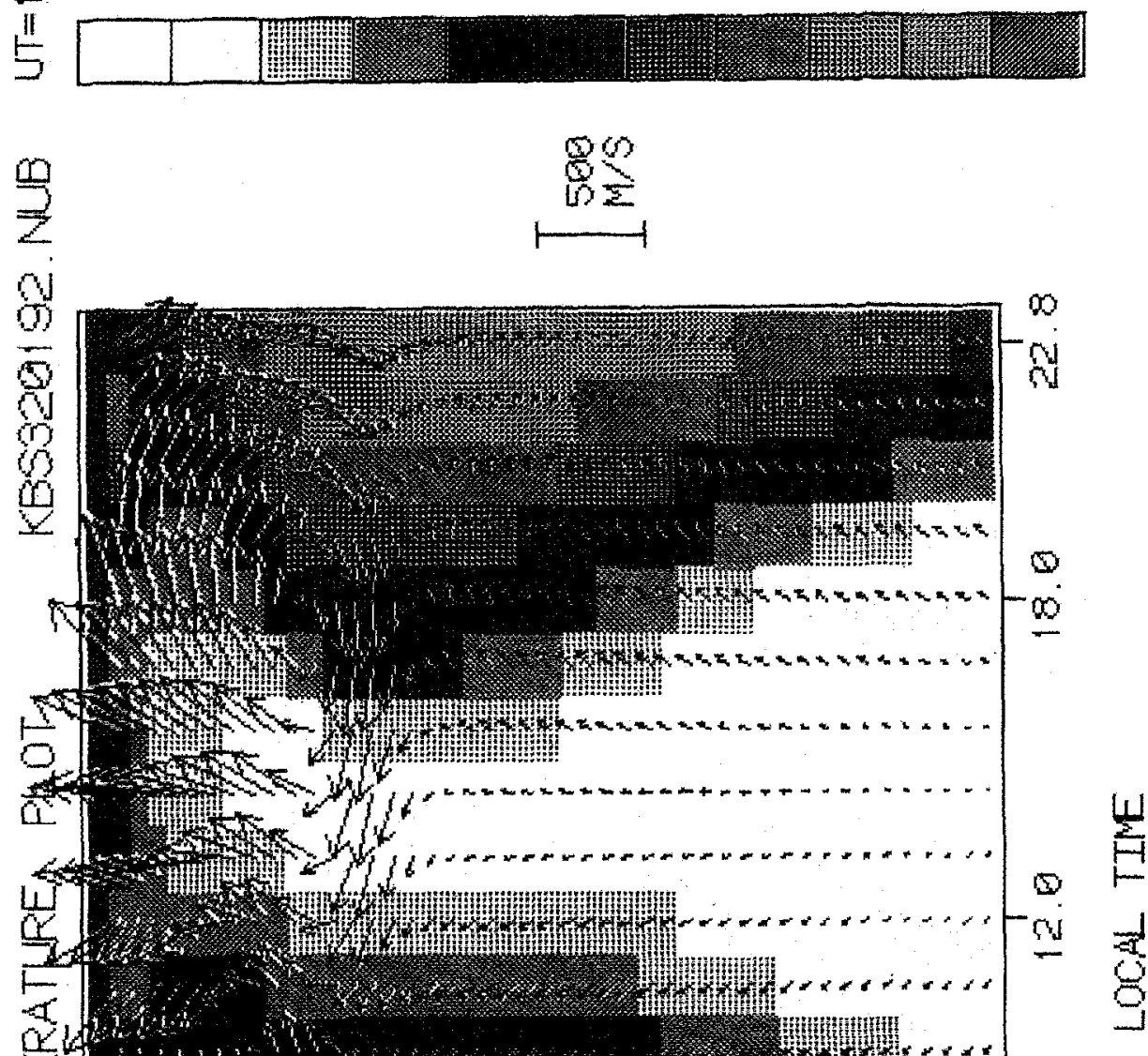

5
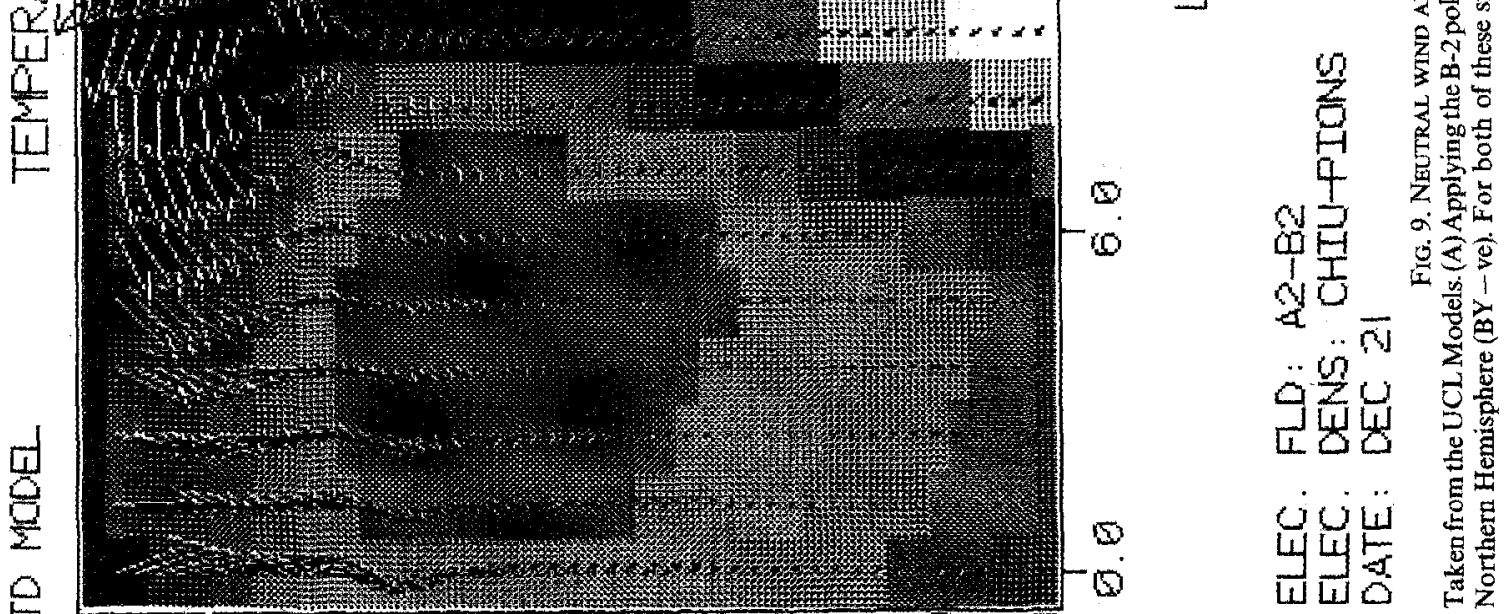

\section{2
0
0}

$\frac{1}{3}$
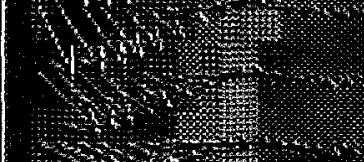


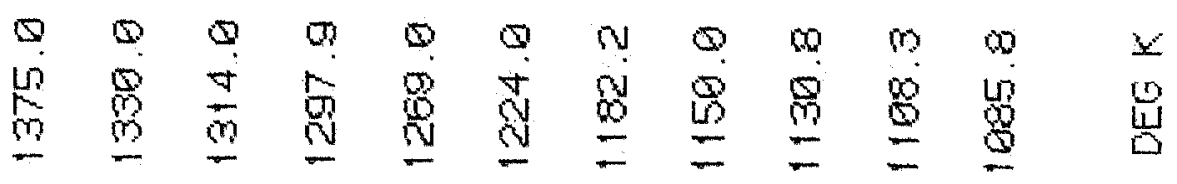
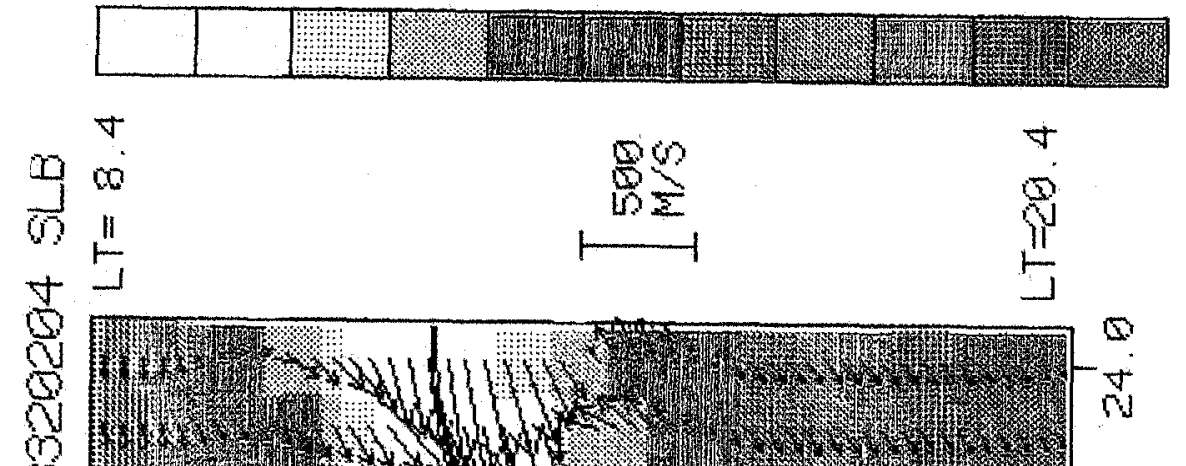

离 F, Wxy

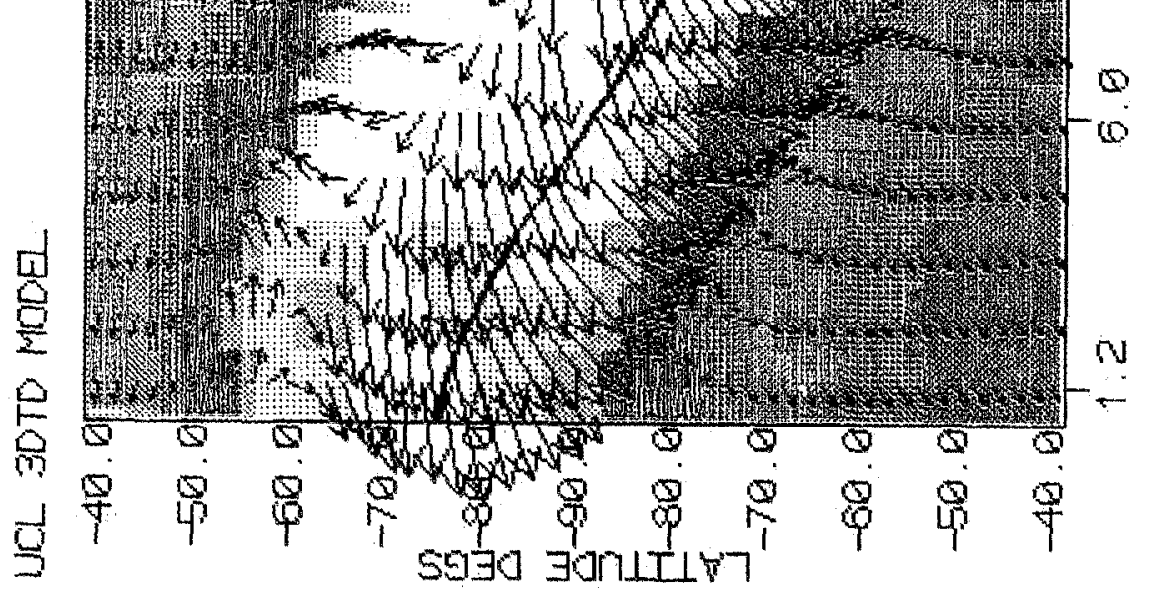

$\frac{9}{0}$

$\vec{G}$

\section{$\infty$

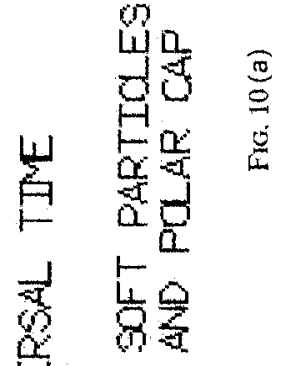

5

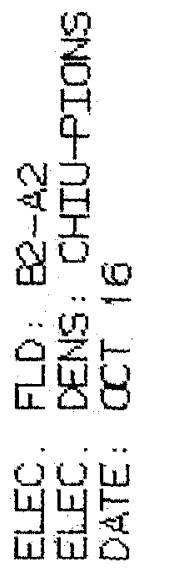



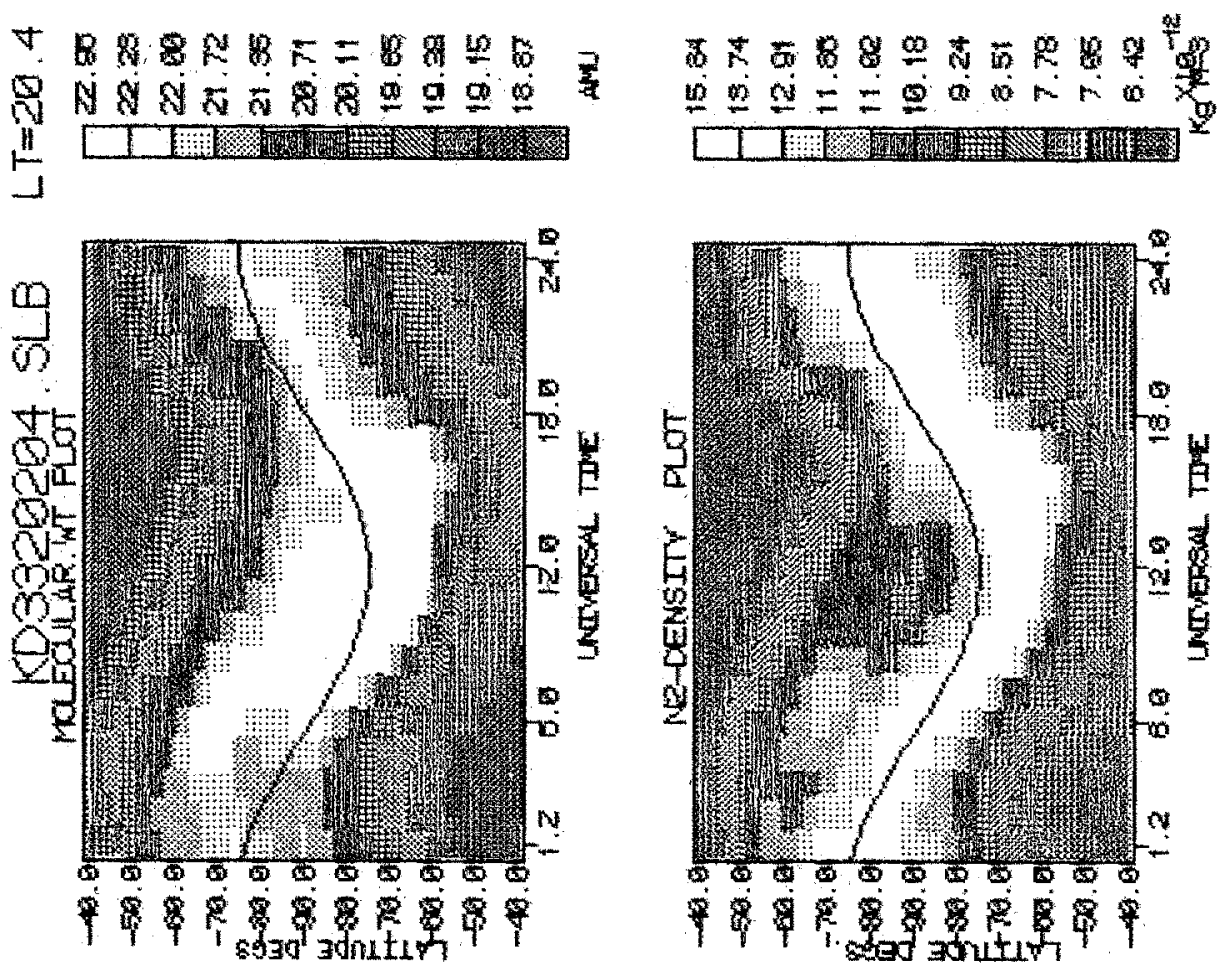

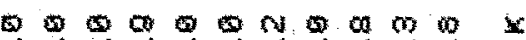

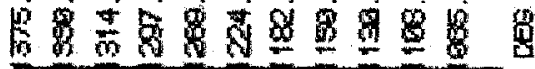

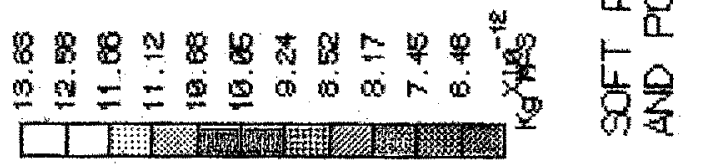

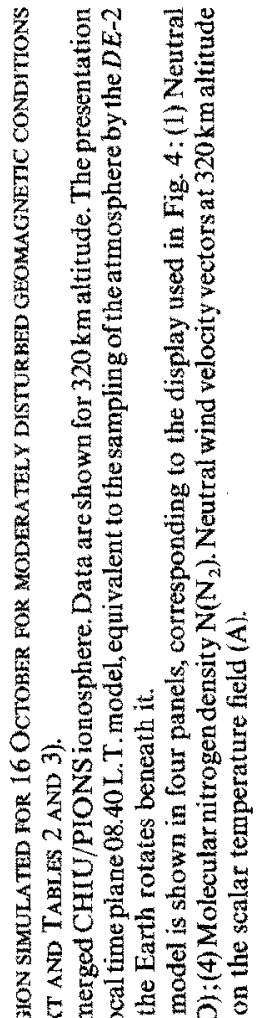

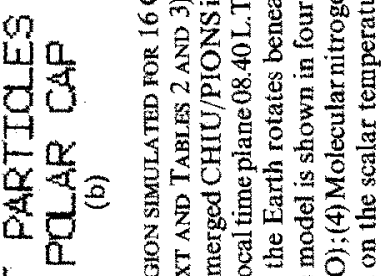

$\frac{9}{0}$

F

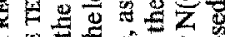

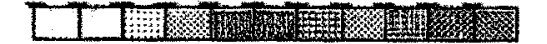
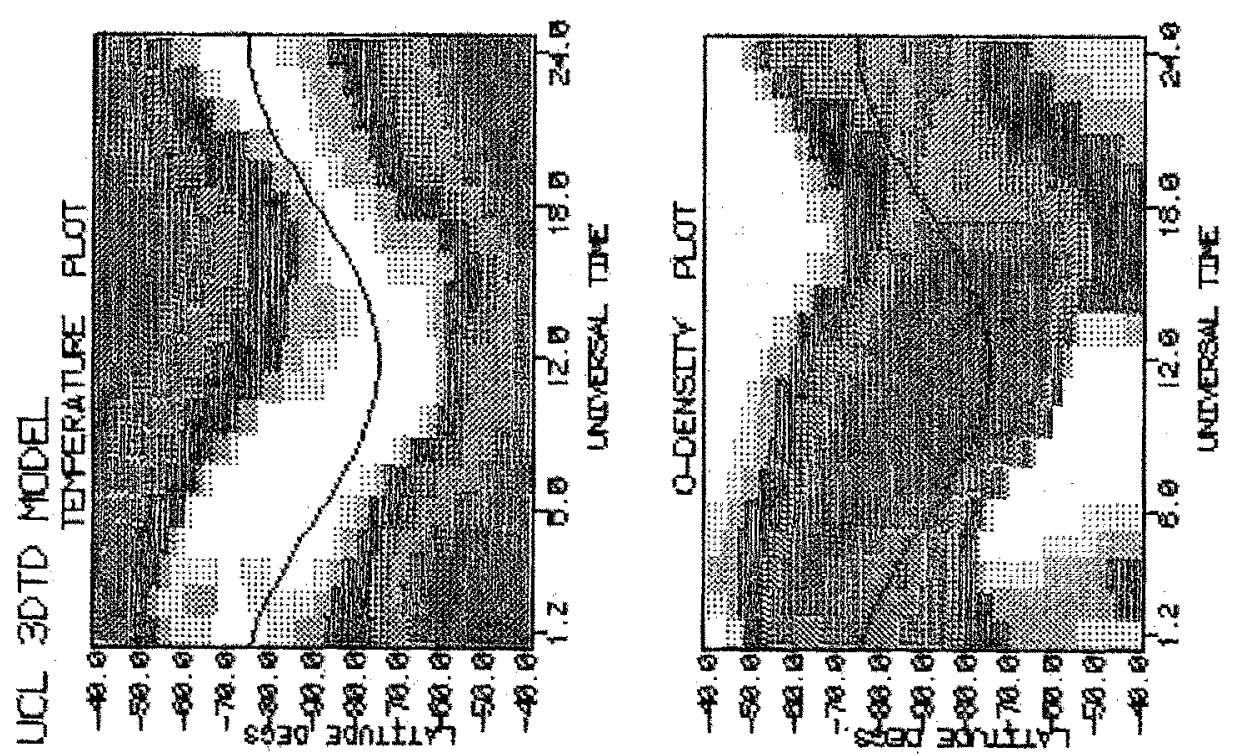

$\frac{9}{9}$

ज㟧与

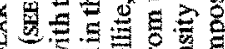

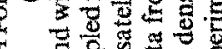

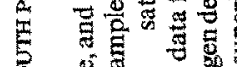
马

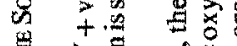




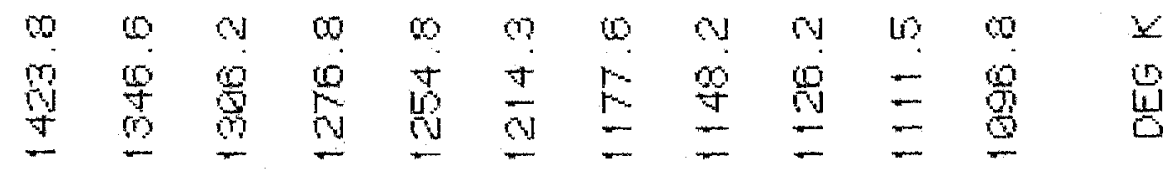
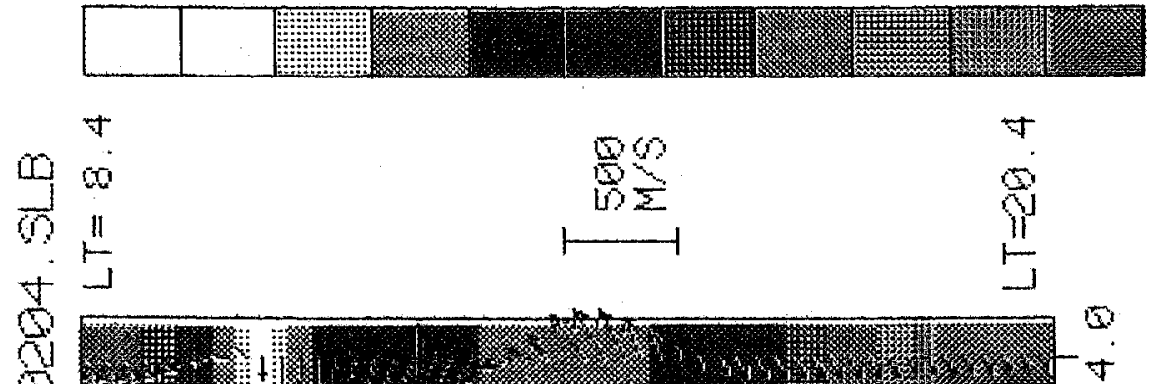

b
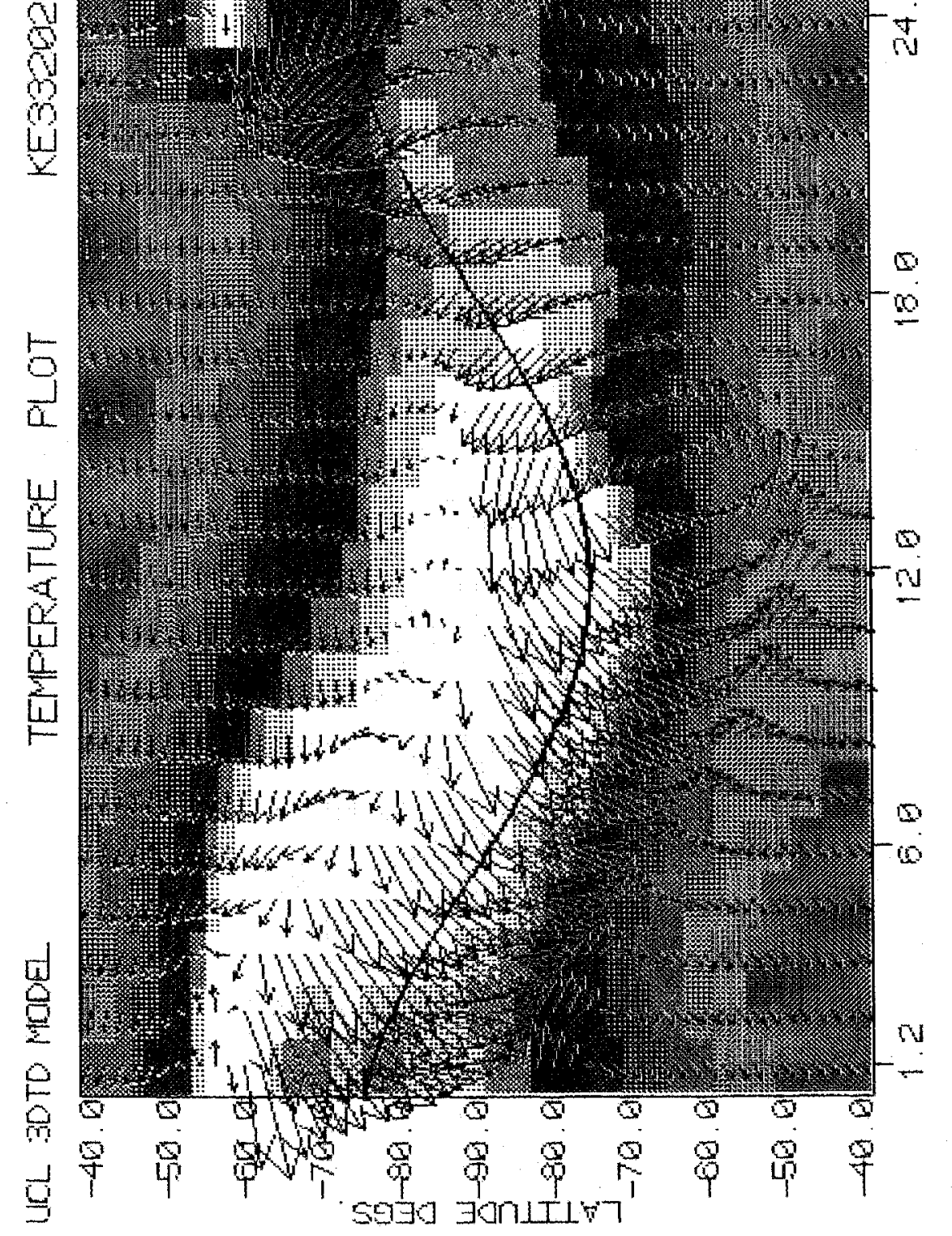

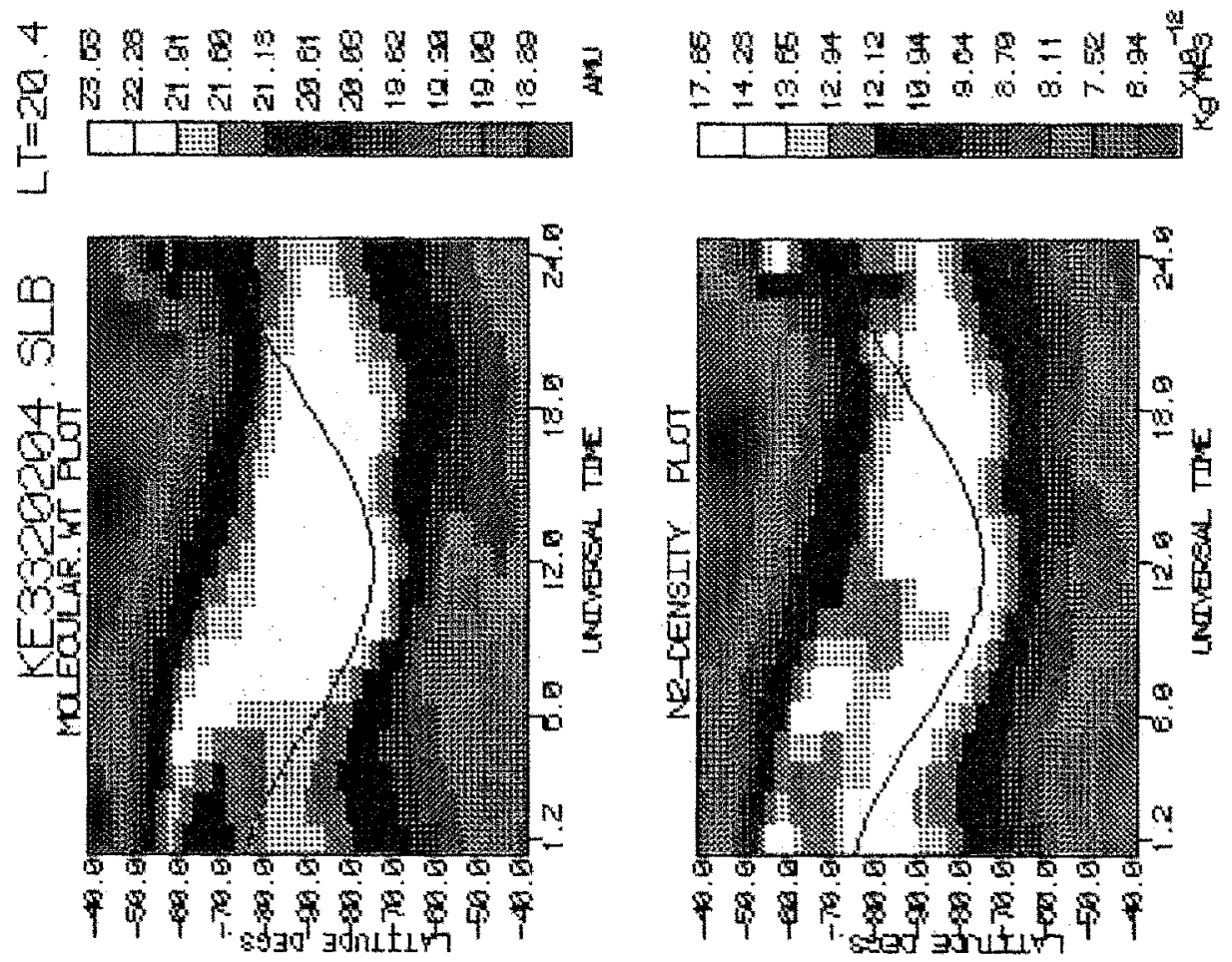

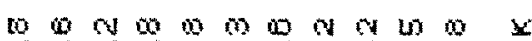

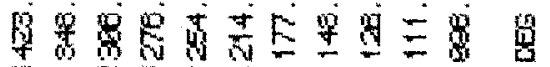
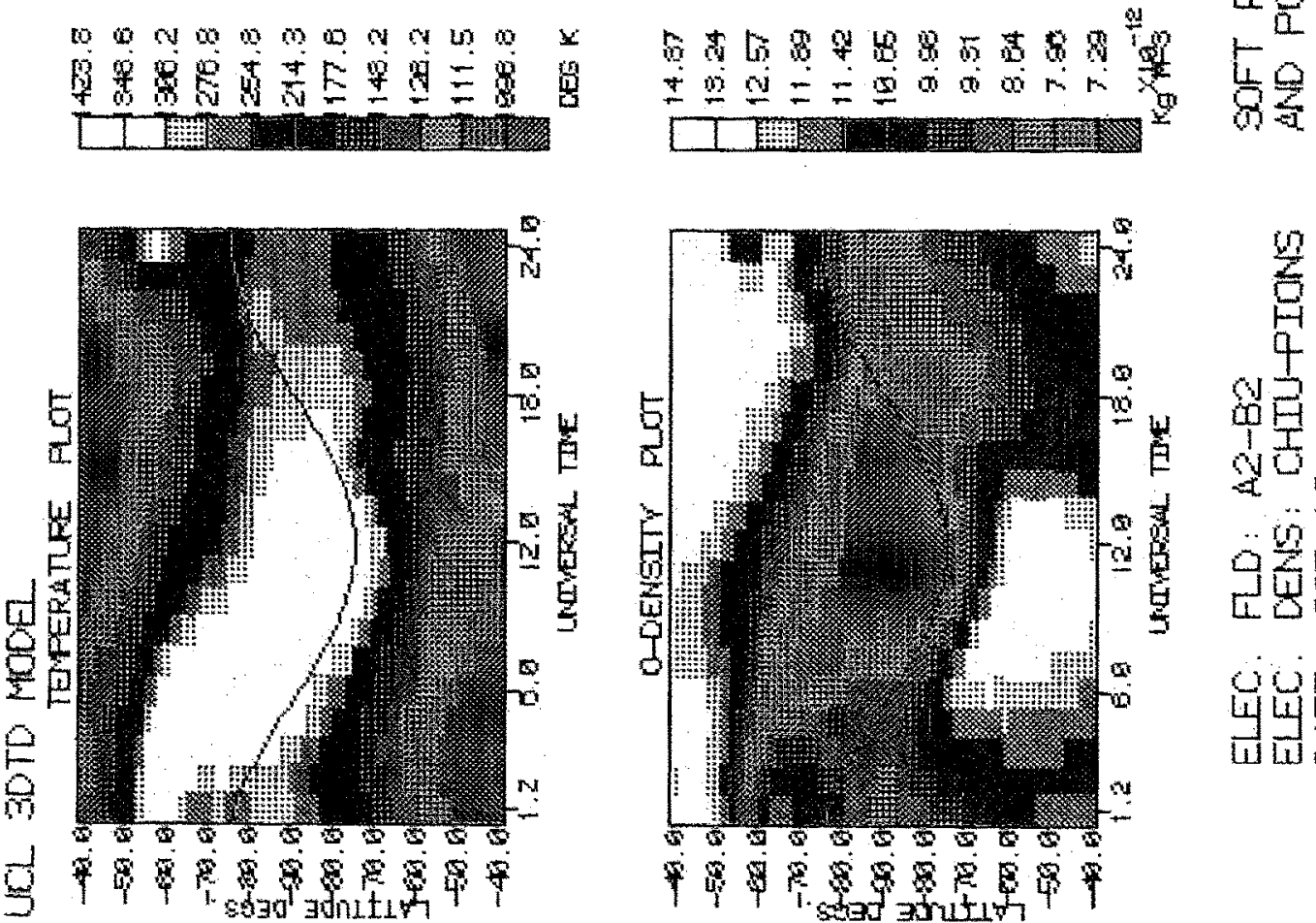

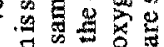




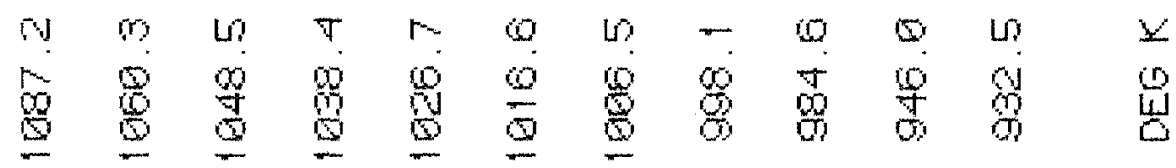
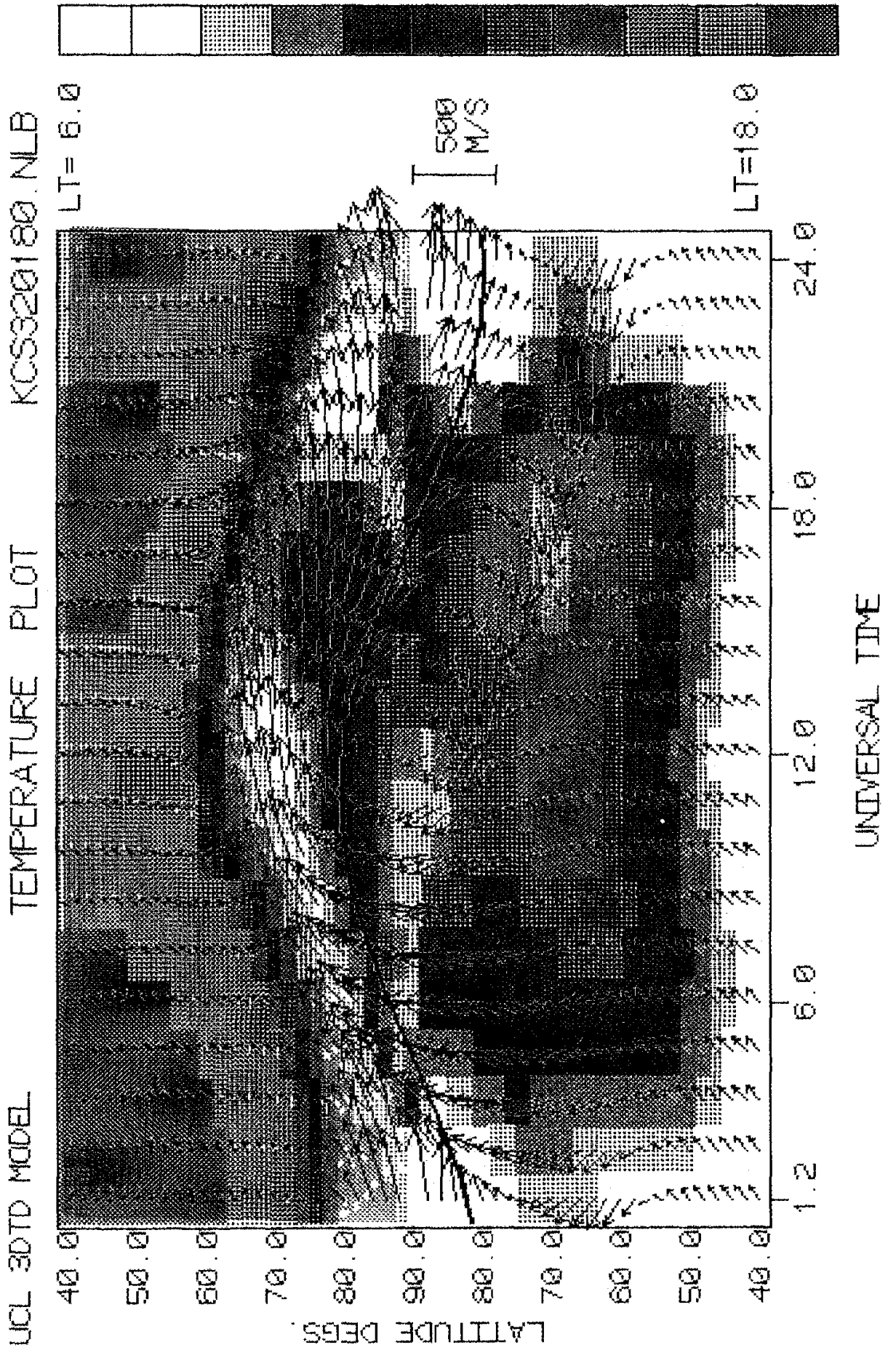

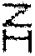

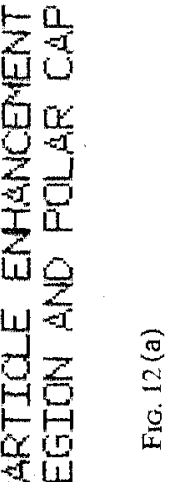
it

$5 \frac{a}{0}$

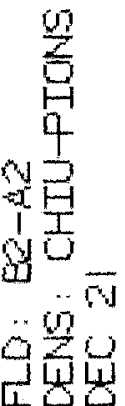

남형 


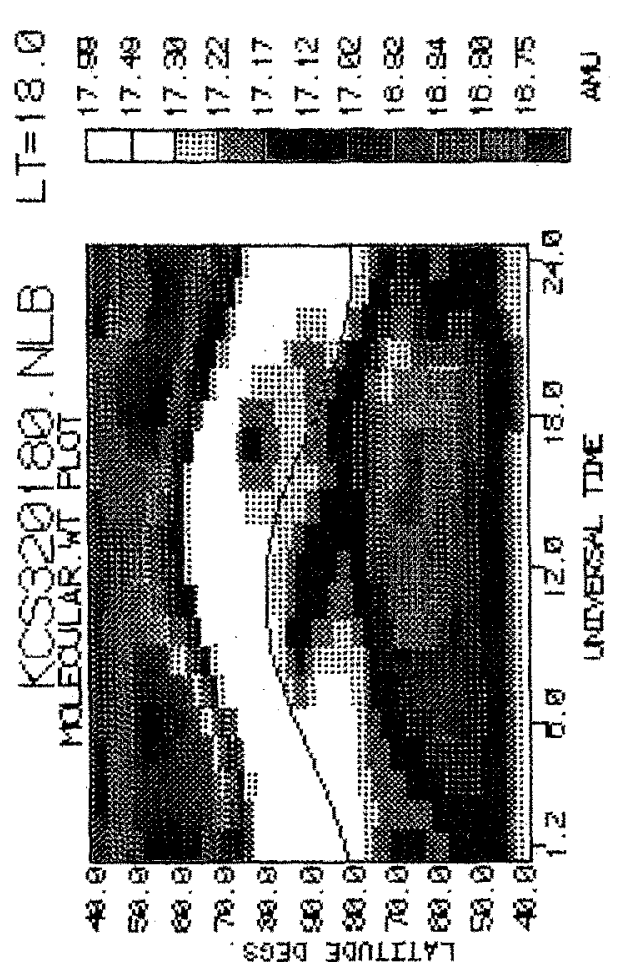

1.

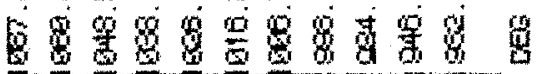

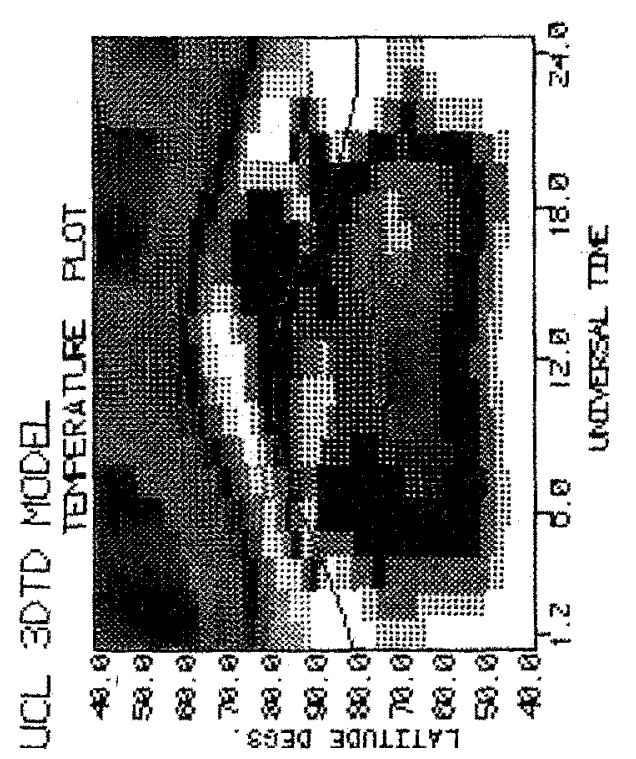

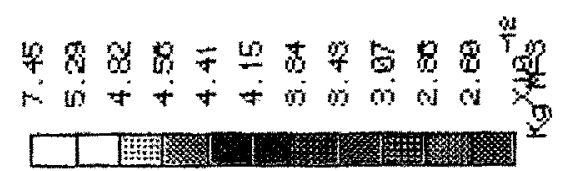

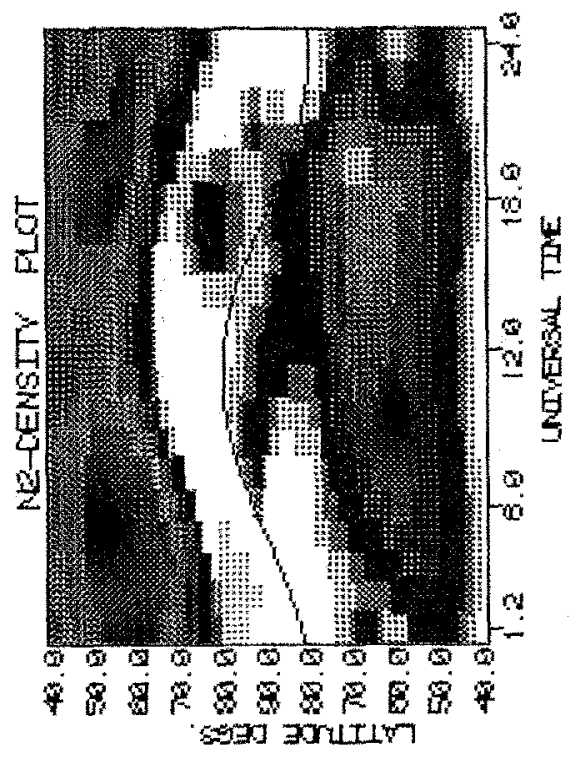

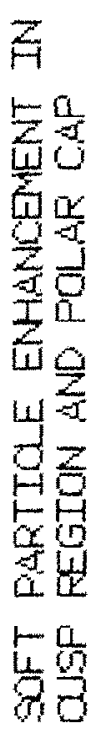
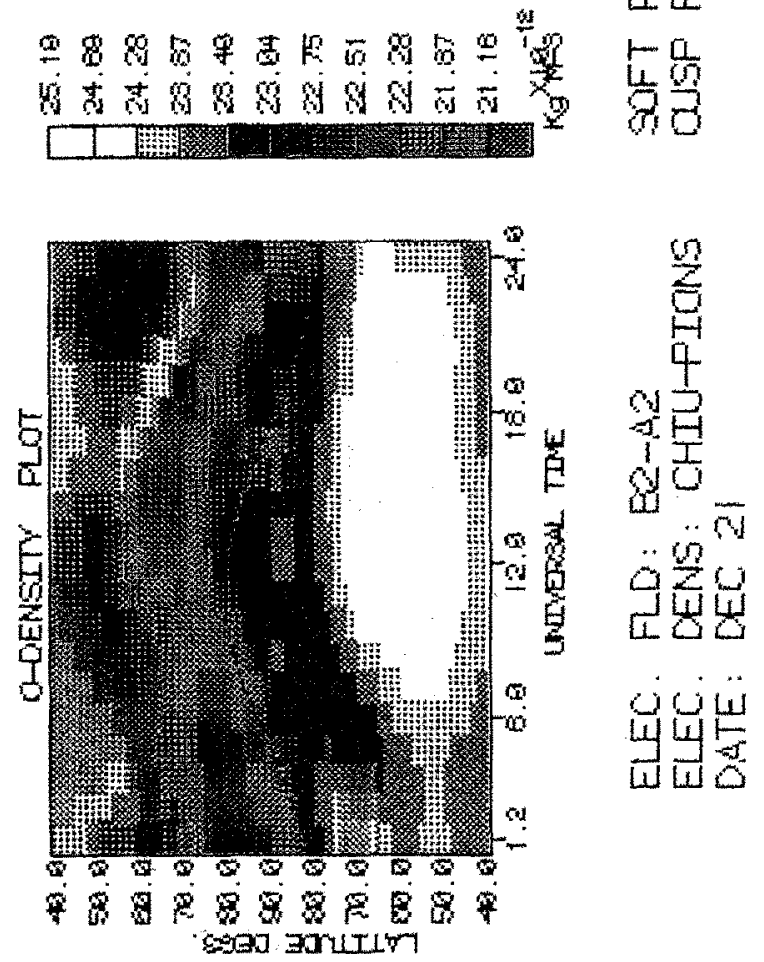

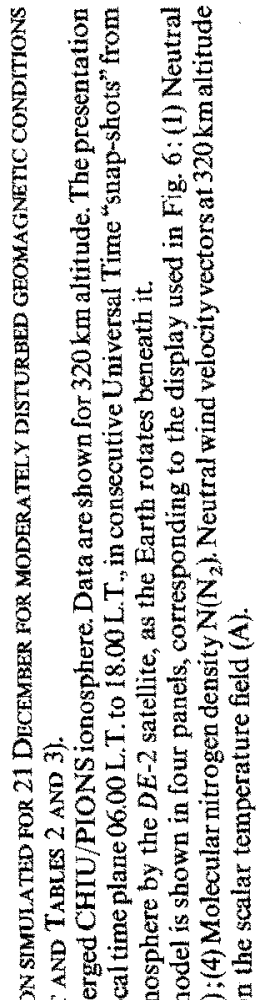

造要要

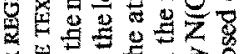

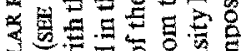

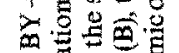

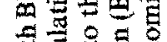

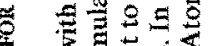

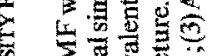

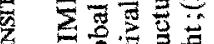

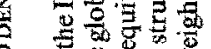

会 


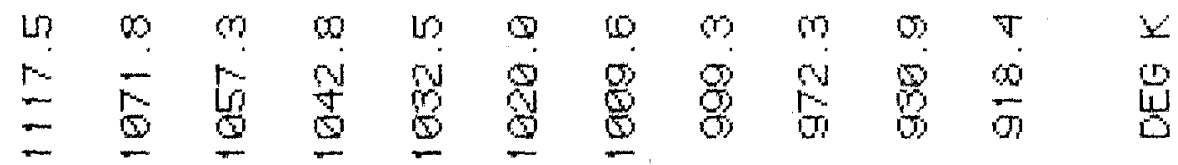
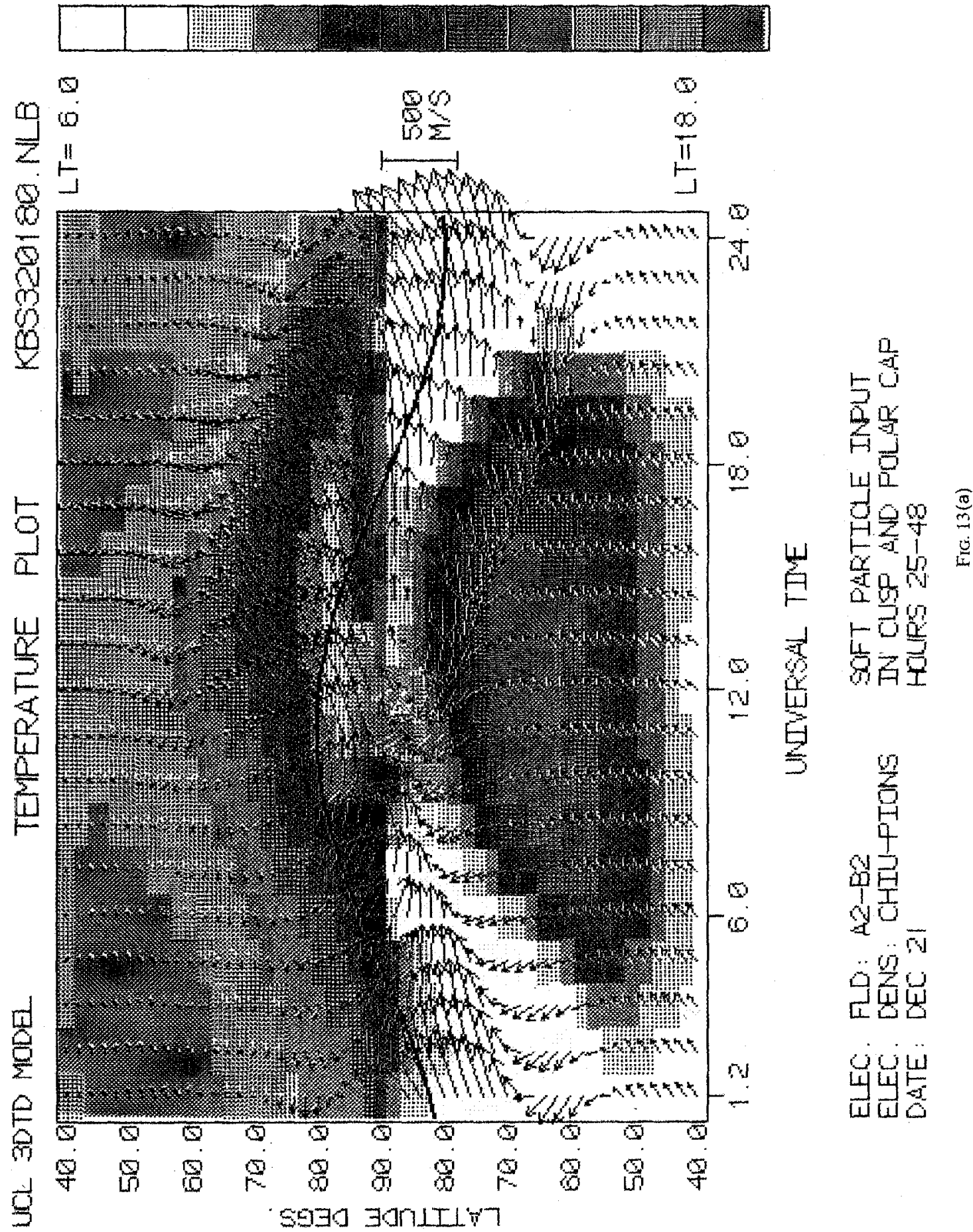

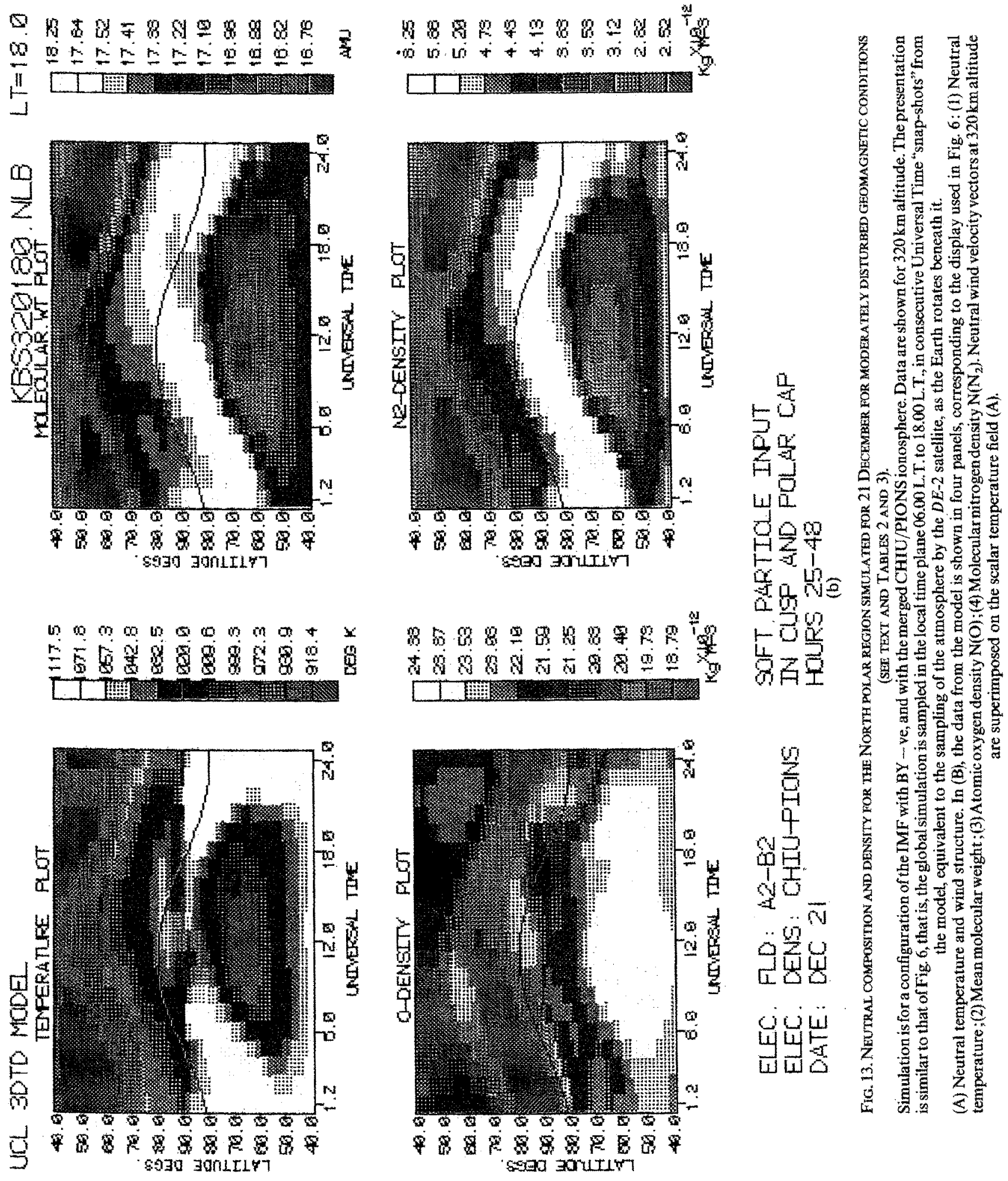


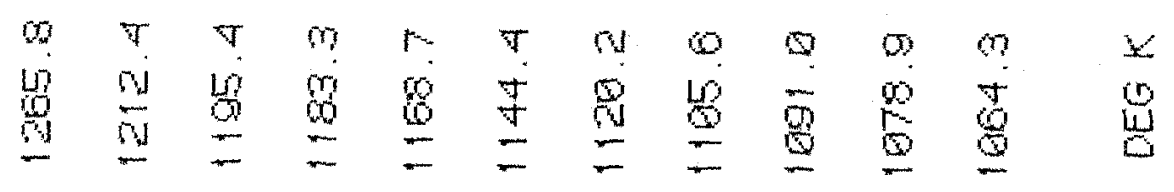
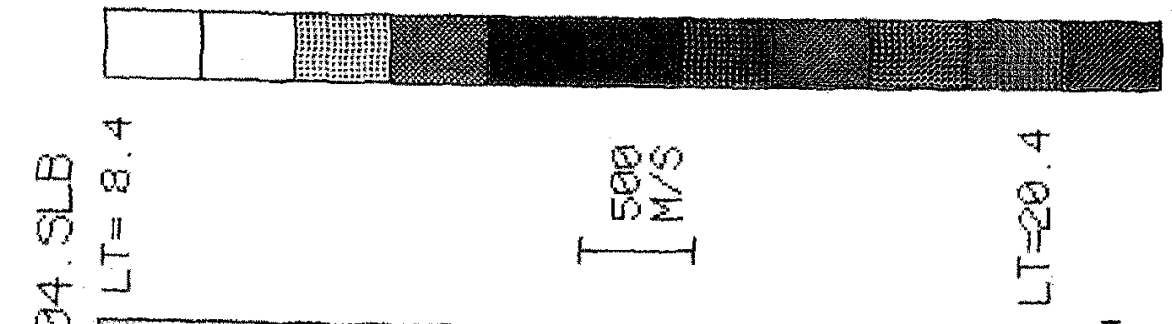

5
5
0
1
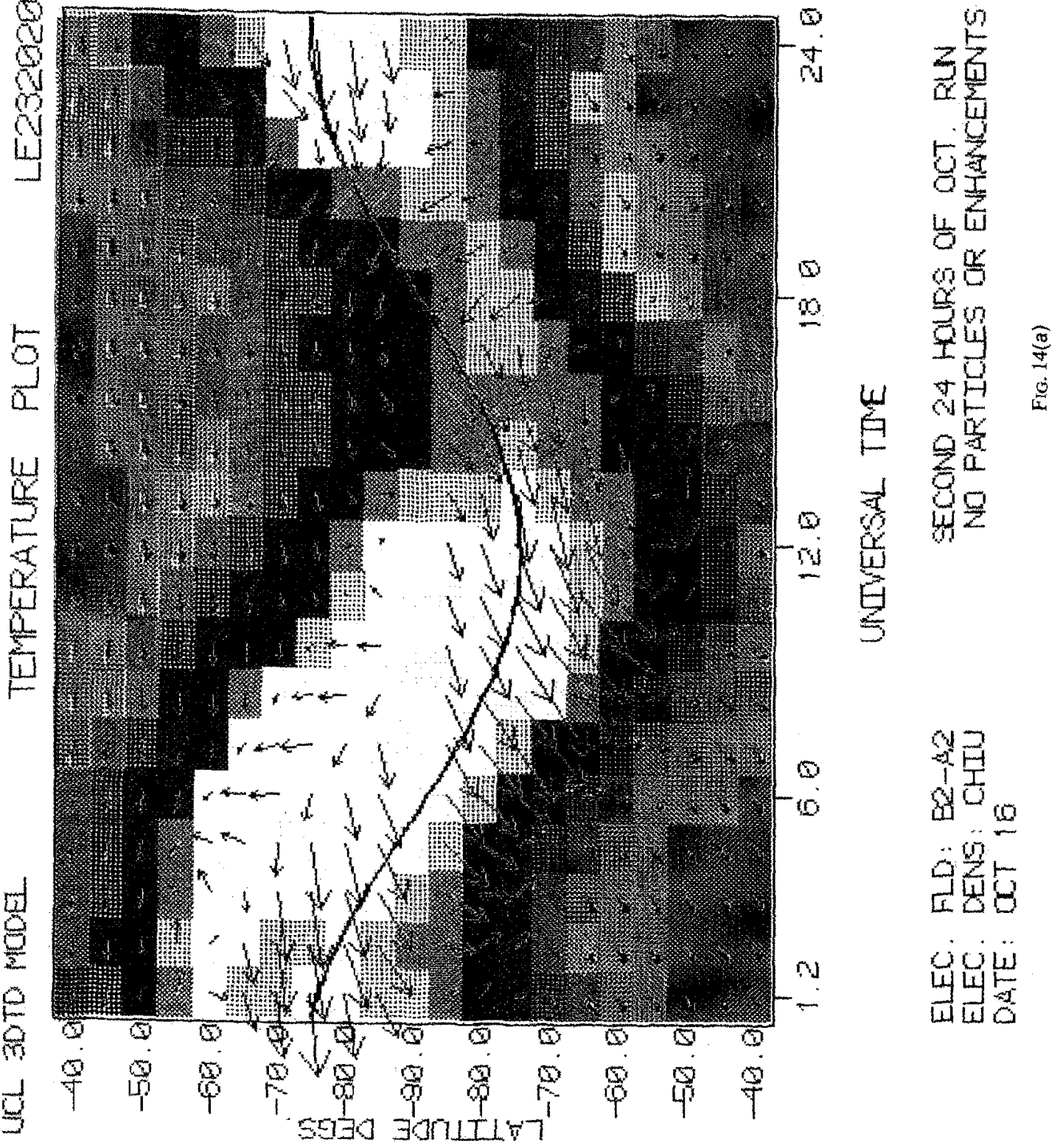

$\frac{4}{5}$

5

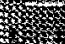

10.



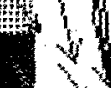

$x$
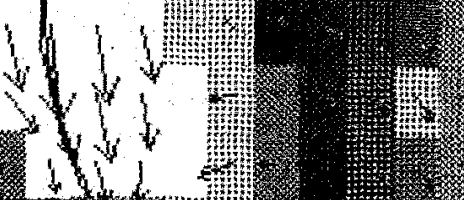

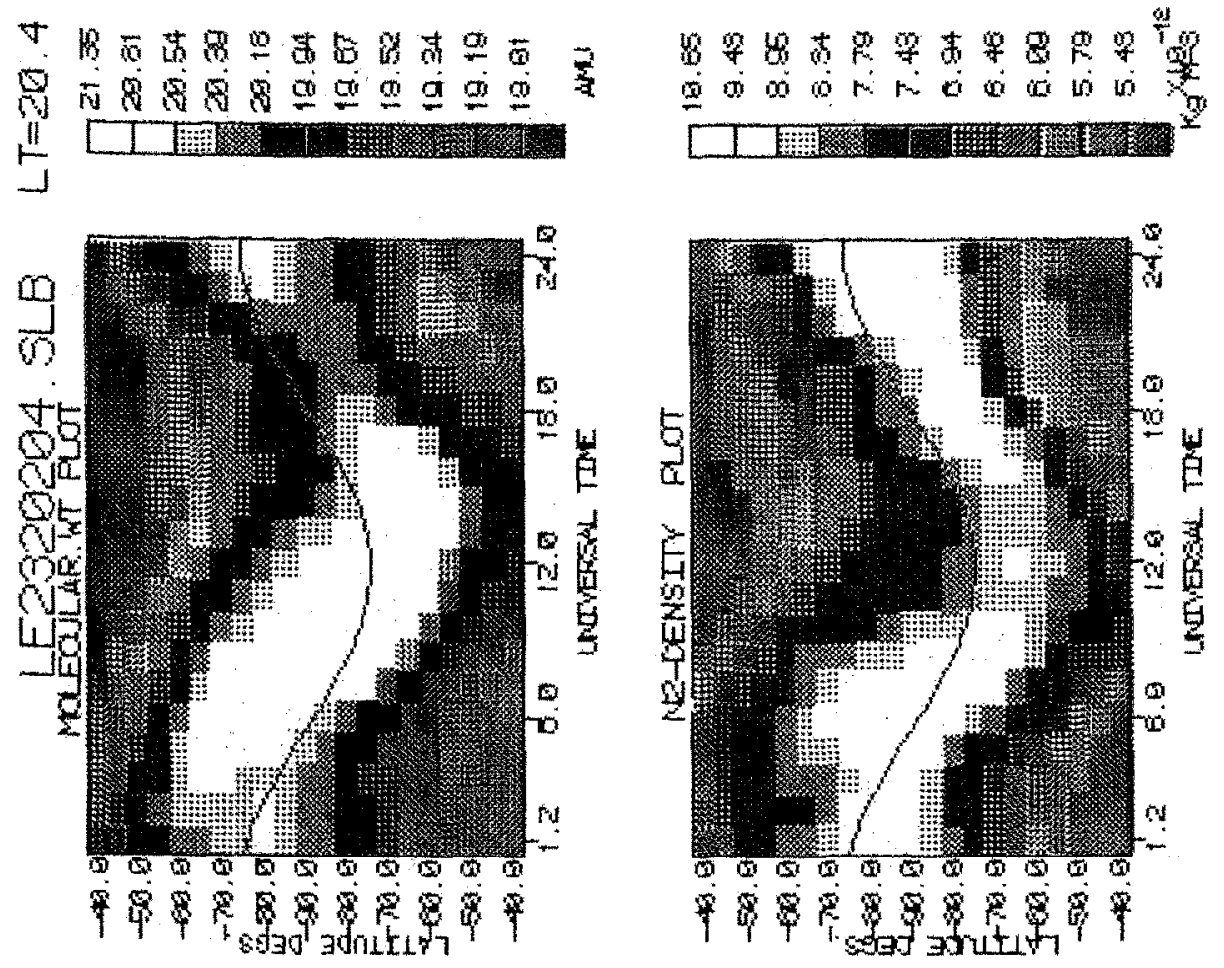

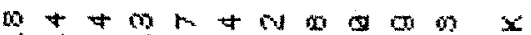

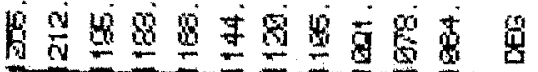

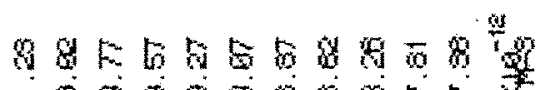

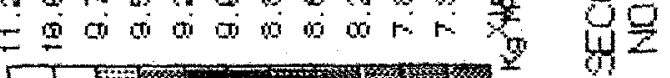
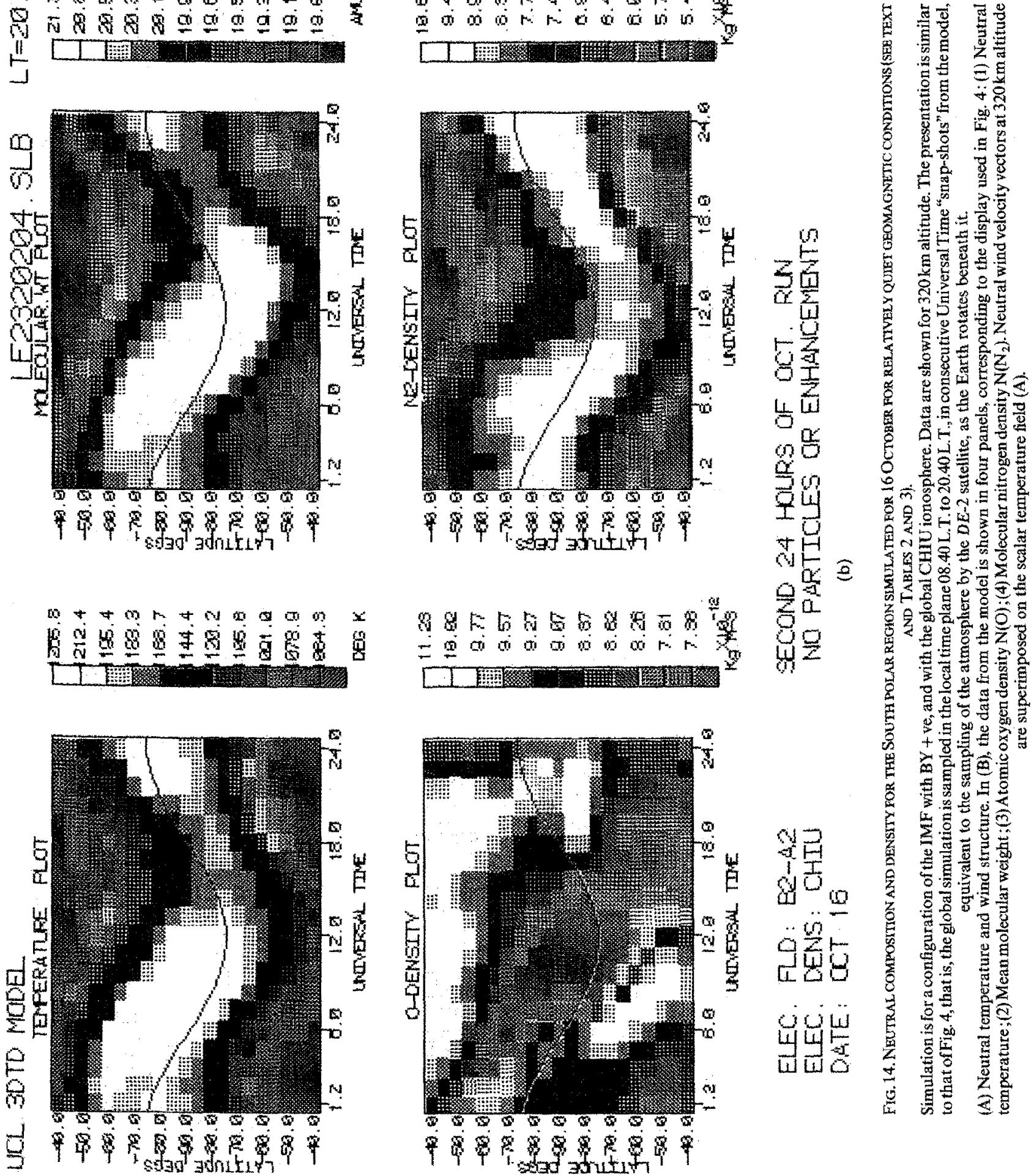


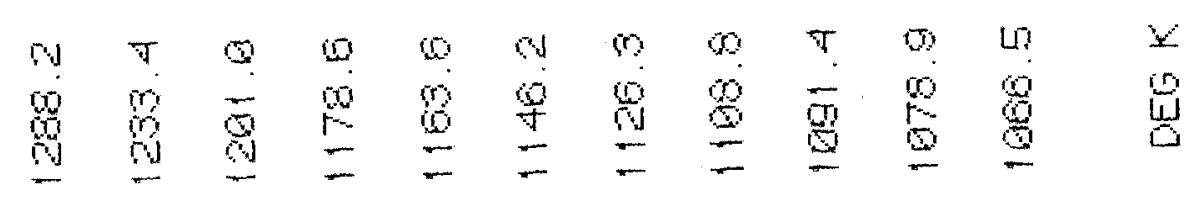
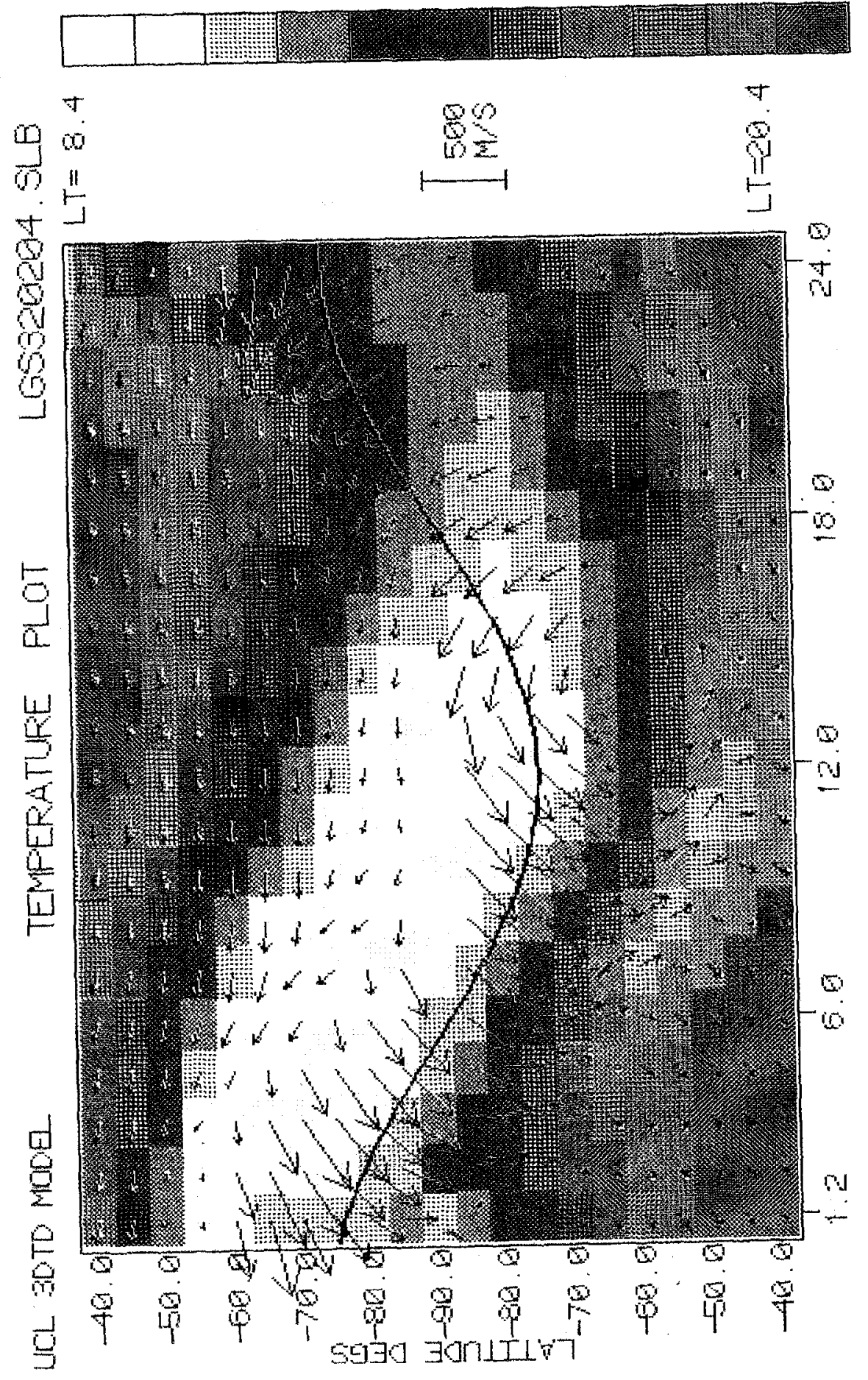

$\infty$ 

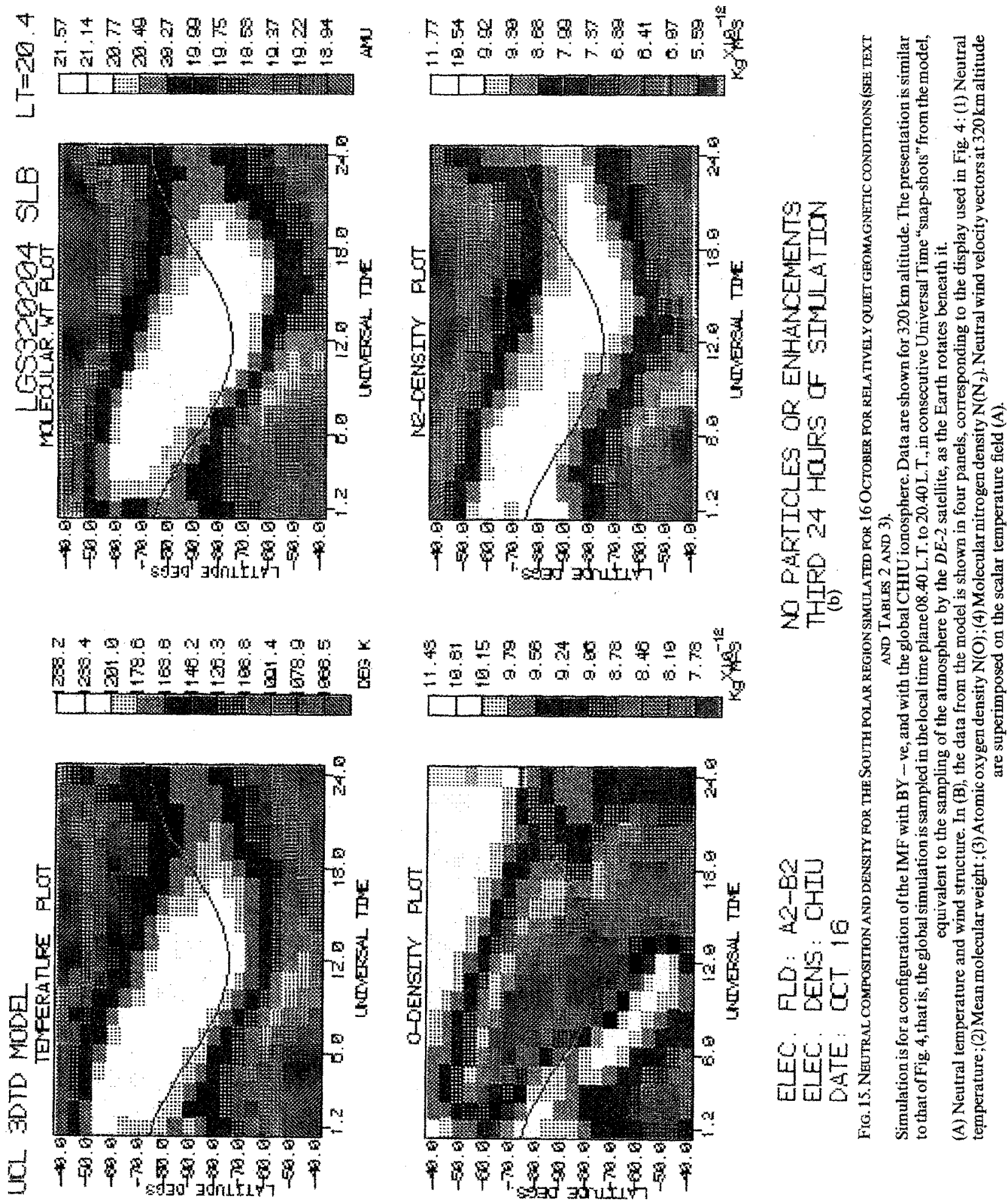

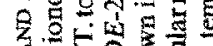
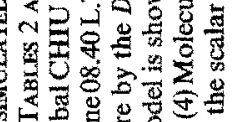

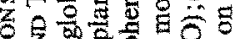

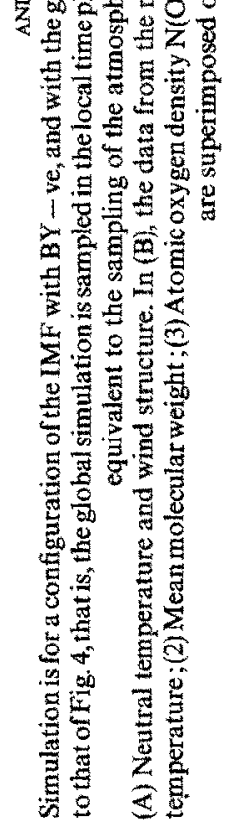

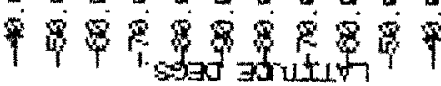

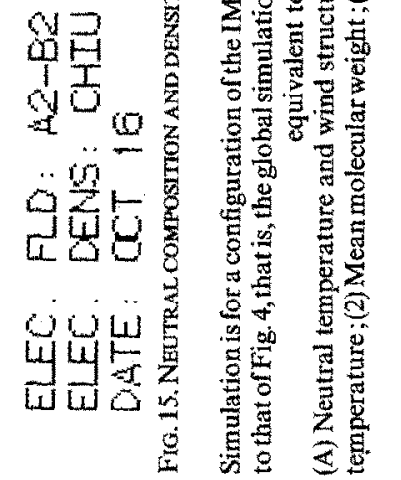




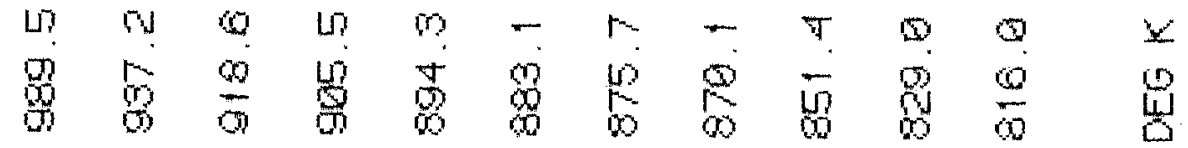
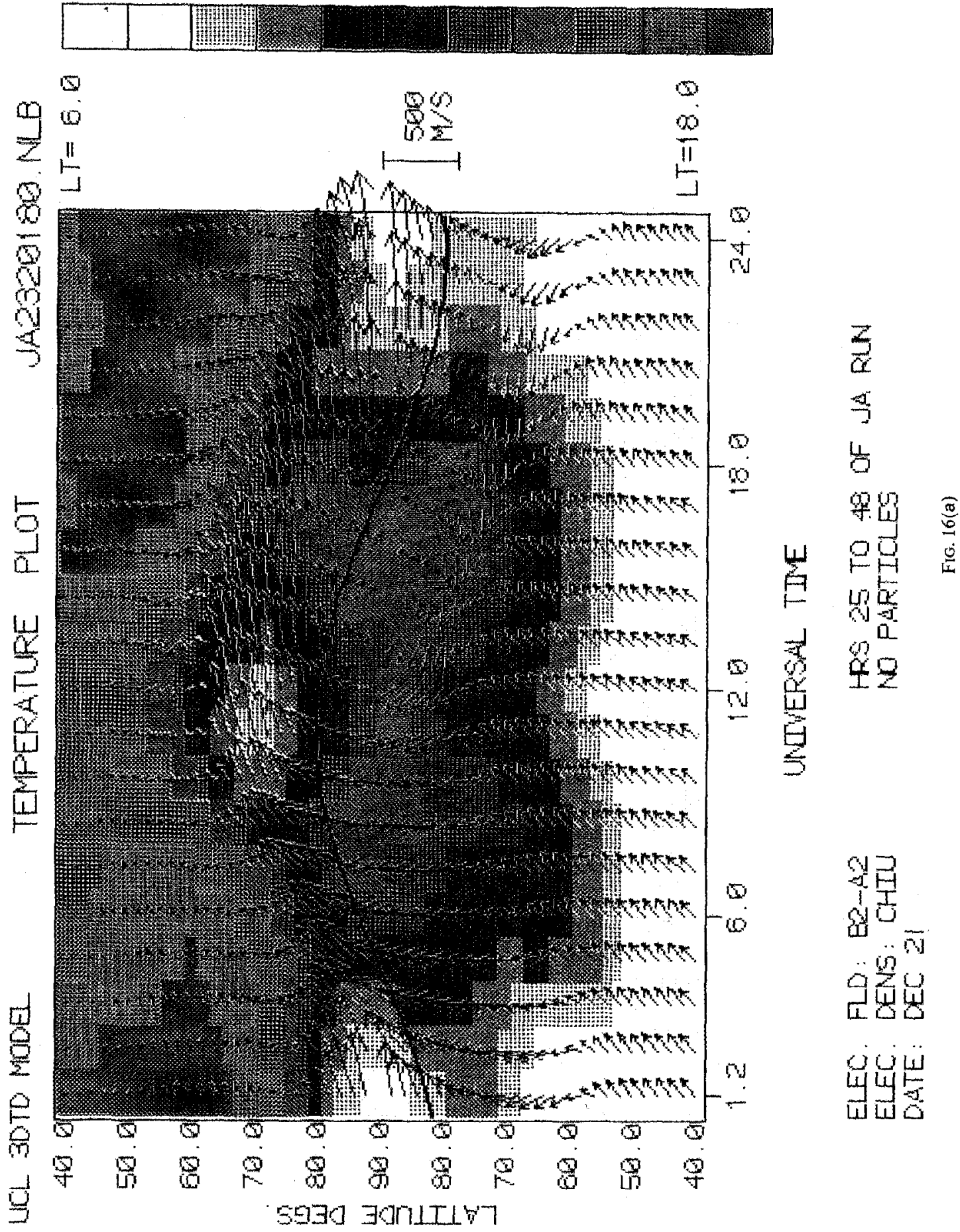
$$
\text { 然 }
$$

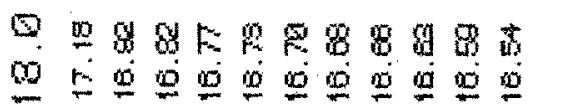
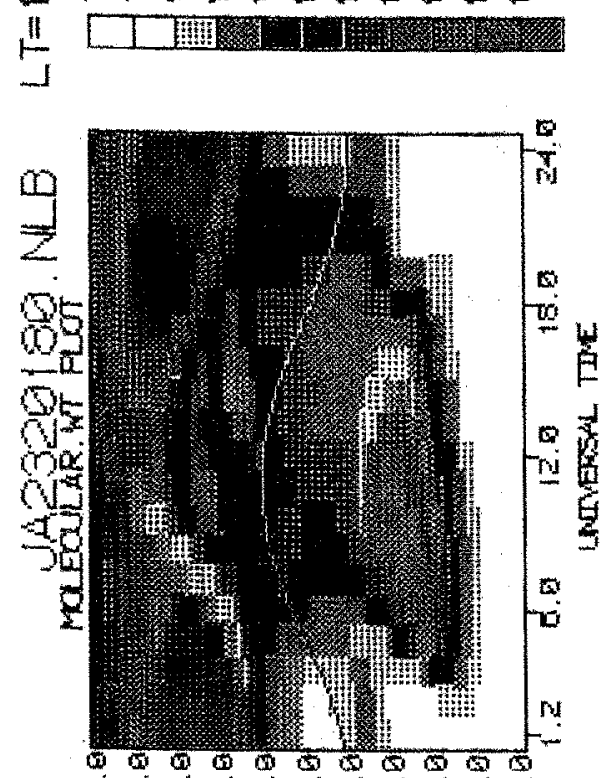

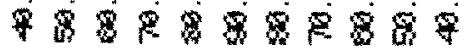
soja JuriLL7?

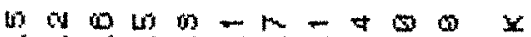

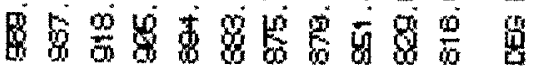

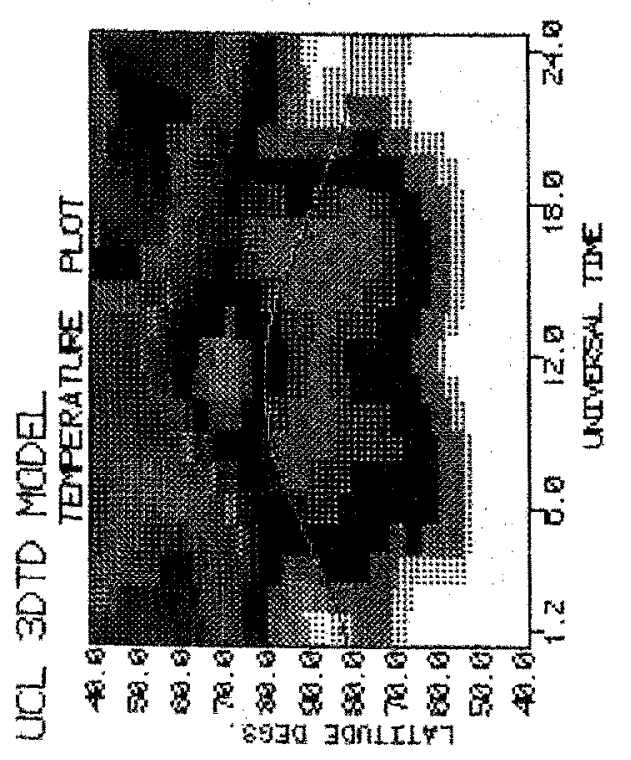

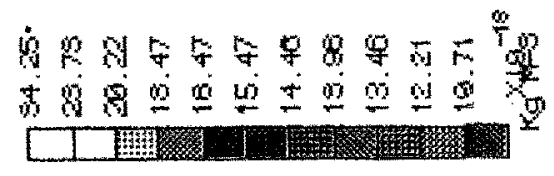

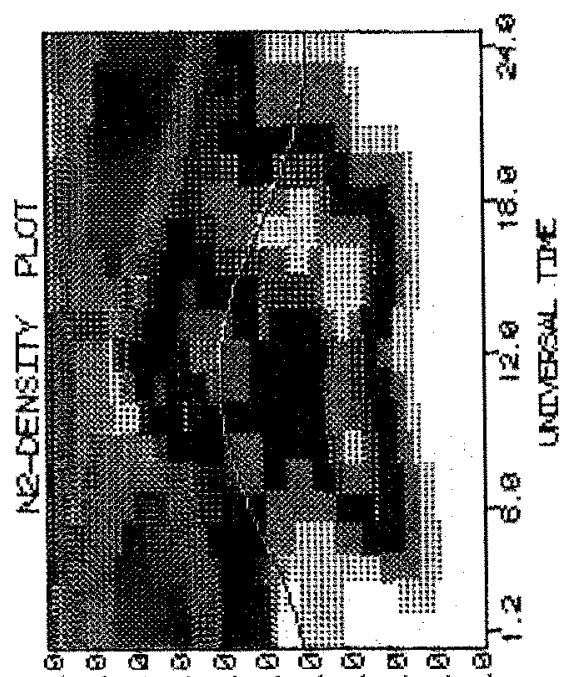

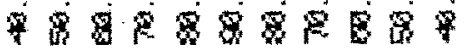
6000 mantirl
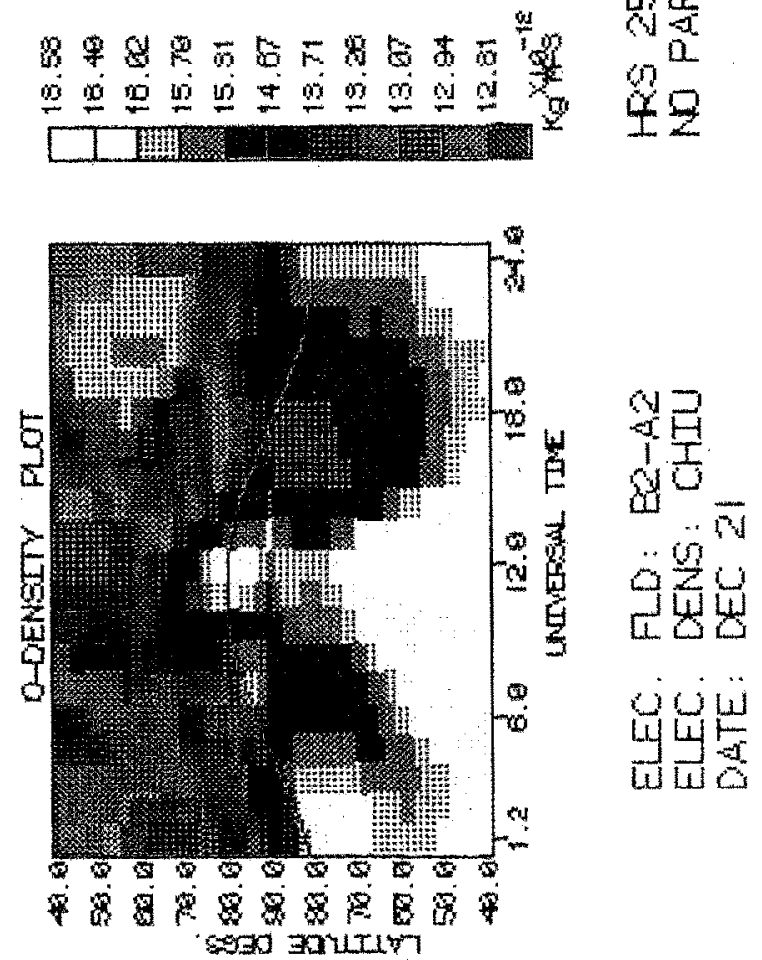

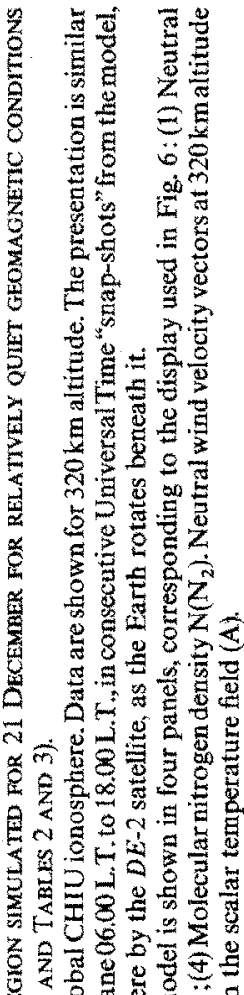

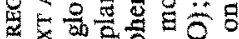

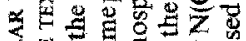

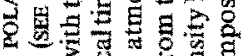

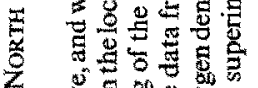
Z *

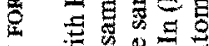

- 5.

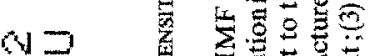

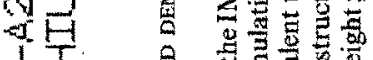

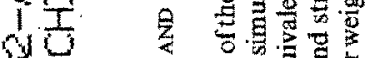

aif

$+\pi \mathrm{r}$

3. 홍ㅎㅀ

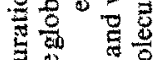

总 d

की

jo

Ly 1 남

8. 部

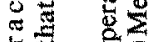

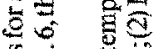

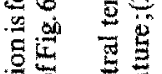

(1) 1 


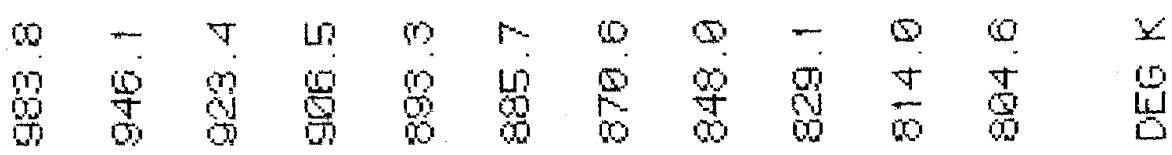
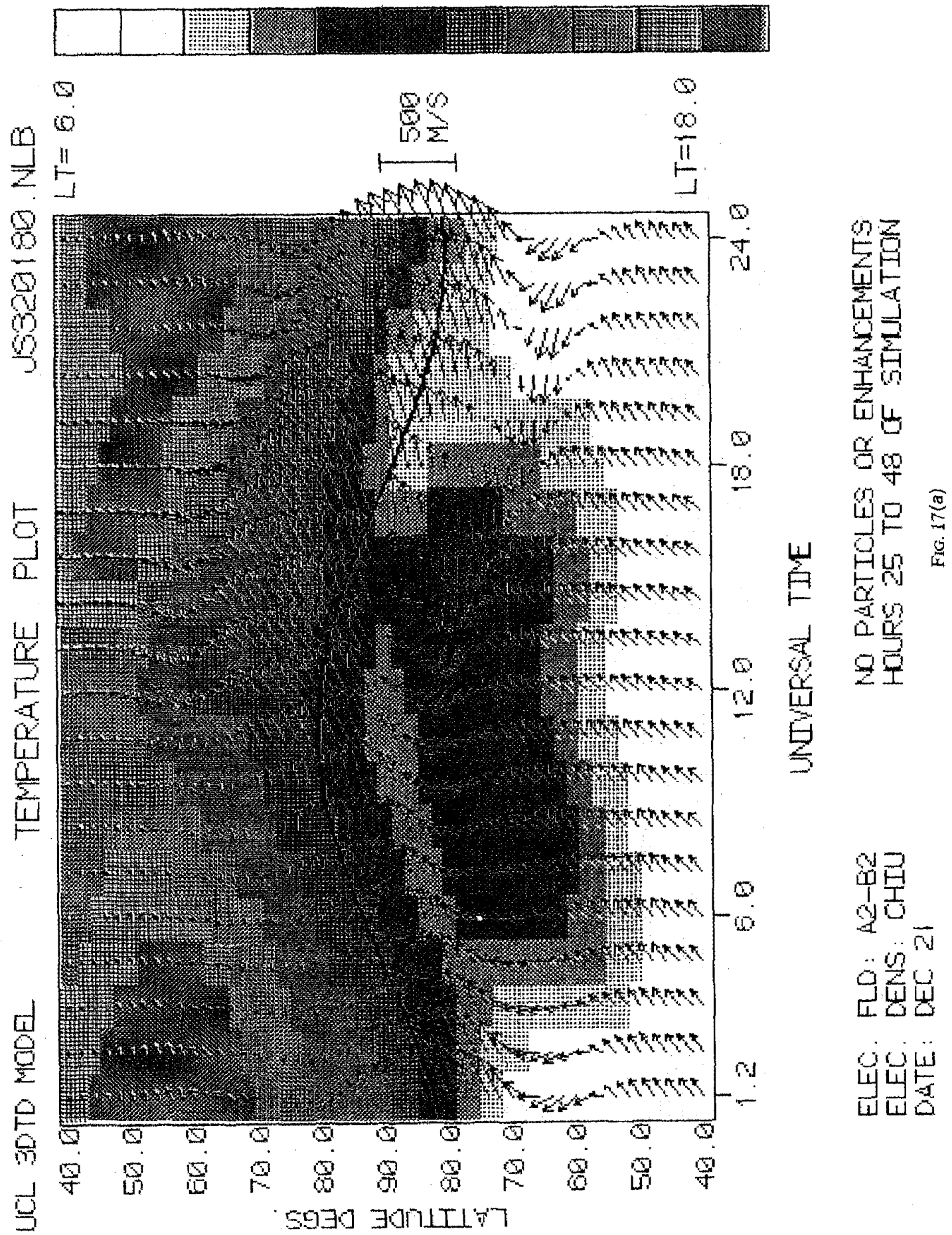


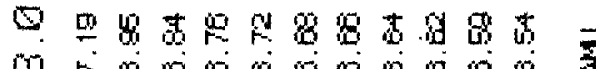

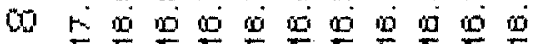

iI

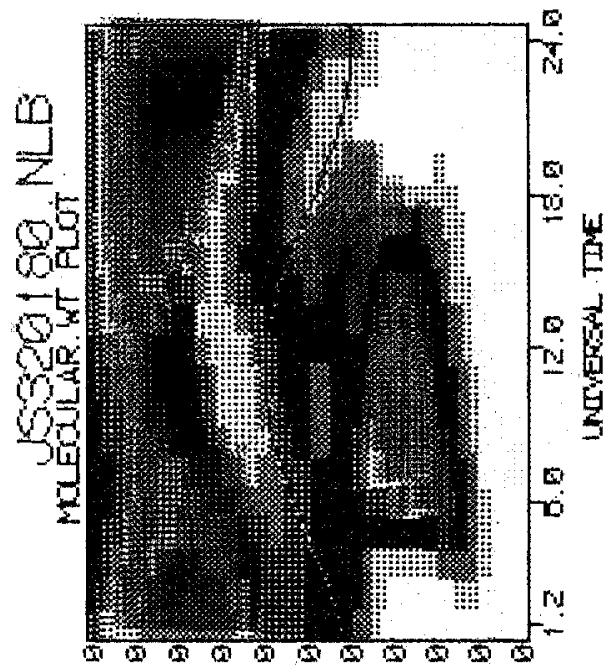

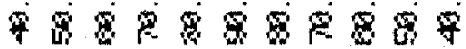
8930 J0ILILT?
B

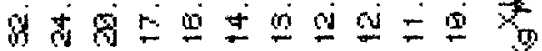

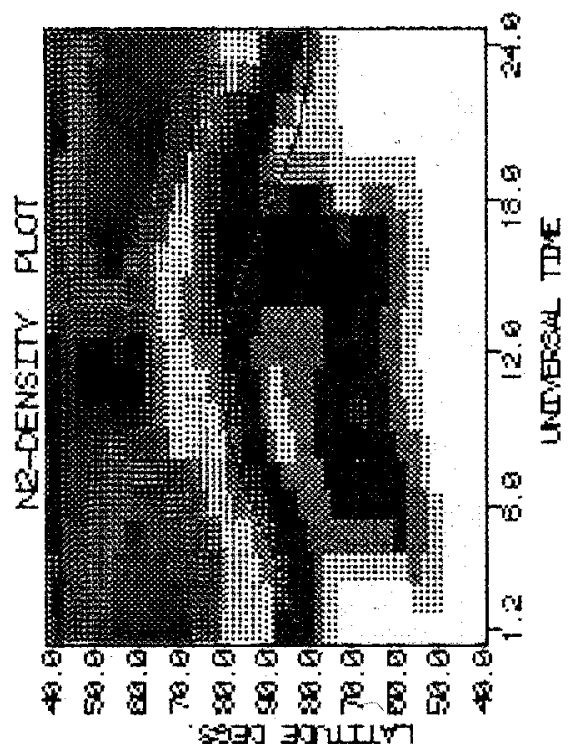

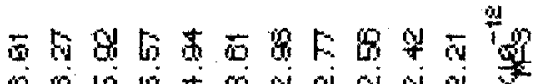
w

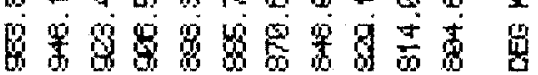

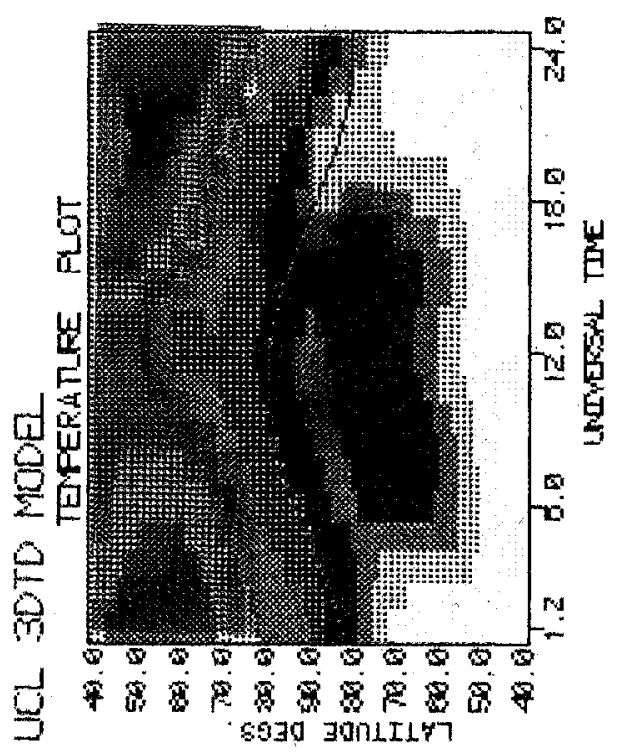

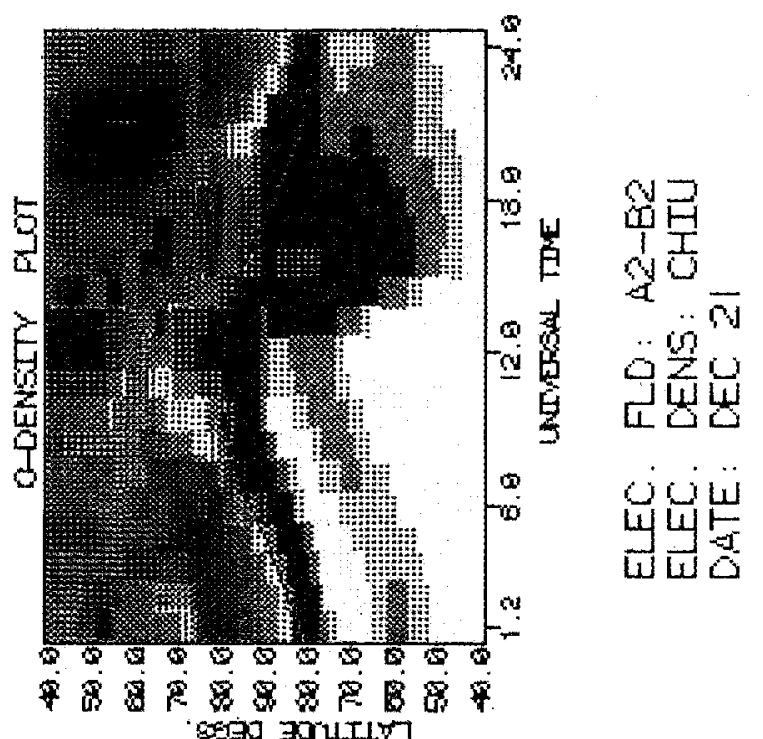

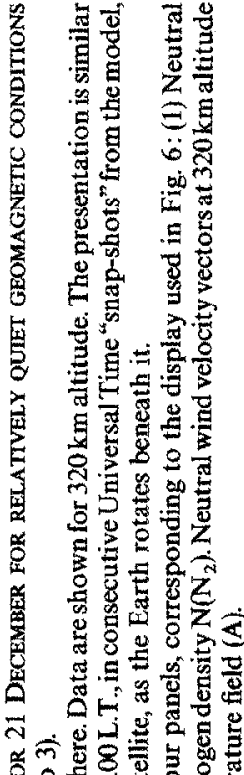

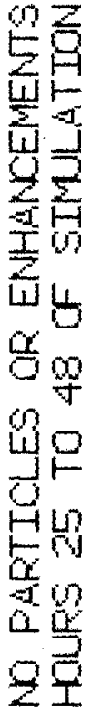

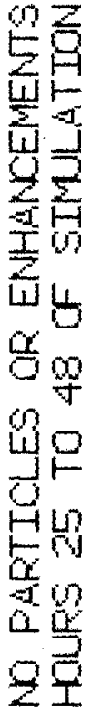

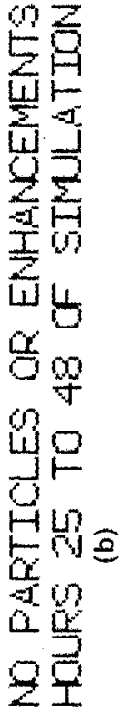

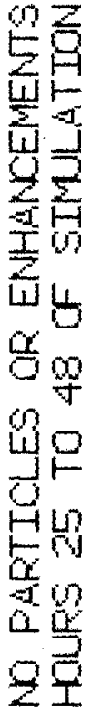

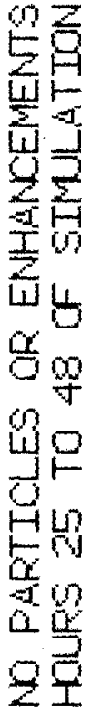

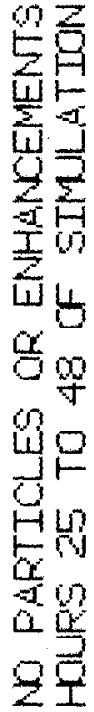

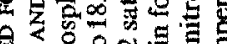

N

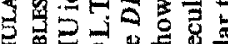

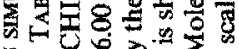

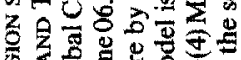

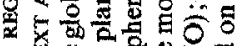

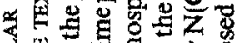

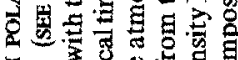

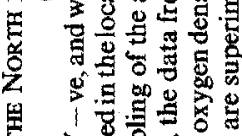

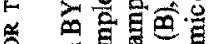

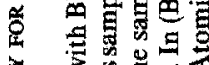

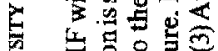

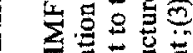

5 可豆

安 青要 क

z

8

융유

को 5

题

氞. 要

牙

농

6

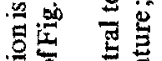

ㄷ.

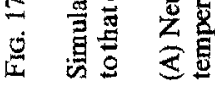




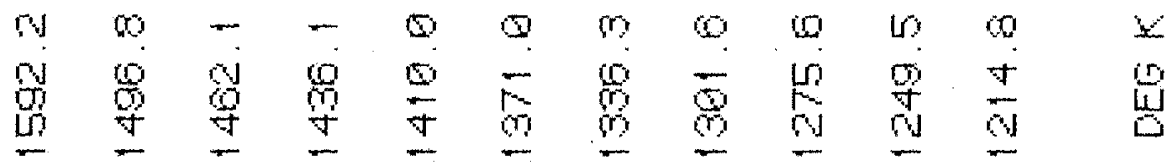
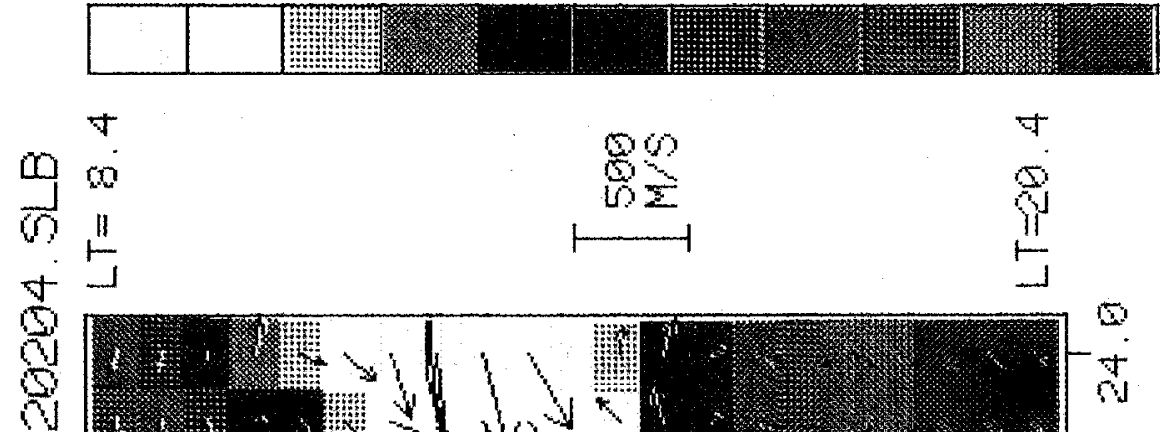

告

8

L.

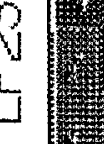

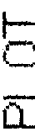

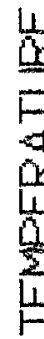

a
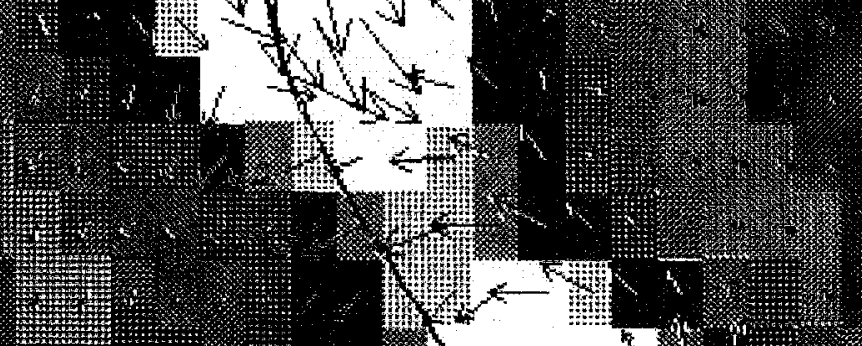

$1+$ W
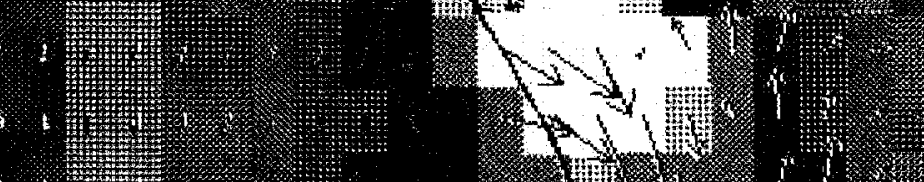

i.tom

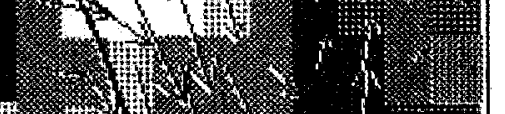

5

0
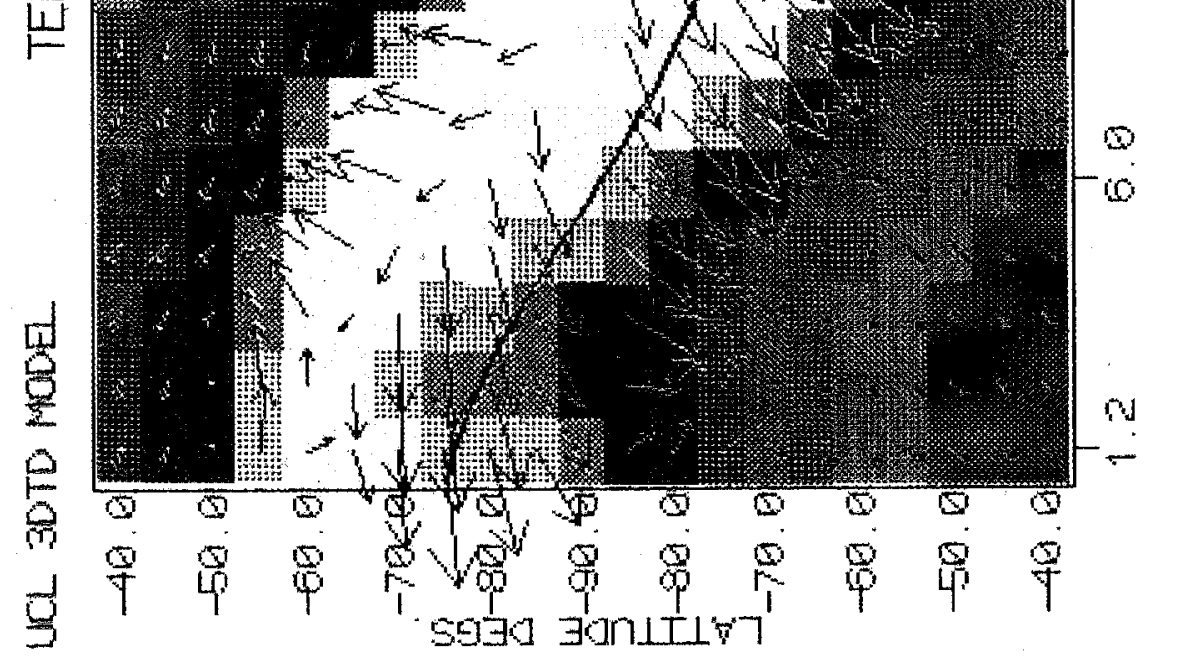

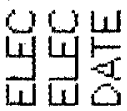



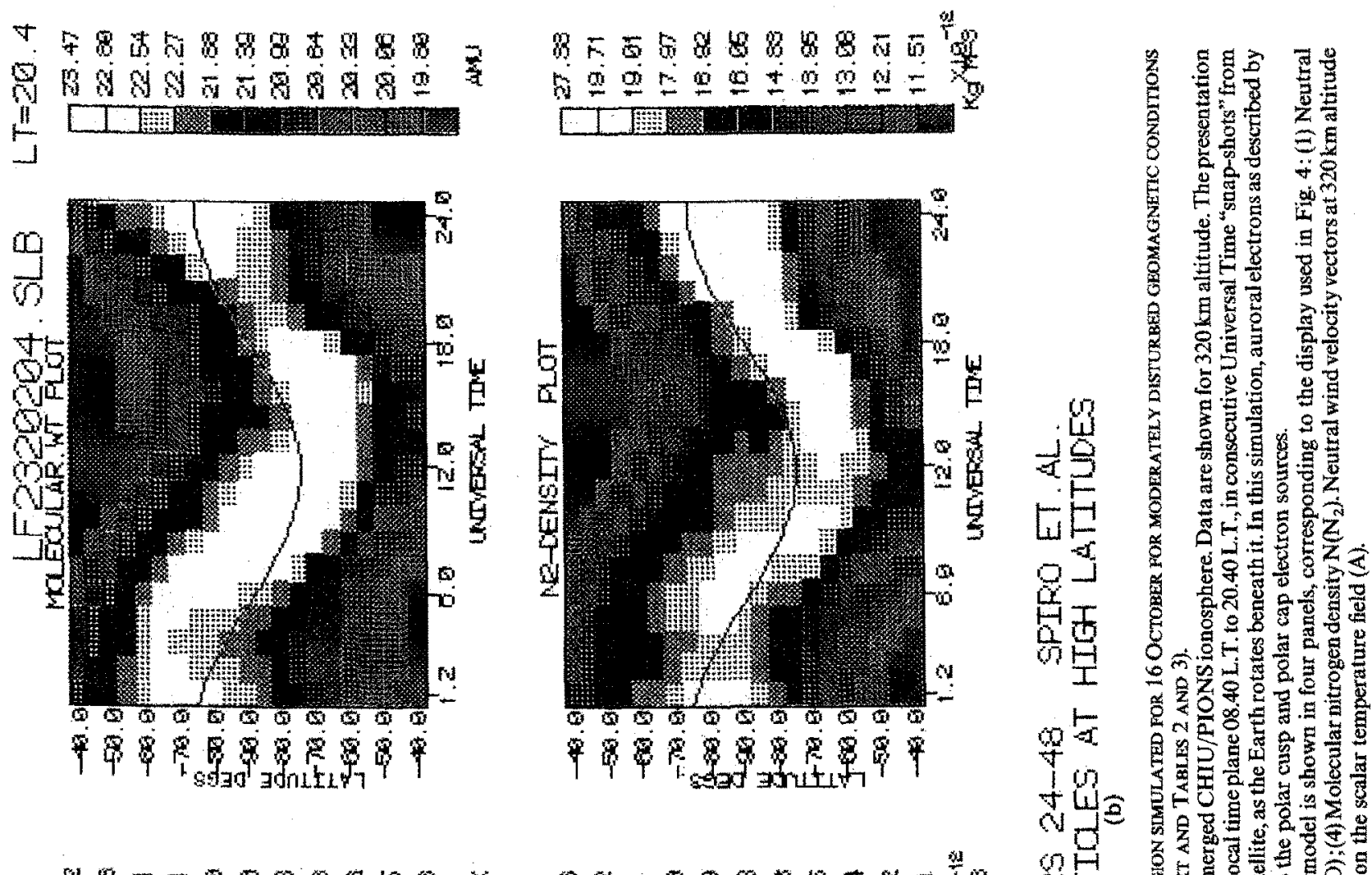

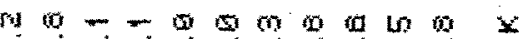
8采娄安 $89588 \div 4 \div 8 \%$

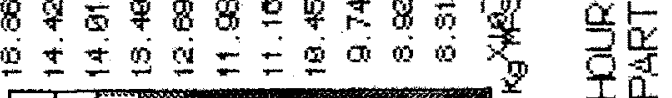

㥼

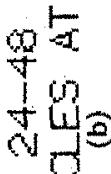

OH

舟 $8=0$

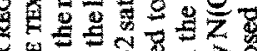

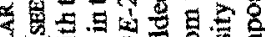

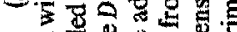

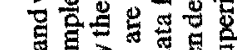

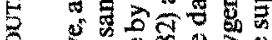

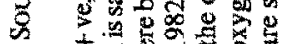
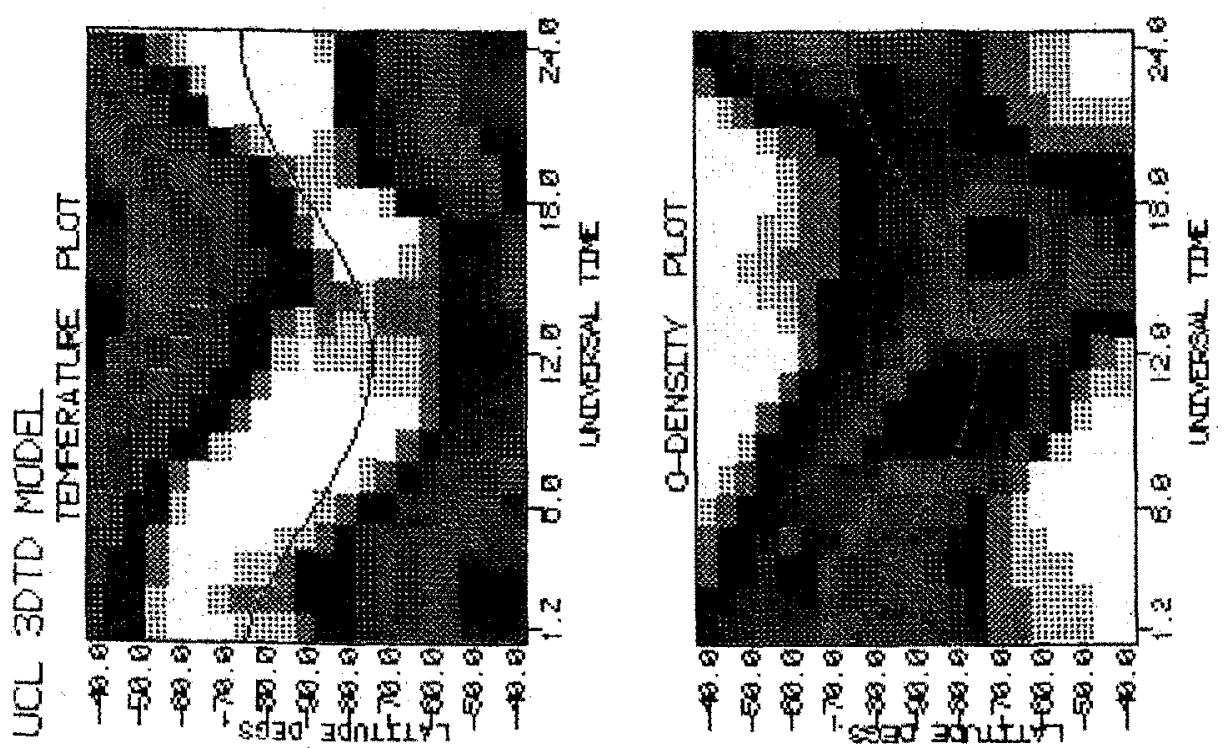

$\frac{4}{4}$ a $\frac{\ddot{2}}{4}=8$

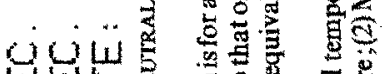
$44=x$ แ. $\mathrm{U} \bigcirc$

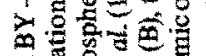

进焉

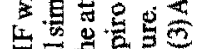

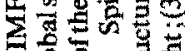

承

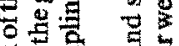

둥.

递焉

$80 \div 0$ 的是

을

结通焉

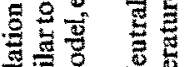

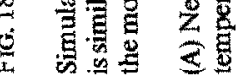




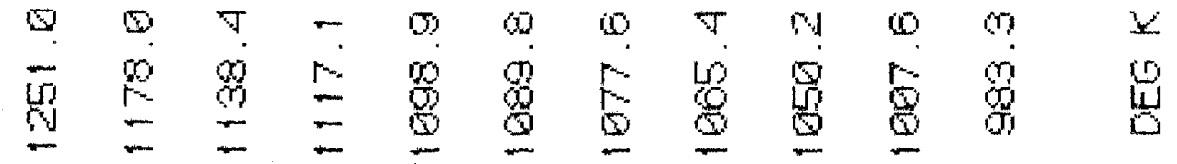
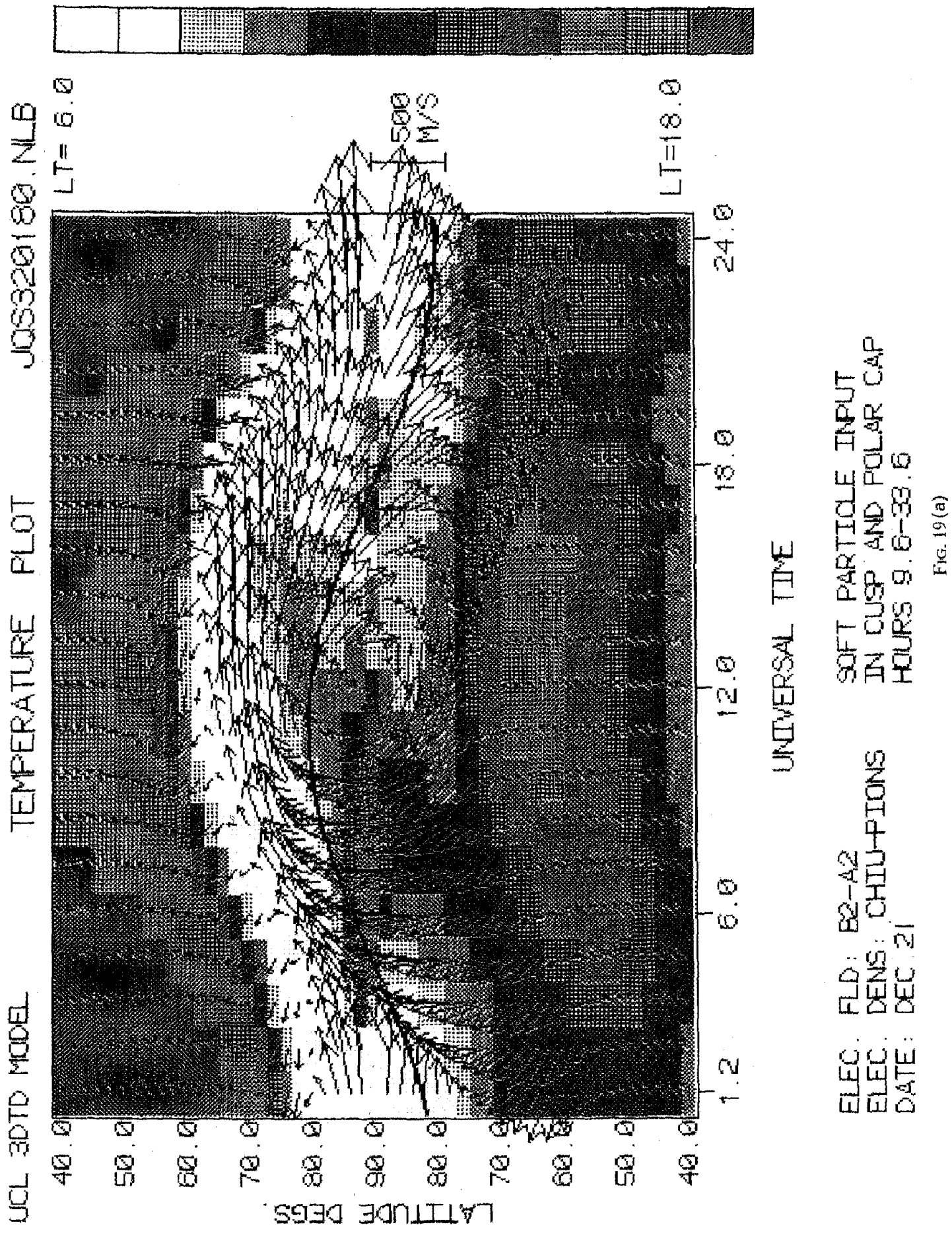


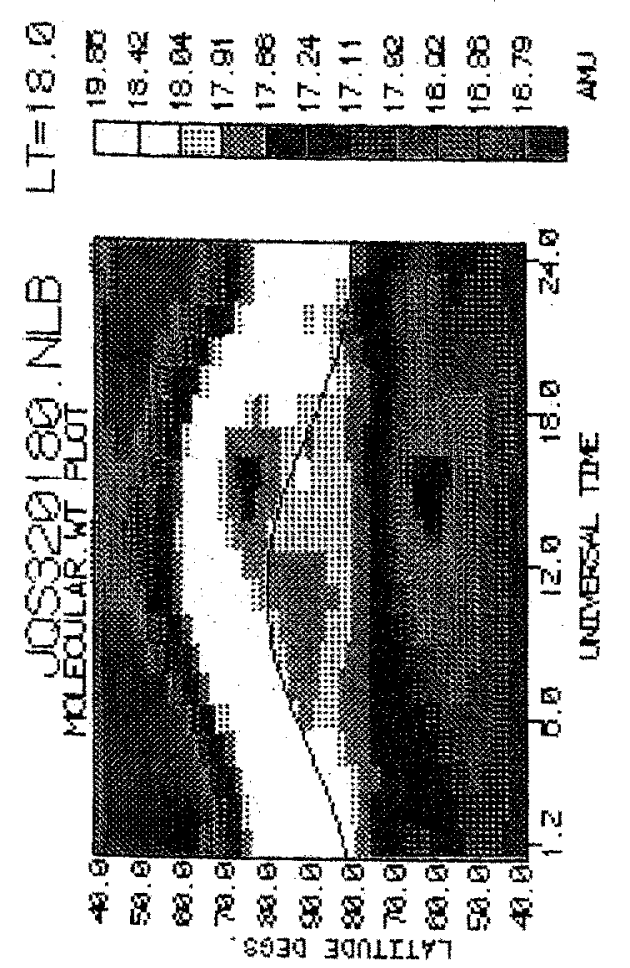

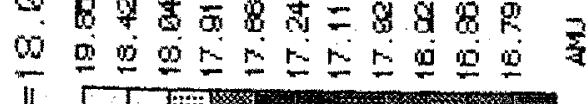

$00-\infty 00+\alpha \infty \pi x$

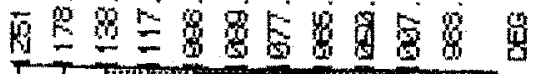

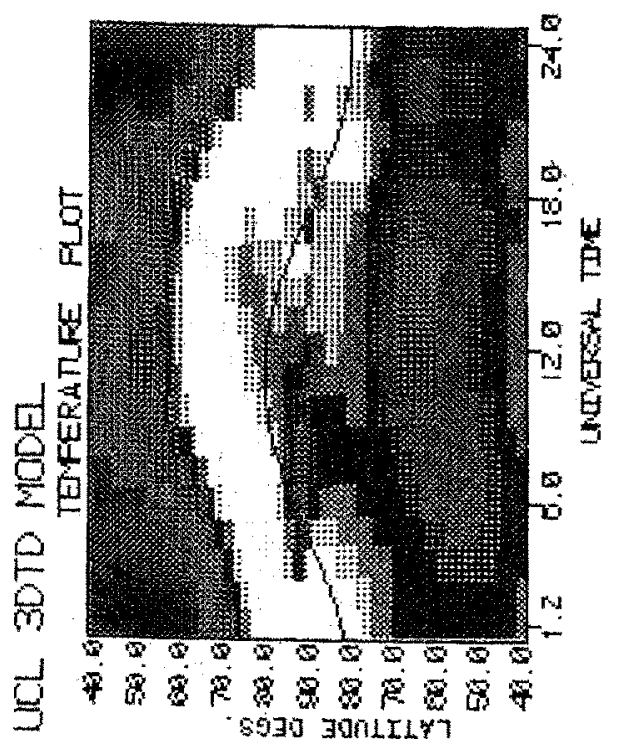

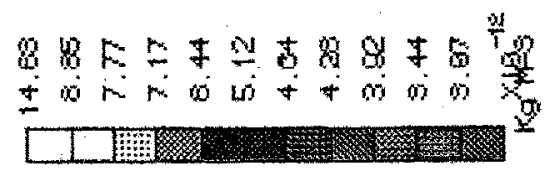

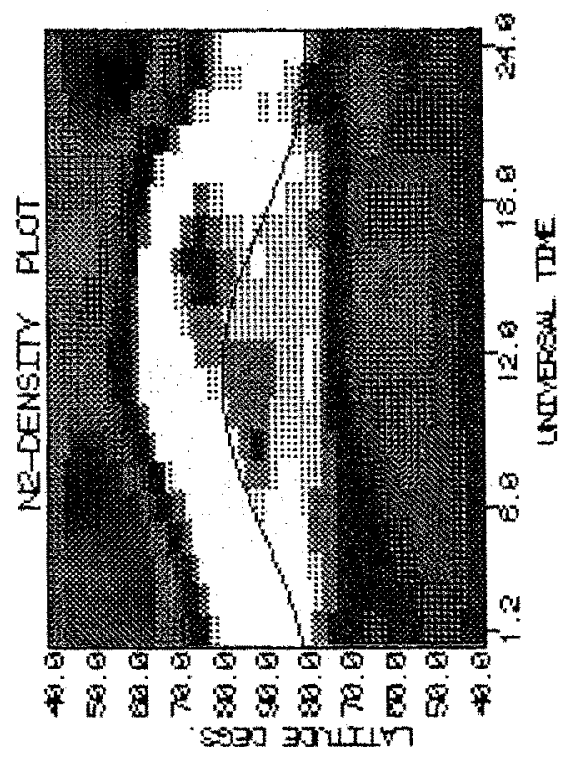

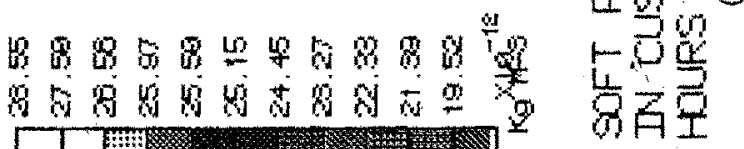

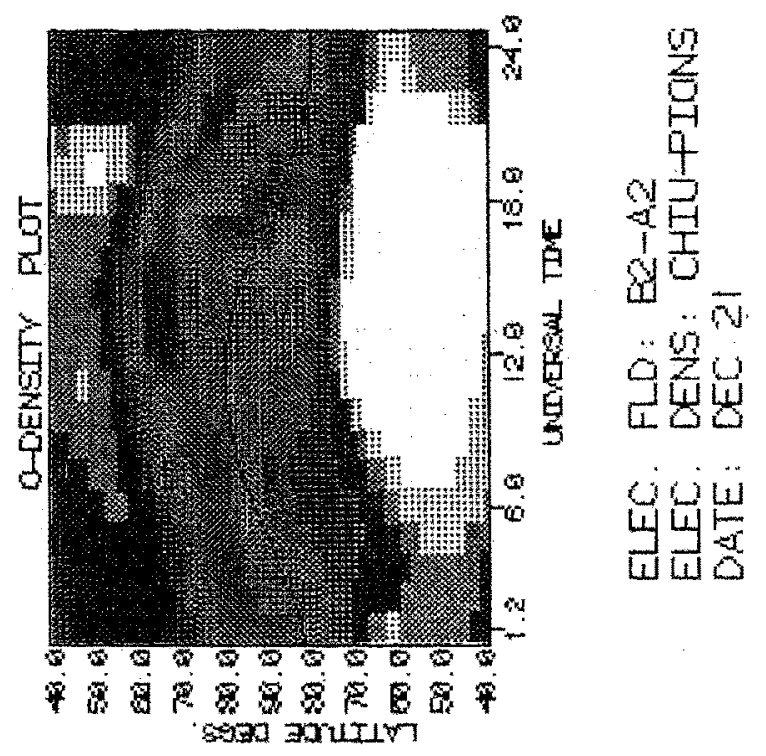

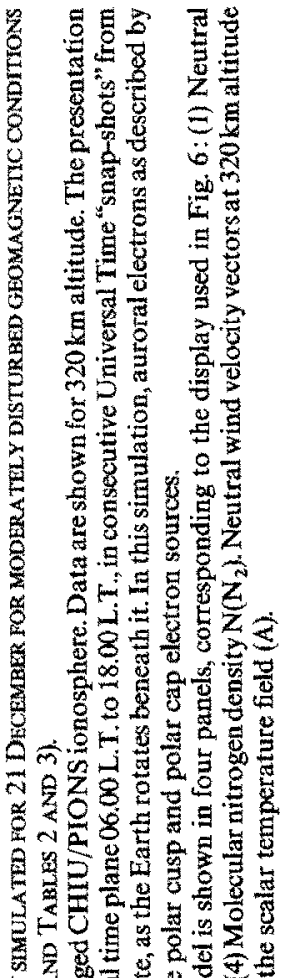

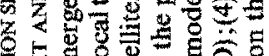
政 $\alpha$ w

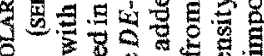

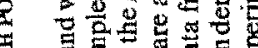

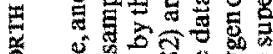

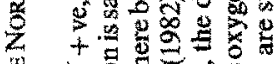
田

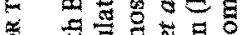

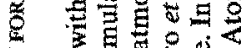

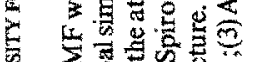

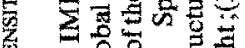
罗总品 安 先

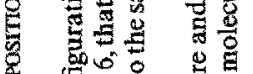

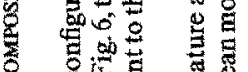

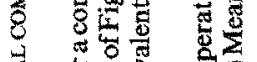

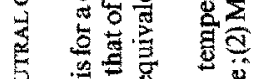
尊

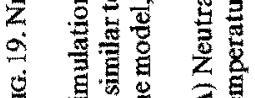

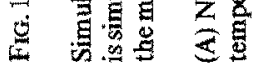


TABLE 3. COMMON DATA ON THE GEOMAGNETYC ENERGY AND MOMENTUM INPUTS TO THE THREE MODEL GROUPS

The asymmetric polar convection fields of Heppner (1983)

\begin{tabular}{|c|c|c|}
\hline & $\begin{array}{l}\text { The A2 field } \\
\text { IMF BY - ve }\end{array}$ & $\begin{array}{l}\text { The B2 field } \\
\text { IMF BY + ve }\end{array}$ \\
\hline Cross-polar cap potential: & $76 \mathrm{kV}$ & $76 \mathrm{kV}$ \\
\hline Potential of dusk boundary: & $-40 \mathrm{kV}$ & $-42 \mathrm{kV}$ \\
\hline Potential of dawn boundary: & $36 \mathrm{kV}$ & $34 \mathrm{kV}$ \\
\hline Cusp entry to polar cap: & 10 L.M.T. & 11.5 L.M.T. \\
\hline $\begin{array}{l}\text { Harang discontinuity at } \\
\text { centre of auroral oval: }\end{array}$ & 00 L.M.T. & 01 L.M.T. \\
\hline $\begin{array}{l}\text { Diameter of polar cap: } \\
\text { (degrees geomagnetic } \\
\text { latitude) }\end{array}$ & 32 & 28 \\
\hline $\begin{array}{l}\text { Diameter of auroral oval: } \\
\text { (fastest sunward } \\
\text { convection) }\end{array}$ & 42 & 40 \\
\hline
\end{tabular}

reflects solar illumination of 16 October, corresponding approximately to the mid-point of the $D E-2$ South polar study.

In Fig. 9(A) and (B), two comparable snapshots of the North (winter) Hemisphere are shown at 19.20 U.T. for the $\mathrm{B} 2$ and $\mathrm{A} 2$ convection fields respectively, and with the solar illumination representative of 21 December, and the same geomagnetic activity as that used to obtain the Southern Hemisphere simulations.

Major changes in the polar neutral wind circulation and in the temperature structure result from switching between the two convection patterns. In both hemispheres, there is a strong antisunward wind jet on the dusk side of the polar cap in the A2 simulation, which switches to the dawn side of the polar cap for the B2 simulation. The sunward circulation of the dawn auroral oval is strong for the A2 simulation, and weak or absent for the $\mathbf{B} 2$ simulation.

In the Southern Hemisphere, regions of eastward and equatorward winds which appear equatorward of the morning auroral oval for the $\mathrm{A} 2$ model are occupied by equatorward and westward winds for the $\mathrm{B} 2$ model. The entire anti-sunward flow in the dawn part of the polar cap (seen here at about $55-70^{\circ}$ latitude and 00.00 06.00 L.T.) is directed more westward for the $B 2$ model and more equatorward for the A2 model.

In the Northern Hemisphere, the westward wind jet associated with the evening auroral oval is well defined for both models. However, the extent of the clockwise polar vortex, of which the westward jet of the evening auroral oval forms a part, is much larger under the influence of the B2 model. For this model, the vortex extends to the dawn edge of the polar cap, where there is a region of high speed anti-sunward winds. By comparison, for the A2 model, the dusk vortex is terminated sharply near 12.00 L.T. by a region of eastward and poleward winds driven sunward through the dawn auroral oval, and continuing anti-sunward toward the dusk side of the polar cap.

In the northern winter polar region, the B2 convection model drives very weak sunward winds in the dawn auroral oval. However, the A2 model drives a complete cyclonic vortex including the dawn auroral oval and the dusk side of the polar cap. For this case (A2), the strongest anti-sunward winds occur on the dusk side of the polar cap, contrasting with the location of the antisunward wind jet on the dawn side of the polar cap for the $\mathrm{B} 2$ model. With either the $\mathrm{B} 2$ or the $\mathrm{A} 2$ model, there is a significant U.T. modulation of the details of the polar circulation in both hemispheres as the Earth rotates and the solar illumination of each geomagnetic polar region changes. There will also be changes in the polar winds, and the other structures of the polar regions, if the size of the auroral oval, the magnitude of the cross-polar cap potential, or the amount and distribution of precipitation in the auroral and polar regions is changed. The snap-shots which are shown are, however, representative of the general circulation leatures.

\section{Thermal structure}

In the Southern Hemisphere (19.20 U.T.), a small temperature change of about $50 \mathrm{~K}$ can be associated with the change from the $A 2$ to the $B 2$ convection field. For the 82 field, the highest temperatures occur in the dawn part of the polar cap, while for the $\mathrm{A} 2$ field, the highest temperature region is located more centrally in the polar cap or on the dusk side near the boundary with the evening auroral oval.

In the Northern Hemisphere, the temperature structure at lower latitudes is virtualiy unchanged as a result of using the $\mathrm{A} 2$ or the B2 model. However, at higher latitudes, there are major changes. In the B2 simulation, the dawn side of the polar cap, which has strong anti-sunward winds driven by the strong antisunward ion convection, is associated with a region of enhanced temperature which extends from the dayside polar cusp. Conversely, for the A2 model, the region of enhanced temperatures extends from the cusp to the dusk part of the polar cap. For each of the B2 and A2 simulations, those polar regions where temperatures were elevated for the one polar convection field model are seen to have depressed temperatures for the complementary convection model. That is, the dusk part of the polar cap and auroral oval is a cool region in the B2 simulation, while the dawn part of the polar cap and the dawn auroral oval is a cool region in the $A 2$ simulation.

Two processes are involved in causing the polar temperature maxima. Firstly, the "soft" dayside cusp 
electron source strongly heats the upper thermosphere in both of the simulations. The extension of the heated regions antisunward over the polar cap appears to be due partly to a thermal "plume", carried out of the cusp region, by the respective anti-sunward winds generated by either the $\mathrm{A} 2$ or the $\mathrm{B} 2$ convection patterns. A second process is local heating caused by enhanced Joule or frictional heating due to the changes in the convection patterns. This process appears to be rather less important than the wind-driven thermal plume in the present simulations. A part of the reason for the smalier importance of this process is the acceleration of fast anti-sunward winds by the anti-sunward ion jets, reducing the ion-neutral differential velocity and thus the frictional heating.

\subsection{Simulations of thermospheric structure and dynamics} at constant $L T$.

The results of the model simulations will be presented in the format of the $D E-2$ data shown in Figs. 1 and 2, and 4.6. The full 3-D global model is normally used at 1.2-h Universal Time intervals (although the numerical time-step in the model is $1 \mathrm{~min}$ ). The individual data sets (at constant U.T.) are sampled for the particular local times corresponding to the orbit plane of the $D E-2$ spacecraft appropriate to the October (South) or December (North) epochs.

5.2.1. Models for moderately disturbed geomagnetic conditions with sources of low energy electrons in the cusp and polar cap. A pair of simulations have been generated using the merged "hybrid" CHIU/PIONS global ionosphere, where the geomagnetic polar cap and the region of the dayside cusp have been enhanced by the inclusion of "soft" electron precipitation. There is no auroral electron precipitation in the $\mathrm{KB}, \mathrm{KC}, \mathrm{KD}$ or the $\mathrm{KE}$ models. These models are denoted as the $\mathrm{KC}$, $\mathrm{KD}(\mathrm{B2} / \mathrm{A} 2)$ model (when the $Y$ component of the IMF is positive), and the $\mathrm{KB}, \mathrm{KE}(\mathrm{A} 2 / \mathrm{B} 2)$ model (when the $Y$ component of the IMF is negative). For the Southern. Hemisphere, the Local Time region studied by $D E-2$ during October 1981 was the plane from 09.00 to 21.00 . In Fig. 10, the polar thermospheric structure is shown for the local time plane $08.40-20.40$ L.T. The format is the same as that displayed in Fig. 4, and this simulation corresponds to the situation with the IMF BY positive, that is with the $A 2$ convection model applied to the southern polar region (and B2 to the North). In Fig. 11, the same format is used to display the simulation using the $\mathrm{B} 2$ convection model in the Southern Hemisphere (i.e. IMF BY is negative), again for the $08.40-20.40 \mathrm{~L}$.T.

In Fig. 12, the same format is used to display the Northern Hemisphere structure for the 06.00-18.00 local time plane (cf. Fig. 6) for the simulation corresponding to a positive $Y$ component of the IMF, i.e. with the B2 convection field. In Fig. 13, the corresponding situation when the IMF BY is negative (i.e. the A2 field applied to the Northern Hemisphere) is shown.

5.2.2. The geomagnetic "quiet" simulations. Using the global "CHIU" model instead of the merged CHIU/ PIONS model, a corresponding set of simulations to those shown in Figs. 10, 11, 12 and 13 have been prepared and are shown in Figs. 14 (LE), 15 (LG), $16(\mathrm{JA})$ and $17(\mathrm{JS})$ respectively. These simulations correspond to relatively quiet geomagnetic conditions. However, the reduction in "geomagnetic input" reflects an absence of magnetospheric energetic plasma precipitation at high latitudes, thus reducing ionospheric plasma densities, ion drag, Joule heating and with no direct deposition of particle energy. The same convection fields (A2, B2), with a cross-cap potential of about $80 \mathrm{kV}$, are used as in the moderately disturbed simulations. The global mean thermospheric temperature of the JA and JS simulations are about $200 \mathrm{~K}$ lower than those of the KB and $\mathrm{KC}$ simulations (moderately disturbed).

A more realistic way of decreasing the geomagnetic input might be to allow the polar convection pattern to contract poleward, and to decrease simultaneously both the total cross-polar cap electric potential and the magnetospheric energetic particle precipitation. Simulations have been completed with such a poleward-contracted polar convection model. However, these simulations show features of the polar thermospheric circulation, driven by ion convection in the auroral oval, to be located further poleward than shown in the statistical $D E-2$ wind analyses presented here and in Hays et al. (1984). These additional simulations will not be discussed further in this paper.

\subsubsection{Simulations representing moderately disturbed} geomagnetic conditions, with auroral oval as well as cusp and polar cap precipitation sources. One simulation for the southern October period and a second for the northern winter solstice period have been completed, where an auroral electron source described by Spiro et al.(1982) for $100<A E<300$ has been added to the soft cusp and polar cap electron sources. These simulations are shown in Figs. 18(LF) and 19(JQ) respectively, with the same representations used previously. The characteristics of these simulations are that the sunward wind speeds within the auroral oval considerably increased, as would be expected from the increase of ion drag acceleration due to the increased thermal plasma densities. There is also an increase of 
about $100 \mathrm{~K}$ in the polar and global mean temperatures above those of the $\mathrm{KD}$ and $\mathrm{KC}$ simulations.

\section{DISCUSSION}

The major objective of this study is to investigate the overall morphology of energy and momentum inputs to the thermosphere due to geomagnetic sources corresponding to average conditions present during the two epochs covered by the samples of $D E-2$ data. Of particular importance is the comparison between observed and modelled imprints of major geomagnetic forcing processes on the structure or dynamics of the upper thermosphere. At upper thermospheric levels, density and composition reflect both the integrated height profiles of solar and geomagnetic heating throughout the thermosphere and the balance between various energy sources and sinks in different regions. This is due to the effect on thermospheric composition of systematic upwelling and downwelling when there is a connecting horizontal wind. In contrast, the observed wind structures indicate the driving forces at the level of the wind observations. The combination of wind, temperature and composition data thus allow a critical evaluation of the descriptions of geomagnetic energy and momentum inputs at all thermospheric levels which are used in the theoretical model.

\section{Wind and temperature structures of the Southern (summer) Hemisphere}

The measured wind data (Fig. 1) are similar to those of the simulation with stronger evening auroral oval/weaker morning auroral oval winds generated by the $\mathrm{B} 2$ convection model (Fig. 11). The average magnitudes of the polar cap winds and those of the evening auroral oval compare better with the "moderately disturbed" KE simulation (Fig. 11) than the less disturbed LG simulation (Fig. 15). The winds generated in the auroral oval by the most disturbed $\mathrm{LF}$ model (i.e. with auroral electron enhancement, Fig. 18) are stronger than the mean observed winds. However, they agree quite well with the instantaneous peak winds (Rees et al., 1983) observed by $D E-2$ as the satellite crosses the auroral oval. The peak winds observed in individual orbits are somewhat averaged and reduced in the statistical analysis presented here, due to the latitudinal migration of the auroral oval with varying geomagnetic activity within the large number of individual orbits contributing to the data base.

If the observed and modelled wind structures in the dawn auroral oval between 00.00 and 06.00 U.T. are compared (Fig. 1 and Figs. 10 and 11), it can be seen that there is a weak sunward wind response of the neutrals which is a characteristic response to the $B 2$ convection field. Even with the ion convection of the B2 model, there is relatively strong ion drag forcing and the lack of response has heen interpreted as due to the advection of eastward momentum out of the auroral oval (FullerRowell et al., 1984; Fuller-Rowell, 1984). This intrinsic property of the themospheric response to a driven anti-clock wise vortex is linked with upward convection and horizontal divergence of the thermospheric wind system. In turn, the upward convection and horizontal divergence enhances molecular nitrogen density, which is a feature of the dawn auroral oval in the simulations and in the observations.

Between 06.00 and 12.00 U.T., the satellite crosses the polar cap region previously scanned in the period 00.00-06.00 U.T. (see Fig. 3). The wind structures are thus similar. From 18.00 to 24.00 U.T. and from 13.00 to 18.00 U.T., the satellite again scans similar geomagnetic regions, this time the dusk auroral oval and midnight region of the polar cap. There are corresponding switches of wind direction about 14.00 U.T. and about 22.00 U.T. as the geomagnetic region beneath the satellite orbit changes from the polar cap to the dusk auroral oval, which can be identified in the data and in the KE (B2 field) model simulation (Fig. 11).

The hot region of the dayside polar cusp is better simulated with the KE model (B2 convection field, Fig. 11). The cusp region is located over the geographic pole at about 12.00 U.T. and, in the model, has a combination of cusp particle heating and a relatively high level of solar e.u.v. input due to the (relatively) high solar elevation at this time. The mean polar temperature of the $\mathrm{KD}$ and $\mathrm{KE}$ models are of the order of $100-200 \mathrm{~K}$ lower than the mean $D E-2$ observations, a difference we believe can be attributed to the value of $F$ $10.7 \mathrm{~cm}$ flux (150) used in the models.

\section{Wind and temperature structure of the Northern (winter) Hemisphere}

The "CHIU" simulations (Figs. 16, 17) show winter polar temperatures which are $200-300 \mathrm{~K}$ below the values observed by $D E-2$ in December 1981. When a cross-polar cap potential of $80 \mathrm{kV}$ is applied, simultaneously enhancing the ionospheric plasma densities and including the energy directly deposited by soft magnetospheric electron precipitation within the polar cusp and polar cap (as discussed by Rees et al., 1980a and by Smith et al., 1982) (Models KC and KB, Figs. 12,13), average winter polar temperatures rise to values about $100 \mathrm{~K}$. lower than the average peak values observed by $D E-2$. This difference is most likely attributable to the value of $F 10.7 \mathrm{~cm}$ flux (150) used in the model. When further enhancements of the auroral oval precipitation are included, the polar and average global temperatures rise close to the mean values 
observed by $D E-2$ (Figs. 2 and 19). In this case, however, the agreement is probably resulting from an overestimate of the geomagnetic input, coupled with an underestimate of the solar input.

One of the greatest observational constraints is the observed temperature contrast (Fig. 2) of $200 \mathrm{~K}$ or more between the "cold" region found at 70 geographic latitude at 12.00 U.T., and the two hotter regions, one at mid-latitude regions (at 18.00 L.T.), and the second in the polar cap. Without the enhanced geomagnetic energy sources, i.e. using the CHIU ionosphere (Figs. 16,17 ), the contrast is only about $50 \mathrm{~K}$. In the simulation which includes the effects of soft electron precipitation within the polar cap and cusp, in addition to the momentum sources, a contrast of $100 \mathrm{~K}$ is obtained for the A2 convection field (with BY negative) (Fig. 13), and this contrast is increased to $200 \mathrm{~K}$ with the B2 field (IMF BY positive), as shown in Fig. 12.

Using this latter configuration, considerably better agreement is obtained between the observed winds and the model winds, and the temperature structures in this simulation also follow the observations rather better. That is, the maximum anti-sunward wind velocities and the highest temperatures occur on the dawn side of the polar cap. It appears thereforc, that the entire temperature and wind data sets, representing the average of the data from about 80 orbits of $D E-2$, during a 4-week period in December 1981, favour the energy and momentum inputs that have been associated in the simulations with the $\mathrm{B} 2$ convection field, a situation associated with a positive $Y$ component of the IMF. Neither the complementary field configuration (A2) or the symmetric field configurations used in the model simulations discussed by Rees et al.(1983), and by Hays et al. (1984) fit the observations as well. The strong temperature contrast $(200 \mathrm{~K})$ between the polar cap and the mid-latitudes in the 18.00 L.T. plane, and which is strongest at $12.00 \mathrm{U} . \mathrm{T}$., is only produced in the $\mathrm{KC}$ and $J Q$ simulations, using the $B 2$ convection field (BY positive). The high-speed sunward winds of the dusk auroral cval, contrasting with the weak sunward winds of the dawn auroral oval, reflect the relative ease with which ion drag can generate a clock wise vortex in this region. This has been discussed in detail by Rees et al. (1983) and by Fuller-Rowell et al. (1984), and the reduction of ion-neutral differential velocity contributes to the temperature contrast by reducing frictional heating in the vicinity of the dusk auroral oval, despite the high ion velocities.

\section{Composition and density structure in the Southem (summer) Hemisphere}

The simulation which uses the $\mathrm{B} 2$ convection field model (BY negative) predicts the region of enhance- ment of molecular weight in the morning auroral oval slightly better than does that using the $\mathrm{A} 2$ field. The distinction is not particularly significant, however, except perhaps for the polar cusp region sampled near 90 geographic latitude about 12.00 U.T., where heating by sof cusp electrons is important.

Let us consider the changes in mean molecular weight between the models using the "CHIU" ionosphere, and those using the "CHIU/PIONS" ionosphere. The geomagnetic energy input required to support the mean composition reflected in the $D E-2$ sample for $A_{p}>20$ (Fig. 5) is significantly larger than that required by the "quiet" sample(Fig. 4). Comparing the composition changes in Figs. 4 and 5 with those shown in Figs. 14, 15 and 10,11 respectively, the global geomagnetic input required (Table 3 ) is approx. $1.1 * 10(11) \mathrm{W}$ for the $A_{p}<20$ sample, and approx. $1.4 * 10(11) \mathrm{W}$ for the $A_{p}>20$ sample. The simulation (for the B2 field - Fig. 18) with auroral as well as cusp and polar cap precipitation somewhat overestimates the temperature and the amount of molecular nitrogen at $320 \mathrm{~km}$ compared with that ohserved by $D E-2$ corresponding to the $A_{p}>20$ sample.

\section{Composition and density structure in the Northern (winter) Hemisphere}

The contrast between the compositional structures predicted for the two senses of the HY component of the IMF is very pronounced for the Northern (winter) Hemisphere (compare Figs. 12 and 13). The geomagnetic polar region near winter solstice has very little solar insolation. The geomagnetic input is thus the major direct energy source. The effect of the contrast between the geomagnetic energy sources in different regions should thus appear more clearly than in the study of the summer southern hemisphere. In the simulation generated with the 32 convection model there is a significant increase in temperature and mean molecular weight (due to an enhancement of molecular nitrogen density) in the dawn side of the polar cap. For the $\mathrm{A} 2$ convection field, the temperature and nitrogen density enhancement shifts to the dusk side of the polar cap. The $D E-2$ data shows very clearly that it is the dawn side of the polar cap which shows the average enhancement of mean molecular weight during the period of the data sample in December 1981. This conclusion is precisely that reached in evaluating the wind and temperature structures.

Comparison of the absolute number densities between data and the models

There are three particular difficulties involved in making comparisons of absolute number densities between the NACS data for October and December 
1981 and the model results. Firstly, the data are not selected for specific solar and geomagnetic activity levels, but encompass a wide tange of each. The range of density values predicted for the polar regions when geomagnetic input alone is allowed to vary $(3: 1$ in [O], and $4: 1$ in [N2]) gives some indication of the absolute number range to be found within the empirical data.

The second problem is associated with the lower boundary conditions of the theoretical model. It is certainly true that within about $60 \mathrm{~km}$ of the lower boundary (i.e. by $140 \mathrm{~km}$ ), the wind and temperature structures of the model are insensitive to conditions at the lower boundary. The same condition does not, however, apply to total density. A systematic difference of $20 \%$ in total density at $80 \mathrm{~km}$, well within the possible error range, would cause a comparable change in total density at all higher levels in the model.

The third difficulty is highlighted by intercomparing the JQ and LF (rather disturbed) density values with those of the $\mathrm{KC}$ and $\mathrm{KD}$ models. The additional heating in the polar regions is mainly at relatively low thermospheric levels, due to the inclusion of kilovolt auroral electrons. This additional low-altitude (110$200 \mathrm{~km}$ ) heating forces large increases of oxygen density (*3), and an order of magnitude increase of [N2] in the summer polar region. In other words, density is particularly sensitive to the altitude distribution of heating. It is no less sensitive to the altitude distribution of solar heating than to auroral heating.

In view of these three difficulties, a detailed discussion of the absolute number densities of the individual constituents and total density will be deferred to a later paper (Hedin and Rees, in preparation, 1985), where the MSIS 83 empirical model will be used as the basis of comparison between theoretical model and data, for solar and geomagnetic conditions which can be specified independently.

\section{Sensitivity of the wind, temperature and composition} structures to the polar convection models

Initially, it was not expected that this study of a large sample of data, acquired over a period of several weeks, would show a systematic bias favouring one or other of the asymmetric convection field models. For example, the Southern Hemisphere study (October 1981) demonstrates only a marginally better agreement with the simulations generated by the $\mathrm{B} 2$ model (IMF BY negative), and the preference could not be claimed to be significant in comparison with many other uncertainties involved in modelling the geomagnetic input to the thermosphere. For example the location and magnitude of the soft cusp electron source in the model is not defined by observation.

The Northern Hemisphere data for late November and December 1981 show a very significant bias toward those simulations generated for conditions when the IMF BY was positive. The IMF data from ISEE-3 have been examined for this entire period and the IMF data do show a systematic trend, during this period, in favour of a positive $Y$ component of the IMF. For periods when ISEE-3 data was available, and when its interpretation was straightforward, there were more than twice as many days for which $\mathrm{BY}$ was predominantly positive, as for which it was predominantly negative. Integrating the number of hours for which the BY component could be identified clearly, the ratio was almost exactly two to one in favour of $B Y$ positive.

This study has not been taken to the level of a full statistical survey of $I S E E-3$ and $D E-2$ data, for the following reasons :

(a) The ISEE-3 data have significant breaks in coverage, and the orbital motions of ISEE-3 about the forward libration point also introduce considerable difficulty in interpreting the effect on the Earth's magnetosphere at times of rapid changes. In periods of rapid change and rapid oscillation of the $Y$ component, which are quite frequent, the effect on magnetospheric convection is unpredictable.

(b) The $D E-2$ data bases for wind and temperature, and for composition, are quite distinct, being from separate instruments. Untangling the common subsets of data where all data were available for individual orbits, and where ISEE-3 data could be interpreted without ambiguity, represented a task far beyond the resources available for this study.

The causes of the major changes in structure and dynamics caused by the $A 2$ and B2 convection models are complex, and it is important to distinguish between those due to the convection and which are nearly independent of the polar precipitation, and those which may be dependent on the magnitude and location of energetic electron sources. The strong antisunward wind jet on the dawn side of the polar cap generated by the $\mathrm{B} 2$ model (BY positive, $\mathrm{N}$ hemisphere) is driven by the ion convection. Plasma density enhancements will only modulate the magnitude of the generated winds. Indeed, without any source of polar precipitation, plasma densities will be relatively enhanced in this region due to rapid convection from the sunlit dayside and polar cusp (Quegan et al., 1982). The converse is true for the A2 convection model, when ion and neutral jets may be found on the dusk side of the polar cap.

The evidence of the polar winds, temperature and composition in the Northern Hemisphere study therefore directly supports the conclusion that there 
was a prevailing positive $Y$ component of the IMF throughout the late November and December period in 1981.

A first-order analysis of the composition and temperature data would describe the observed maxima of temperature and molecular nitrogen density on the dawn side of the polar cap as "plumes" carried from the cusp region, where the enhancements are generated by "soft" electrons, by the anti-sunward winds which are augmented by geomagnetic forcing. However, strong upwelling and horizontal divergence is also caused in this region by a combination of rictional heating due to the strong antisunward ion flow in this part of the polar cap and the anti-clockwise vortex forced by the convection cell involving the dawn auroral oval. The combination of all of these processes means that the temperature and nitrogen densily enhancement in the dawn polar cap is more sensitive to the location and magnitude of magnetospheric electron sources (i.e. the cusp) than is the strong anti-sunward wind jet. The compositional data should thus be considered to be strongly supporting the primary evidence of the polar wind data in favouring the systematic positive sense of the $Y$ component of the IMF during December 1981. The compositional and temperature data also strongly support the general assumptions which have been used in generating these models and the consequent simulations of thermospheric behaviour.

The major geomagnetic processes affecting the polat regions cause extreme and sudden changes in thermospheric structure, and are difficult to deduce a posteriori, let alone predict a priori. The features of polar thermospheric structure and dynamics which are explained well in this study of "average" data may also be examined with simulations targeted to specific geomagnetic disturbances. Rees et al. $(1985 \mathrm{a}, \mathrm{b})$ have shown that an acceptable agreement between observation and simulation can be achieved with a reasonable covariance of convection and precipitation in simulating data during isolated geomagnetic disturbances. The nature and magnitude of the geomagnetic disturbances themselves will be harder to predict or analyse in the absence of routine IMF data since ISEE-3 has been re-targetted for its cometary encounter. Major progress in thermospheric modelling now requires an improved empirical description of the relationships between convection and precipitation, including the soft electron sources which have such important effects in the upper thermosphere. The interdependence of convection and precipitation, and the co-dependence of both on the IMF and solar wind are another area of critical importance.

The temperature and composition enhancement observed in the southern dawn auroral oval in October
1981 was considerably larger than that associated with the southern dusk auroral oval. Examination of the global simulations indicates that a major contribution toward this apparently important effect is that, for the particular geometrical situation of $D E-2$ orbit plane in October 1981 (09.00 to 21.00 L.T.), the solar elevation at the times of crossings of the dawn oval is considerably greater than at the dusk oval crossings (later in the U.T. day). Had the local time plane of the orbit been different (i.e. 03.00-15.00 L.T.), a different conclusion might have been reached, since for this latter local time plane, the solar illumination at the time and place of dusk auroral oval crossings exceeds that of the corresponding dawn auroral oval crossings. Further samples of the polar thermospheric regions, at different Local Times and seasons are now available from $D E-2$, which may shed light on this, and a number of additional topics of considerable importance.

Acknowledgements - We are grateful to Dr. J. P. Heppner and Dr. N. C. Maynard for provision of their models of the polar convection electric field with dependence on the sense of the " $Y$ " component of the IMF and, for detailed discussion of the significance of the polar convection changes. We also acknowledge discussions with $\mathrm{Dr}$. D. Winningham and Dr. D. Evans relating to the structure of energetic particle precipitation over the geomagnetic polar regions. The work at UCL was supported by grants from the U.K. Science and Engineering Research Council, and with a grant of time on the CRAY I-S of the University of London Computer Centre.

The Dynamics Explorer satellites were launched as part of NASA's science programme, and we appreciate many discussions with members of the Dynamics Explorer science team.

\section{REFERENCES}

Blamont, J. E. and Luton, J. M. (1972) Geomagnetic effect on the neutral temperature of the Furegion during the magnetic storm of September 1, 1969. J. geophys. Res. 77, 3534 .

Carignan, G. R., Block, B. P., Maurer, J. C., Hedin, A. E., Reber, C. A. and Spencer, N. W. (1981) The neutral mass spectrometer on Dynamics Explorer. Dynamics Explorer-.-. Space Sci. Instrum. 5, 429.

Chiu, Y. T. (1975) An improved phenomenological model of ionospheric density. J. atmos. terr. Phys. 37, 1563.

Fuller-Rowell, T. 3. and Rees, D. (1980). A three-dimensional lime-dependent global model of the thermosphere. $J$. Atmos. Sci. 37, 2545.

Fuller-Rowell, T. J. and Rees, D. (1981) A three-dimensional, time-dependent simulation of the global dynamical response of the thermosphere to a geomagnetic substorm. $J$. atmos. terr. Phys. 43, 701.

Fuller-Rowell, T. I. and Rees, D. (1983) Derivation of a conservation equation for mean molecular weight for a two constituent gas within a three-dimensional, time-dependent model of the thermosphere. Planet. Space Sci. 5, 345.

Fuller-Rowell, T. J., Rees, D., Quegan, S., Bailey, G. J. and Moffett, R. J. (1984) The effect of realistic conductivities on the high-latitude neutral thermospheric circulation. Planet. Space Sci. 32, 469. 
Fuller-Rowell, T.J. (1984) A two dimensional high resolution nested grid model of the thermosphere. J. geophys. Res. 89, 2971.

Fuller-Rowell, T. J, and Rees, D. (1984) Interpretation of an anticipated long-lived vortex in the lower thermosphere following simulation of an isolated substorn. Planet. Space Sct. 32, 69 .

Hays, P. B., Jones, R. A. and Rees, M. H.(1973) Auroral heating and the composition of the neutral atmosphere. Planet. Space Sci. 21, 559 .

Hays, P. B., Meriwether, J. W. and Roble, R. G. (1979) Night time thermospheric winds at high latitude. J.geophys. Res. 84, 1905.

Hays, P. B., Killeen, T. L. and Kennedy, B. C. (1981) The Fabry Perot interferometer on Dynamics Explorer. Space Sci. Insirum. 5, 395.

Hays, P. B., Killeen, T. L., Spencer, N. W., Wharton, L. E., Roble, R. G., Emery, B. A., Fuller-Rowell, T. J., Rees, D., Frank, L. A. and Craven, J. D. (1984) Observations of the dynamics of the polar thernosphere. J. geophys. Res. 89. 5597.

Hedin, A. Z. (1983) A revised thermospheric model based on mass spectrometer and incoherent scatter data: MSIS-83.J. geophys. Res. 88, 10170.

Hedin, A.E. and Reber, C.A. (1972) Longitudinal variations of thermospheric composition indicating magnetic control of polar heat input. $J$. geophys. Res. 77, 2871 .

Hedin, A. E., Reber, C. A. Spencer, N. W., Brinton, H. C. and Kayser, D. C. (1979) Global model of longitudinal/UT variation in thermospheric composition and temperature based on mass spectrometer data. $J$ geophys. Res. 84, 1.

Heppner, J. P. and Maynard, N. M. (1983) Paper presented at the Chapman Conference at Irvington, Virginia. March, 1983.

Heppner, J. P. and Miller, M. L. (1982) Thetmospheric winds at high latitudes from chemical release observations. $J$. geophys. Res. 87, 1633.

Hinton, B. B. (1978) Global effect of auroral particle and Joule heating in the undisturbed themosphere. J. geophys. Res. 83, 707

Hofmann, R. A. and Schmering, E. R. (1981) Dynamics Explorer program: an overview. Dynamics Explorer-. Space Sci. Instrim. 5, 345.

Kelley, M. C., Jorgensen, I. S. and Mikkelsen, 1. S. (1977) Thermospheric wind measurements in the polar region. $J$. atmos. terr. Phys. 39, 211.

Killeen, T. L., Hays, P. B., Spencer, N. W. and Wharton, L. E. (1982) Neutral winds in the polar thermosphere as measured from Dynamics Explorer. Geophys. Res. Lett. 9, 957.

Killeen, T. L., Hays, P. B., Spencer, N. W. and Wharton, L. E. (1983) Neutral winds in the polar thermosphere as measured from Dynamics Explorer. Adv. Space Res. 2 , 133.

Loux, U. and von Zahn, U. (1979) Lot gitudinal variations in thermospheric composition under geomagnetically quiet conditions. $J$. geophys. Res. 84, 1942.

Mayr, H. G. and Harris, I. (1978) Some characteristics of electric field momentum coupling with the neutral atmosphere. J. geophys. Res. 83, 3327 .

Meng, C. 1. (1983) Dynamics variation of the auroral oval during intense magnetic storms. J. geophys. Res. 89, 227.

Meriwether, J. W., Heppner, J. P., Stolarik, J. D. and Wescott, E. M. (1973) Neutral winds above $200 \mathrm{~km}$ at high latitudes. J. geophys. Res. 78, 6643 .

Prolss, G. W. and von Zahn, U. (1978) On the local time variation of atmospheric-ionospheric disturbances. Space Res. 18, 159.

Prolss, G. W. (1980) Magnetic storms associated perturbations of upper atmosphere: recent results obtained by satellite-borne gas analysers. Rev. Geophys. Space Sct. 18, 183.

Prolss, G.W. (1981) Latitudinal structure and extension of the polar atmospheric disturbance. J. geophys. Res. 86, 2385.

Prolss, G. W. (1982) Perturbation of the low-latitude upper atmosphere during magnetic substorm activity. $J$. geophys. Res. 87, 5260.

Prolss, G. W. and Roemer, M. (1983) Seasonal and solar activity dependent variations of the geomagnetic activity effect at high latitudes. Adv. Space Res. 3, 99.

Quegan, S., Bailey, G. J., Moffett, R. J., Heelis, R. A., FulletRowell, T. J., Rees, D. and Spiro, R. W. (1982) A theoretical study of the distribution of ionization in the bigh latitude ionosphere and the plasmasphere: first results on the midlatitude trough and light-ion trough. J. atmos. terr. Phys. 44, 619.

Reber, C. A. and Hedin, A. E. (1974) Heating of the high latitude themosphere during magnetically quiet periods. $J$. geophys. Res, 79, 2457.

Rees, 0. . (1971a) lonospheric winds in the auroral zone. J. Brit. Interplan. Soc. 24, 233.

Rees, D. (1971b) Upper atmosphere neutral temperature profiles in the auroral zone 1968-1970. Planet. Space Sci.19, 233.

Rees, D., Fuller-Rowell, T. J. and Smith, R. W. (1980a) Measurements of high latitude thermospheric winds by rocket and ground-based techniques and their interpretation using a three-dimensional, time-dependent dynamical model. Planet. Space Sci. $28,919$.

Rees, D., Fuller-Rowell, T. J. and Rounce, P. A. (1980b) Asymmetric global circulation systems following geomag. netic substorms. Proc. Wth ESA-PAC Symposium on European Rocket and Balloon Programmes and Related Research, Bournemouth. ESA SP-152, June 1980, 81-88.

Rees, D., Rounce, P. A., Charleton, P., Fuller-Rowell, T. J, McWhirter, I. and Smith, K. (1981) Mesospheric and thermospheric winds during the Energy Budget Campaign : Ground-based Fabry-Perot observations supported by dynamical simulations with a three-dimensional, timedependent thermospheric model. Extended abstract, in BMFT-FB-W 81-052: Sounding Rocket Program Aeronomy Project: Energy Budget Campaign 1980 Experiment Summary.

Rees, D., Rounce, P. A., Charleton, P., Fuller-Rowell, T. J., McWhirter, I. and Smith, K. (1982) Thermospheric winds during the Energy Budget Campaign: ground-based Fabry-Perot observations supported by dynamical simulations with a three dimensional, time-dependent thermospheric model. J. Geophys. 50, 202.

Rees, D., Fuller-Rowell, T. J., Gordon, R., Killeen, T. L., Hays, P. B, Wharton, L. E. and Spencer, N. W. (1983) A comparison of wind observations of the upper thermosphere from the Dymamics Explorer satellite with the predictions of a global time-dependent model. Planet. Space Sct. 31, 1299.

Rees, D., Smith, M. F. and Gordon, R. (1984) The generation of vertical thermospheric winds and gravity waves at auroral latitudes. II. Theory and modelling. Planet. Space Sci. 32, 685.

Rees, D., Fuller-Rowell, T. J., Gordon, R., Strith, M. F., Heppner, J. P., Maynard, N. C., Spencer, N. W., Wharton, L. W., Mays, P. B. and Killeen, T. L. (1985a) A theoretical 
and empirical study of the response of the high latitude thermosphere to the sense of the " $Y$ " component of the interplanetary magnetic field. To be submitted to Planet. Space Sci.

Rees, D., Fuller-Rowell, T. J., Smith, M. F., Gordon, R., Killeen, T. L., Hays, P. B., Spencer, N. W., Wharton, L. and Maynard, N. C. (1985b). The westward thermospheric jetstream of the evening auroral oval. Planet.Space Sci.33, 425 .

Roble, R. G. and Rees, M.H. (1977) Time dependent studies of the aurora: Effects of particle precipitation on the dynamic morphology of ionospheric and atmospheric properties. Planet. Space Sci. 25, 991.

Roble, R. G., Dickinson, R. E. and Ridley, E. C. (1982) Global circulation and temperature structure of the thermosphere with high-latitude plasma convection. J. geophys. Res. 87, 1599.

Roble, R. G., Dickinson, R. E., Ridley, E. C., Emery, B. A., Hays, P. B., Killeen, T.L. and Spencer, N. W. (1983) The high latitude circulation and temperature structure of the thermosphere near solstice. Planet. Space Sci. 31, 1479.

Siscoe, G. L. (1982) Polar cap size and potential : a predicted relationship. Geophys. Res. Lett. 9, 672.

Smith, R. W. and Sweeney, P. I. (1980) Winds in the thermosphere of the northern polar cap. Nature 284,437 .

Smith, M. F. (1984) A study of the momentum and energy sources in the thermosphere using a global model. Ph.D. Thesis, University College, London.
Smith, M. F., Rees, D. and Fuller-Rowell, T. J. (1982) The consequence of high latitude particle precipitation on global thermospheric dynamics. Planet. Space Sci. 30, 1259.

Smith, M. F, and Rees, D. (1985) Solar EUV heating efficiencies in the thermosphere. To be submitted to Planet. Space Sci.

Spencer, N. W., Wharton, L. E., Niemann, H. B., Hedin, A. E., Carignan, G. R. and Maurer, J. C. (1981) The Dynamics Explorer wind and temperature spectrometer. Space Sci. Inst. 5, 417.

Spiro, R. W., Reiff, P. F. and Maher, L. J. (1982) Precipitating electron energy flux and auroral zone conductances - an empirical model. J. geophys. Res. 87, 8215.

Taeusch, D. R., Carignan, G. R, and Reber, C. A. (1971) Response of the neutral atmosphere to geomagnetic disturbances. Space Res. 9, 995.

Taeusch, D. R. and Hinton, B. B. (1975) Structure of electrodynamic and particle heating in the undisturbed polar thermosphere. J. geophys. Res. 80, 4346.

Volland, H. (1979) Semi-empirical models of magnetospheric electric fields. Quantitative modeling of magnetospheric processes. Geophys. Monograph 21, 4346.

Winningham, J. D. and Gurgiolo, C. (1982) DE-2 Photoelectron measurements consistent with a large scale parallel electric field over the polar cap. Geophys. Res. Lett. 9,977 . 